UC-NRLF

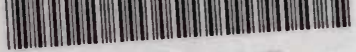

B $3 \quad 108 \quad 163$

MODERN

$\underline{\text { Microscopy }}$

M. I. CROSS

AND

MARTIN F. COLE 





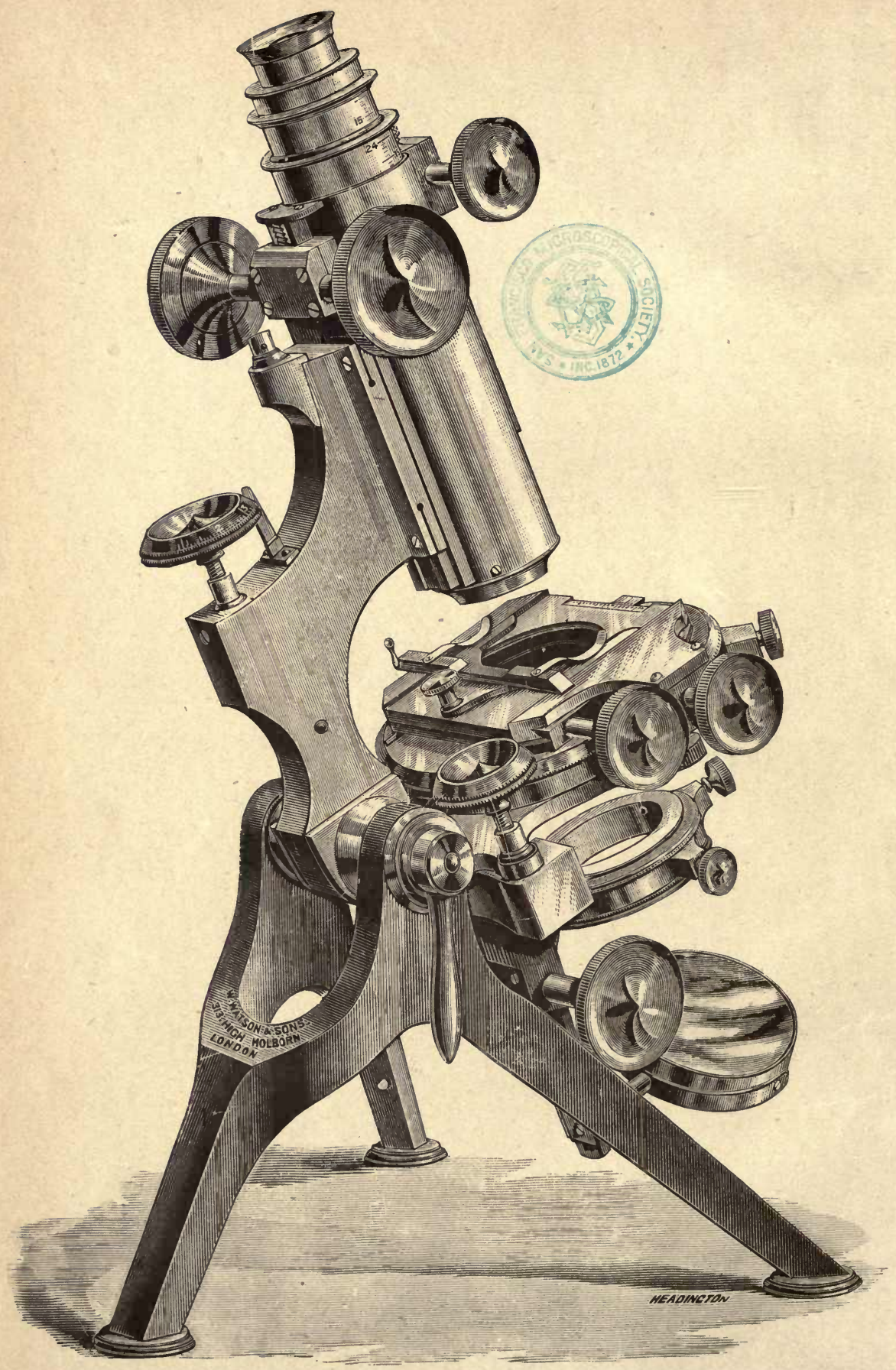

Fig. 1.-A Typical Modern Microscope.-Made by W. Watson and Sons to the specification of Dr. Henri Van Heurck, Antwerp, for Photo-Micrographic and High Power work. 


\section{MODERN MicRoscopy.}

A HANDBOOK FOR BEGINNERS,

IN TWO PARTS.

I. THE MICROSCOPE, AND INSTRUCTIONS FOR ITS USE, BY

M. I. CROSS.

II. MICROSCOPIC 0BJECTS: How PREPARED AND MOUNTED,

BY

\section{A R T I N . J. C OLE,}

LECTURER ON PRACTICAL MICROSCOPY, BIRKBECK INSTITUTION, LONDON ; LECTURER IN HISTOLOGY AT MR. COOKE'S SCHOOL OF ANATOMY.

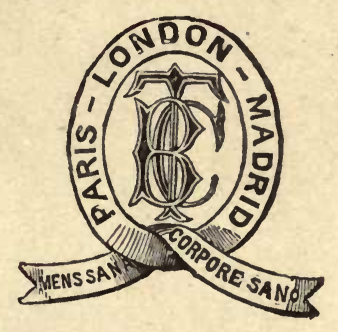

LONDON :

B A I L L I ÈRE, T I N A L L A N D C O X, 20 \& 21, King-William Street, Strand.

[PARIS AND MADRID.]

[All rights reserved.] 
211205

CII
BIOLOCY
LBRARY 


\section{PREFACE.}

This handbook is not intended as a treatise on the microscope, nor to give particulars of the various patterns of instruments made, details of which can be seen in the maker's' catalogues, but to afford such information and advice as will assist the novice in choosing his microscope and accessories, and direct him in his initial acquaintance with the way to use it.

The directions for preparing microscopic objects by $\mathrm{Mr}$. Martin J. Cole are the outcome of a very long experience as a preparer of Microscopic Objectş of the highest class, and cannot fail to be of the greatest service to the working microscopist.

M. I. CROSS. 



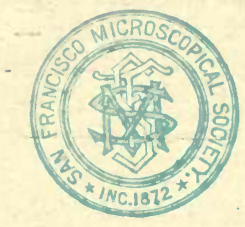

\section{CON T E N T'S.}

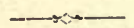

\section{PART I.}

\section{CHA P TER I.}

THE MICROSCOPE-STAND.

On ehoosing a microscope-stand-Designation of the parts of a microscope-Different forms of feet compared-The stage-Substage and underfitting-Fine adjustment to sub-stage-Coarse and fine adjustments-The limb-Lengths and diameters of body tubes-The Rackwork draw-tube-Tailpiece and mirrorsOblique illumination-Testing a microscope-Binocular microscopes-High-power prisms-Dissecting microseopes -

\section{CHAPTER II.}

\section{OPTICAL CONSTRUCTION.}

Magnifying power, how produced-Objectives, apochromatic and achromatic compared-Angular and numerical apertures-Immersion lenses - Abbé apertometer-Aperture and powerCorrections for thickness of cover-glass-Test objects-Huy. ghenian eyepieces-Kelner eyepieces-Projection eyepiecesBinocular eyepieces-Illuminating apparatus-The Abbé illuminator and Abbé achromatic condenser-Webster condenserSwift's condenser-Powell and Lealand's apochromatic condenser--How to work with the condenser-How to produce a dark background - Spot lens - Paraboloid - Polariscope Darker's selenites-Mica selenite stage--Stand condenserNelson's aplanatic bull's eye - The microscope lamp - Nosepiece-Drawing apparatus-Dr. Beale's neutral tint reflectorThe Abbé camera lucida-The measurement of objects by mechanieal stage $-\mathrm{B}_{\mathrm{y}}$ camera lucida and stage micrometer- 
Eyepiece micrometer and stage micrometer-Jackson's micrometer - Ramsden screw micrometer - Botterill's trough Rousselet's live-cage-Stage forceps-Text-books recommended 38-68

\section{P A R T I I. \\ LESSON 1.}

HARDENING ANIMAL TISSUES FOR MICROSCOPICAL EXAMINATION.

Absolute alcohol-Chromic acid and spirit-Potassium bichromate -Ammonium bichromate-Müller's fluid-Methylated spiritDecaleifying fluid-General directions for hardening . $.69-71$

\section{LESSON 2.}

EMBEDDING TISSUES AND SECTION-CUTTING.

Cutting sections with a razor by hand-Embedding in paraffin, wax and lard-Infiltrating a tissue with paraffin-Cole's microtome and embedding in carrot-Catheart microtome for freezing -Embedding in celloidin-Cambridge rocking microtome $\quad-72-77$

\section{LESSON 3.}

STAINING ANIMAL SECTIONS AND MOUNTING IN CANADA BALSAM.

The preparations of borax carmine-Logwood or hæmatoxylinStaining processes-Double staining with logwood and rosinMounting in Canada balsam . . . . . $\quad$ - 77-80

\section{LESSON 4.}

STAINING BLOOD AND EPITHELIUM, TEASING OUT TISSUES AND MOUNTING IN AQUEOUS MEDIA.

Double staining nucleated blood corpuscles-Preparing blood of mammals - Non-nucleated corpuscles - Epithelium - Teasing out muscle, fibrous tissue, yellow elastic tissue, nerve fibres, and non-striped muscle-Farrant's medium and glycerine jelly, low prepared and used

\section{LESSON 5 .}

STAINING AND MOUNTING MICRO-ORGANISMS.

Staining and mounting micro-organisms-Staining bacteria on cover-glass-Ehrlich's method of double-staining 


\section{Contents.}

\section{LESSON 6.}

\section{INJECTION OF BLOODVESSELS.}

How to make carmine and gelatine injecting mass-Prussian or Berlin blue and gelatine mass-Watery solution of Berlin blueDirections for injecting - Injection of lymphatics (puncture method)-Injection of lymph-sinuses of glands

\section{LESSON 7.}

CUtTing, StaINing, and MOUNTING VEgetable Sections.

Bleaching-Staining in borax carmine-Hæmatoxylin-Formula for acid green and carmine stains and double-staining in same -Eosin stain

\section{LESSON 8.}

PREPARING AND MOUNTING IN GLYCERINE JELLY, ACETATE OF COPPER, ETC.

Epidermal tissues for stomata-Annular vessels - Sealariform vessels-Spiral vessels-Yeast-Preserving fluid for green algæ and mounting in same - Protococcus - Volvox - Red algæ Antheridia and archegonia of mosses - Fertile branch of chara

\section{LESSON 9.}

CUTTING, GRINDING, AND MOUNTING SECTIONS OF HARD TISSUES.

Bones-Rock sections $-93,94$

\section{LESSON 10.}

PREPARING AND MOUNTING ENTOMOLOGICAL SPECIMENS FOR THE MICROSCOPE.

Preparation for mounting an insect with pressure in Canada balsam-Mounting without p"essure in Canada balsam and glycerine

\section{LESSON 11.}

CRYSTALS AND POLARISCOPE OBJECTS.

Crystals, how prepared and mounted-Starches-Cuticles containing raphides-Fish scales-Palates-Hairs-Horns, hoofs, and whalebone. 
FIG.

25. R. and J. Beck's Ramsden Screw Micrometer _

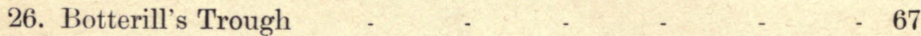

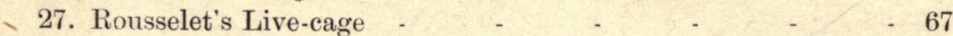

28. Cole's Microtome, by Watson and Sons - $\quad-73$

29. The Catheart Freezing Microtome - _ _ _ - 74

30. The Cambridge Scientific Instruction Company's Rocking Microtome

\section{ERRATUM.}

Page 30 , line 10 , for 'page 41 ' read 'page 45. ' 


\section{MODERN MICROSCOPY.}

\section{INTRODUCTION.}

THe history of the development of the microscope is exceedingly interesting, and itself would fill a small volume: suffice it to say that it was but sixty-eight years ago, or in 1824, that Tully made the first achromatic microscope. Since that time, step by step, such progress has been made in its construction as would be searcely realizable to those who have not followed it. Ten years ago the President of the American Society of Microscopists, in his annual address, remarked 'that lenses which were believed to have so nearly reached the limit of perfection fifteen years ago are antiquated now, and the theoretical limit of perfection has moved forward like the horizon, and is as far off as ever.' The same statement applies to-day, and even within the last five years lenses have been placed at our disposal by the leading opticians giving results that our microscopical predecessors of fifteen or twenty years ago would never have dreamed of ; and still further experiments are going forward, with the view of giving greater advantage in microscopical research. What has been done in the lens part of the microscope has also been effected in the mechanical, and a far better microscope can be purchased to-day for a given sum than a few years ago could be obtained at nearly double the cost, bringing that 
which was a luxury, and acquirable only by the wealthy, within the reach of the slenderest purse. This is largely due to the work of enthusiastic amateurs. At leading microscopical societies, notably the Royal Microscopical Society and the Quekett Club, which meet in London, are to be found men whose recreation is in the microscope, and whose suggestions, as the result of personal practical experience and research, are of such weight and value that manufacturers, rivalling one another, have taken advantage of the ideas of these workers. Also in the medical world its advantages have become appreciated, and necessitated the introduction of reliable and high-class instruments at a moderate price. Not many years ago a hospital rarely possessed more than one or two microscopes, and these were generally kept under a glass shade, more for ornament than use; but to-day every student has to provide himself with one, and become practically acquainted with the ultimate structure of every organ and tissue both in health and disease. The chemist finds it indispensable, and our medical officers of health employ it for detecting adulterations, entozoa, etc. ; so that not only is it one of the most intelligent means of recreation, but it is also invaluable in many duties affecting our immediate comfort and welfare.

The demand for microscopes caused by their large employment by professional men and students caused a corresponding competition among manufacturers to produce the best possible instruments at the lowest price, suitable for the purposes for which they were required, and this has been an important factor in the present state of good quality at low cost.

Some people hesitate in taking up the microscope at all, not caring to use it merely as an amusement, and thinking they have no special genius for science, or the ground has been gone over so repeatedly that there are no new worlds to conquer, and that it is perfectly hopeless for them to discover any new organism, or for any novel idea to cross their minds. This is quite a mistake, and it will surprise 
any microscopist who uses his instrument thoughtfully how the love for the work will grow upon him, and how gradually he will become master of some special line which he has adopted as his own. On this point we would echo the words of a well-known microscopist: ' It needs no marvellous intellect, no special brilliancy, to succeed in a scientific study; work at it ardently and perseveringly, and success will follow.'

We will now proceed to consider the microscope itself, apart from its optical relations, which will follow in another chapter. 


\section{$P A R T I$.}

\section{CHAPTER I.}

\section{THE MICROSCOPE-STAND.}

As one looks through the catalogues of the various dealers, and notices the microscope-stands varying in price from $£ 2$

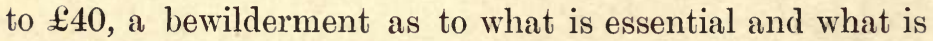
not is the first feeling. We will, then, examine the parts, describe their uses and advantages, and state what is essential to a beginner.

Here let us advise intending purchasers not to buy a microscope unless it bears the name of a manufacturer : a good workman is never ashamed of his handiwork. There are many very inferior instruments that look tempting, but a practical acquaintance with them soon discovers their weak points and inefficiency. Happening to attend the conversazione of a well-known microscopical society some little time since, at which there were exhibited over one hundred instruments, it was surprising to note the many makeshifts of microscopes belonging to some of the exhibitors-and many of them had probably cost a fair price, too. A manufacturer remarked to the writer that he was some time since in a provincial town, when an auctioneer asked him whether he could not make him up a job lot of microscopes for sale by auction, as he was very successful in disposing of a certain class of pictures in this way. The disgust of the scientific workman can be better imagined than described. The microscopes often seen in the novice's possession seem to be of this genus. This lind of instru- 
The Microscope-stand.

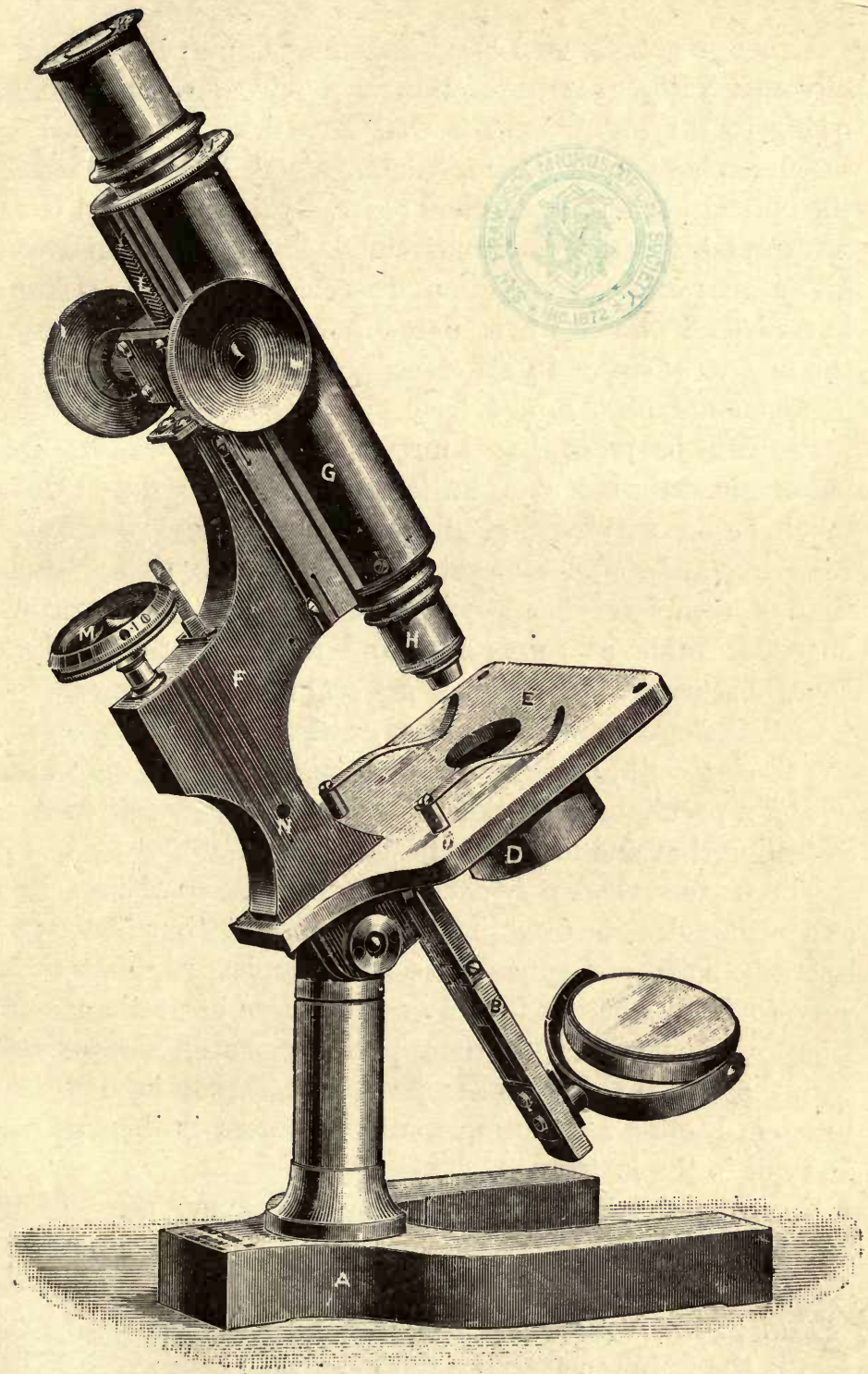

FIG. 2.-Edinburgh Student's Microscope, Stand B, by Watson and Sons.

ment is soon discarded, and little pride is felt in its possession after seeing a well-made one. 
Although good second-hand instruments may be occasionally met with, great discretion is required in purchasing, owing to the improvements that have been introduced in the first place, and that some damage may have occurred to the optical parts in the second place. If it be obtained from a respectable dealer who understands his business and will give a guarantee of condition, there is some inducement; but a friend who is up to date in microscopy is generally the best to advise. In all cases, before purchasing, a catalogue should be obtained from the maker whose name the instrument bears, so that it may be ascertained whether the pattern is still made or is antiquated and out of date. It is much better to buy a good stand capable and worthy of receiving additional apparatus from time to time, rather than a complete cheap instrument. These latter rarely engender pride of ownership, and are often relegated to some obscure corner after a short acquaintance; whereas if - a good instrument be purchased, with even only one objective to start with, there is always a pleasure in working with it, and a peculiar fascination from its quality - a satisfaction in feeling that one has something superior.

There are several very cheap microscopes on the market, and although it is sometimes claimed that they foster the scientific spirit and educate the microscopical beginner, it is very doubtful whether they do not do more harm than good from dissatisfaction with their performance on comparison with those of superior make: possessors of such become disheartened, often attributing want of success to themselves, and not to the instrument.

To make the different parts quite elear, on page 17 is figured a student's microscope, of which the following is a description :

Fig. 2.-A is the stand or foot.

$\mathrm{B}$ is the tailpiece carrying the mirror $(\mathrm{C})$ with which light is thrown upon the object.

$\mathrm{D}$ is the under-fitting, into which are fitted the sub-stage condenser, polarizer, etc. 
$\mathrm{E}$ is the stage on which the object is placed.

$\mathrm{F}$ is the limb carrying the body $(\mathrm{G})$.

At the lower end of the body is a screw, into which the objective $(\mathrm{H})$ is fitted.

At the upper end of the body is a sliding fitting called the draw-tube (J), by means of which additional magnification may be obtained, and into this draw-tube the eyepiece or ocular (K) fits.

$\mathrm{L}$ is a rackwork, by means of which the body $(G)$ is raised and lowered in order to focus the objective $(\mathrm{H})$ upon the object which is placed on the stage $(\mathrm{E})$.

$M$ is the milled head controlling the fine adjustment, which imparts a delicate motion to the body, in order that the objective may be more exactly adjusted than would be possible with high magnifying power with the rackwork $(\mathrm{L})$.

$\mathrm{N}$ is a fitting for forceps, or side silver reflector ; and $\mathrm{O}$ are the springs with which the object is held in position.

We have selected the instrument (Fig. 2) as, from practical acquaintance with it, we are able to strongly recommend it for a beginner's microscope, worthy of receiving additions from time to time as means may permit, especially as it may be had on a tripod form of foot similar to that shown in Fig. 1, instead of the horseshoe form. Still, it should be only considered as a typical one.

\section{THE FOOT.}

We would very strongly advise the beginner to purchase an instrument with a tripod foot, as shown in the instrument Fig. 1 (frontispiece). This is the most rigid form of foot in the market, and is in this respect a long way in advance of the horseshoe stand with a single pillar, so largely adopted on the Continent.

If the horseshoe foot be made in proper proportion, it is not so condemnable; but unfortunately it rarely is, and at the best is not nearly so firm as the true tripod foot recommended. This is a most impcrtant feature; and though 
perhaps inappreciable to the novice, yet as he advances all these minor details come up as very real ghosts, haunting him in his work and causing him to avoid that which would have been useful to him. If the foot of the microscope be shod with cork, so much the better, as vibration is thereby partly insulated, and the annoyance caused by scratching tables is avoided. It must be clearly understood, however, that even if this form of foot be not made in proper proportion its advantages will be annulled.

Next to this foot in point of convenience and rigidity we would place the Jackson model, as shown to the instrument on page 29. This, if properly made, is but little inferior to the tripod, but it is heavier.

There are many others made, mostly modifications of the Jackson model, and their rigidity can be tested by placing the instrument in a horizontal position, racking the body out, and then observing whether there is any tendency to topple over. If so, have nothing to do with it. The doublepillar form, with flat tripod foot, as shown on page 34, is a very good and convenient one. It is adopted by several firms for largest size instruments, and is certainly handsome.

Last on our list of feet we should place the horseshoe pattern, as shown on page 17. The great advantage this possesses over all others is its compactness for portability. It originated on the Continent, and is preferred both there and in English medical schools, etc., before any other. It is usual in laboratories to work with the microscope in a vertical position, and while the instrument is so placed the horseshoe foot is quite firm. If it be placed horizontally, however, as the amateur usually employs it, even with a well-made foot there is a tendency to sidefalling. It would be well, therefore, not to select this form of foot when choosing a microscope. The order of preference for the foot of the microscope would be :

1. The tripod foot, as shown to instruments page 31 and frontispiece. 
2. The Jackson form of foot, as shown to instrument on page 29 .

3. The flat tripod and upright pillars, as shown to instrument on page 34 .

4. The Continental or horseshoe form.

\section{THE STAGE.}

It will be noted, on reference to the typical instruments shown in this book, that the stage of the instrument on page 17 , on which the object is placed, is perfectly plain, while those on pages 29,31 , etc., have screws, by means of which plates move in dovetailed grooves one over the other in rectangular directions, carrying the object with them. In a first-class microscope it is well to choose an instrument having this convenience-in fact, there is no means so suitable for systematically examining an object as is afforded by it. In addition to these mechanical movements, if a sliding bar be fitted to slide on the top plate the convenience is greater. For plain stages beyond the springs nothing is really necessary, and it is surprising how with a little education the fingers will do the work of the mechanical screws, so that the object may be carefully examined under high powers. A sliding movement or some form of carrier on a plain stage is preferred by some.

A very great convenience to the mechanical stage is the rotation, and this in a best instrument should be concentric; some stages are fitted to rotate by rackwork, but this is rarely necessary: it is often found convenient for preventing the stage from rotating accidentally, especially in photography, and should always have the pinion wheel so fitted that it may be disengaged from the rack and replaced instantly. Centring screws to the concentric rotating stage, by means of which the rotation of the stage may be made true with any objective, will be found a useful addition. Divisions to the rotation of stages are not very advantageous for ordinary purposes, but for geclogical work 
are a necessity. A scale, reading to parts of a millimetre or inch on the plates of the mechanical stage, will be found useful, as important parts of an object can be noted and refound. For instance, supposing a specimen were being examined, and any important feature observed to which future reference would be convenient, the reading of the divisions on the stage would be marked on the slide-say, horizontal, 24 ; vertical, 20. On future occasions it would only be necessary to set the stage readings at the same points and place the object in the same position on the stage (for which purpose nearly all mechanical stages have a stop-pin for the slide to be set against), and the special feature will be in the field of view. If a mechanical stage be selected, it should be a good one, as if badly made it is worse than a plain stage; also the frictional parts should be fitted with adjusting screws to compensate for wear and tear.

For a stage for a microscope we would therefore place our choice as follows :

For a first-class microscope: Mechanical movements; concentric rotation; screws to make the rotation quite true with any objective; sliding-bar to top plate and stop-pin for object to go against; divisions to plates of stage reading to parts of millimetre or inch ; rackwork rotation to stage; and divisions to outer circle (optional).

For a second-class microscope: Mechanical movements; sliding-bar to top plate.

For a third-class microscope: Plain stage, with springs to hold object in position; if provided with sliding-bar or plate as object-carrier, so much the better.

\section{THE SUB-STAGE OR FITTING UNDER THE STAGE TO CARRY CONDENSER, ETC.}

The sub-stage consists of a ring of what is termed the ' society size,' $1 \frac{1}{2}$ inches full internal diameter, which carries illuminating apparatus for condensing the light on 
the objects, polarizing prism, etc., referred to on a later page. It is adjusted in a vertical direction towards the under surface of the stage by means of a rack and pinion, and the ring carrying the apparatus is provided with screws, by means of which the condenser, etc., can be made exactly central with the objective with which it is working. This central fitting is made to rotate by rack and pinion in some instances for using the polarizer, etc., but this is so rarely needed that it is hardly necessary except for special work. It is essential that this should be substantially made, as it is a most important fitting, often too little appreciated. For the sake of economy, some makers fit a sub-stage without a rackwork, merely sliding up and down in the dovetailed fitting; this is not desirable. If a sub-stage be had, it should have a rackwork, or nearly all its value is lost. A fine adjustment, so that the most exact focus can be obtained with the condenser, is often provided with the best stands, and is very useful if high-power work is intended to be done. It is surprising the convenience this fine adjustment affords. Often it is wished to just alter the position of the light and sub-stage condenser a little. In so doing the tension on the sub-stage milled head is apt to cause vibration, so that the best point of adjustment cannot be at once observed. By communicating this small amount of motion with the fine adjustment the focus is obtained to a nicety.

In the cheaper instruments, instead of the sub-stage as above described, an ordinary plain tube is fitted into the under part of the stage, and in this tube the condenser or other apparatus is moved up and down to focus. This must be truly centred with the optical tube, and it is well to test it by putting a small diaphragm into the under tube, and with an objective in the body to focus the diaphragm. If it be not central its practical importance is annulled. The additional convenience of the centring sub-stage is well worth the extra outlay. The instrument in Fig. 1 has a rackwork; Fig. 2 has a plain tube only. 
A great convenience will be found in many instruments of being able to lift the sub-stage aside out of the optical axis of the instrument on a jointed fitting. It saves a deal of time to students, especially where two or three powers

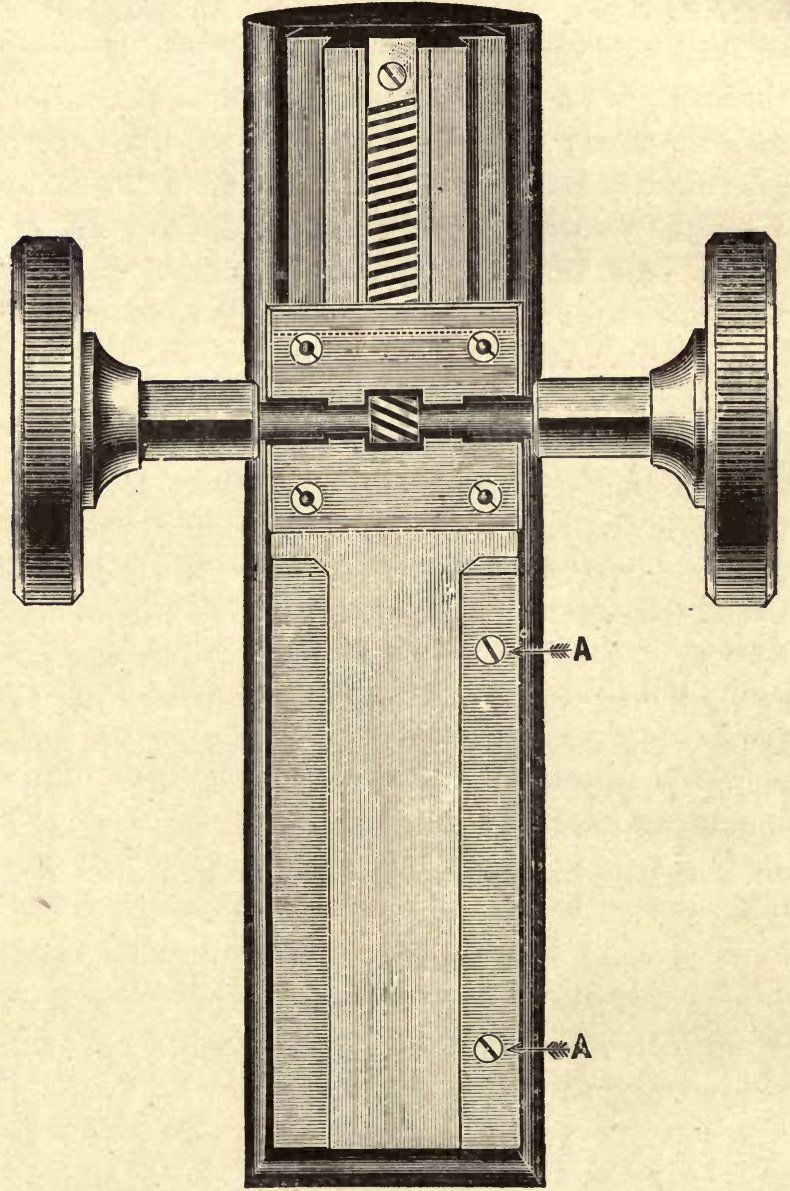

FIG. 3.-View of diagonal Rackwork attached to one of Watson and Sons' Microscopes, showing Dovetailed Fittings to receive Fine Adjustment Slide and Adjusting Screws (marked A).

are constantly being changed, and the condenser may not be required for all of them. Where this arrangement 
exists, it should be fitted in a workmanlike manner, and a proper support given to the fitting when in the optical axis to make it perfectly rigid.

The choice with regard to a sub-stage would therefore be-

In a first-class microscope: Rackwork and centring adjustment and fine adjustment; rackwork rotation, if for examination of crystals or petrology.

Second-class instrument : Rackwork and centring adjustments, and means of lifting aside out of the optical axis.

Student's instrument: The same as the second-class or the plain tube fitting.

\section{ARRANGEMENTS FOR FOCUSSING.}

The next point for consideration is the means of focussing the object-glass. This is done by two adjustments, called the coarse and the fine movements. The former consists of a rack and pinion actuating the body in a very true-fitting dovetailed bearing as per Fig. 3, shown on page 24 . In the illustration it will be seen that the rack is cut diagonally, and this undoubtedly, although rather troublesome in the making, is the best kind, a softer motion being obtainable than with the horizontal form. In order that it may work at its best, each tooth of the rack should be carefully 'ground in'-that is, fitted to a leaf in the pinion-and so that the fitted tooth of the rack may always engage the right tooth of the pinion, it is necessary to so fix the body that when racked up as high as possible it may not be withdrawn from its bearings and rackwork, it being, in fact, provided with a 'stop' screw. It has been recommended that microscopists should take their instruments to pieces in order that they may judge of their workmanship; but in reality a well-made microscope requires as carefully putting together as a watch, and for a novice to attempt to undo the parts means very probable detriment to the instrument, and the name of a first-class maker is a guarantee of the good work, without which he could not possibly maintain his reputation. 
Now as to the Fine Adjustment. A great diversity of opinion is existent with regard to the qualities of the different forms, most writers having their preferences and prejudices. It is a most important movement, and it is compulsory that it shall be quite perfect if high powers are to be used. Personally, after some years of practical acquaintance with Messrs. Watson and Sons' instruments, I can say that with high powers of large aperture I have found their form of fine adjustment perfectly satisfactory. It is shown in position on the instruments (Figs. 1 and 2), and consists of a milled head with a micrometer screw actuating a lever on a pin fixed to the body against a long spiral spring, whereby the body is raised or depressed in a dovetailed fitting. One arm of the lever is four and a half times longer than the other, whereby the weight of the body at the milled-head end of the lever and the motion imparted is reduced in this ratio. Thus the makers give the weight of a body as $17 \mathrm{oz}$. , and this divided by $4 \frac{1}{2}$ reduces the resistance to $3 \frac{7}{9}, \mathrm{oz}$. This system has many advantages. The position on the limb is convenient for manipulation, and is not altered when the body is racked up-that is, it is not carried by the rackwork as in many forms, so that its attachment to a focussing rod of a camera for photo-micrography is easy and convenient. There is also a very simple means of adjustment provided for taking up any slackness through wear. The slide in which the fine adjustment is fitted has sprung slots, to which are fitted screws (shown in Fig. 3, page 24, marked A). By turning these screws slightly, the spring fitting grips the bearing more tightly, and so takes up any wear through friction. Any microscopist can therefore adjust his own instrument.

Another very good and rigid form is that fitted by Messrs. Swift and Son. It consists of a lever in a vertical direction raising and lowering the body tube. The actuating milled head is shown in position on the instrument on page 29 , marked 'patent,' and is carried by the coarse adjustment 
when focussing. This is rather a disadvantage, especially in photo-micrography, as it means altering the position of the connecting arrangements of the camera for different powers; also, being on the side of the instrument makes it additionally awkward, as only one hand can be applied to it; Watson's form in the constant position being more convenient on this account. For their working qualities both of the fine adjustments mentioned are very good-in fact, as perfect as can be desired-but for convenience Watson's is preferable. Powell and Lealand's instruments are also provided with a fine adjustment having special merit, consisting of a lever actuating a long tube sliding up and down inside the body. This, again, has the disadvantage of being carried by the rackwork when focussing for different powers. The differential screw fine adjustment, as made by Mr. Charles Baker, has been well spoken of, but the writer has had very little experience with it.

Nearly every maker has his own system of fine adjustment, possessing features more or less desirable, but they are mostly modifications of those mentioned here. Above all things eschew the form of fine adjustment which carries the whole weight of the body of the instrument, or depresses it against a spring, as in the Continental instruments and cheap students' forms : these are almost worse than no fine adjustment at all, as they invariably soon work loose in the fittings and cause great annoyance.

There is also another form, now almost non-existent, which is fitted on to the microscope at the nosepiece end, and consists of a milled head attached to the body moving a tube inside the body-tube against a spring. This cannot ever work thoroughly well, as, if two round tubes are perfectly true and fit well they clutch, and to overcome this one of the tubes is rendered a little eccentric, giving a lateral shake.

In the choice of a fine adjustment, therefore, eschew the direct acting and the nosepiece forms. 


\section{THE LIMB.}

The limb of the instrument is another important detail. It will be noted by the illustration (Fig. 5) that there is no support for the body-tube from the bar to the top of the eyepiece, and unless this bar be most perfectly fitted, and every detail of construction considered, with such an amount of leverage as there is at the eyepiece end a very apparent shake will soon be noticed. The limb fitted to the other instruments shown, known as the Jackson form, is therefore recommended, as it supports the body from one end to the other, and at the same time is as firmly connected with the other working parts of the instrument as the bar form.

\section{THE BODY-TUBE.}

As to the size of the body. - It has always been the custom, in the construction of English microscopes, to make the body of fairly large size; while on the Continent the reverse is the ease, and it is made as small as possible. Owing to the introduction of Continental oculars and objectives, English makers have in recent years adopted the Continental diameter of body to a considerable extent. For photographic purposes it is held by some workers that a fairly large body should be used, but for ordinary visual work the writer has never experienced any advantage from the large over the small tube. It may here be said that Continental instruments have their bodies constructed very much shorter than the English forms, the rule being to adjust their objectives to a tube 160 millimetres long, while English opticians adjust theirs to one of 250 millimetres. The microseopist who enters enthusiastically into his work invariably has objectives of both Continental and English make, and he therefore requires the convenience of being able to use both perfectly. One or two English opticians make microscopes with a body of 160 millimetres, and a 


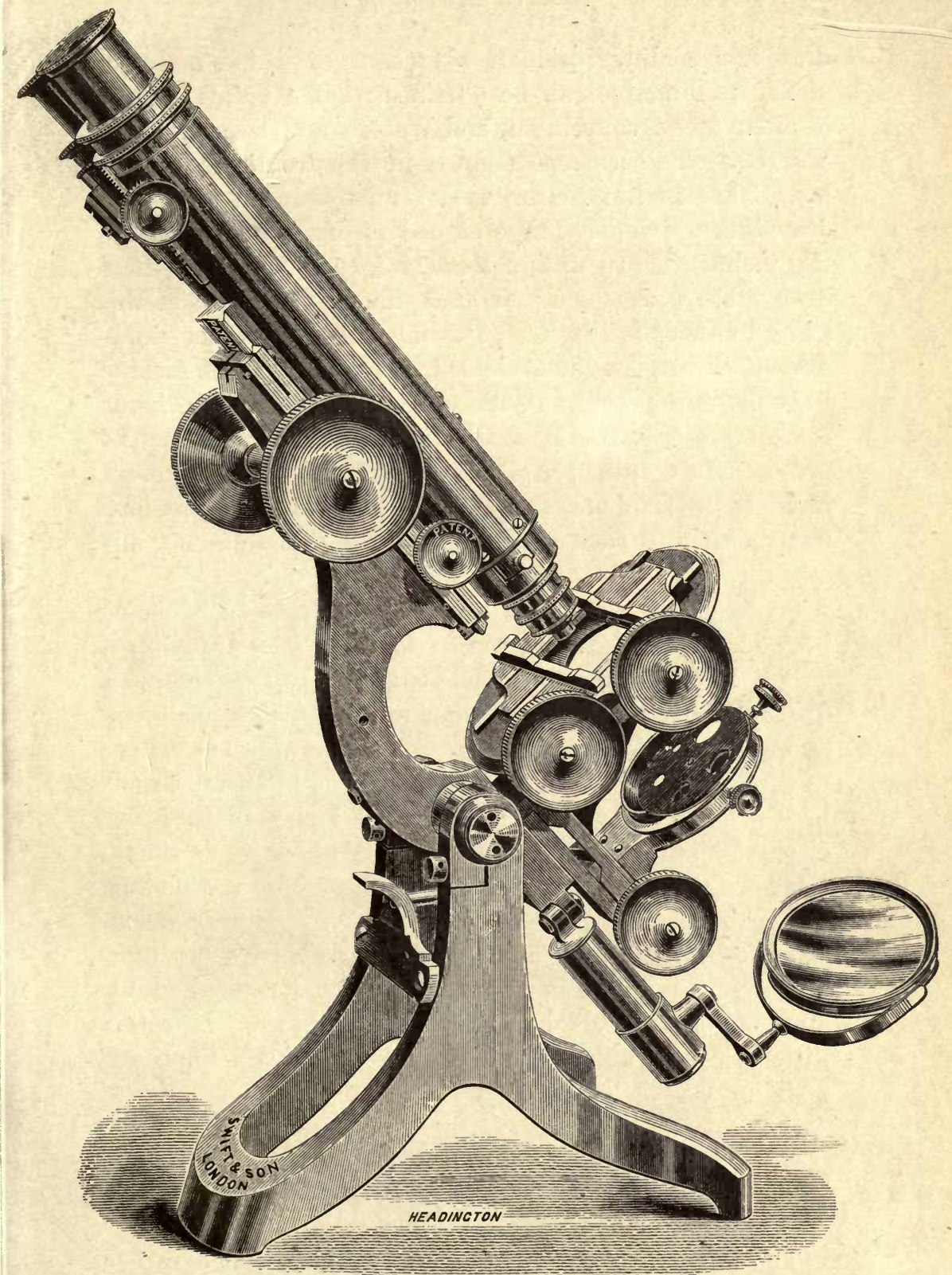

Fig. 4.-Swift and Son's Binocular Challenge Microscope C, with Jackson Form of Foot. A typical amateur's microscope. 
draw-tube sliding inside it by means of which a length of 250 millimetres can be obtained; but a greater range is often found convenient, and Watson and Sons in their Van Heurck microscope (shown in the frontispiece), and Mr. Baker in his Nelson model microscope, supply two draw-tubes giving a range of body from 140 millimetres ( $5 \frac{1}{2}$ inches) to 310 millimetres (12 inches). One of these draw-tubes works by a rack and pinion : the object of this being to afford facility for adjusting the objective for thickness of cover-glass, as described on page 41 . This form of body is coming more and more into use, and will be found a very great convenience to the all-round worker. No precise advice can be given without knowing the work intended to be done, but generally speaking the six-inch body with the two draw-tubes is far preferable to any other.

Some cheaper students' microscopes, instead of being provided with a rack and pinion for the coarse adjustment of the object-glass, are made with the body to slide in a fixed tube. This is a very rough-and-ready arrangement, and accuracy of centring cannot be maintained as with a rack and pinion. These instruments are, however, largely used in hospitals and medical schools, and possessing one element of advantage - namely, cheapness - other considerations are often made subsidiary. Instruments of this kind are generally cast aside or disposed of in favour of an instrument having rack and pinion after a very short time, and anyone purchasing a microscope with a view of adding apparatus to it would be well advised in having one with a little less apparatus, but with a rack and pinion instead of a sliding body.

\section{TAILPIECE AND MIRRORS.}

The mirror should be hung on a tailpiece which can be swung aside. This is usually the case, and is a very great 


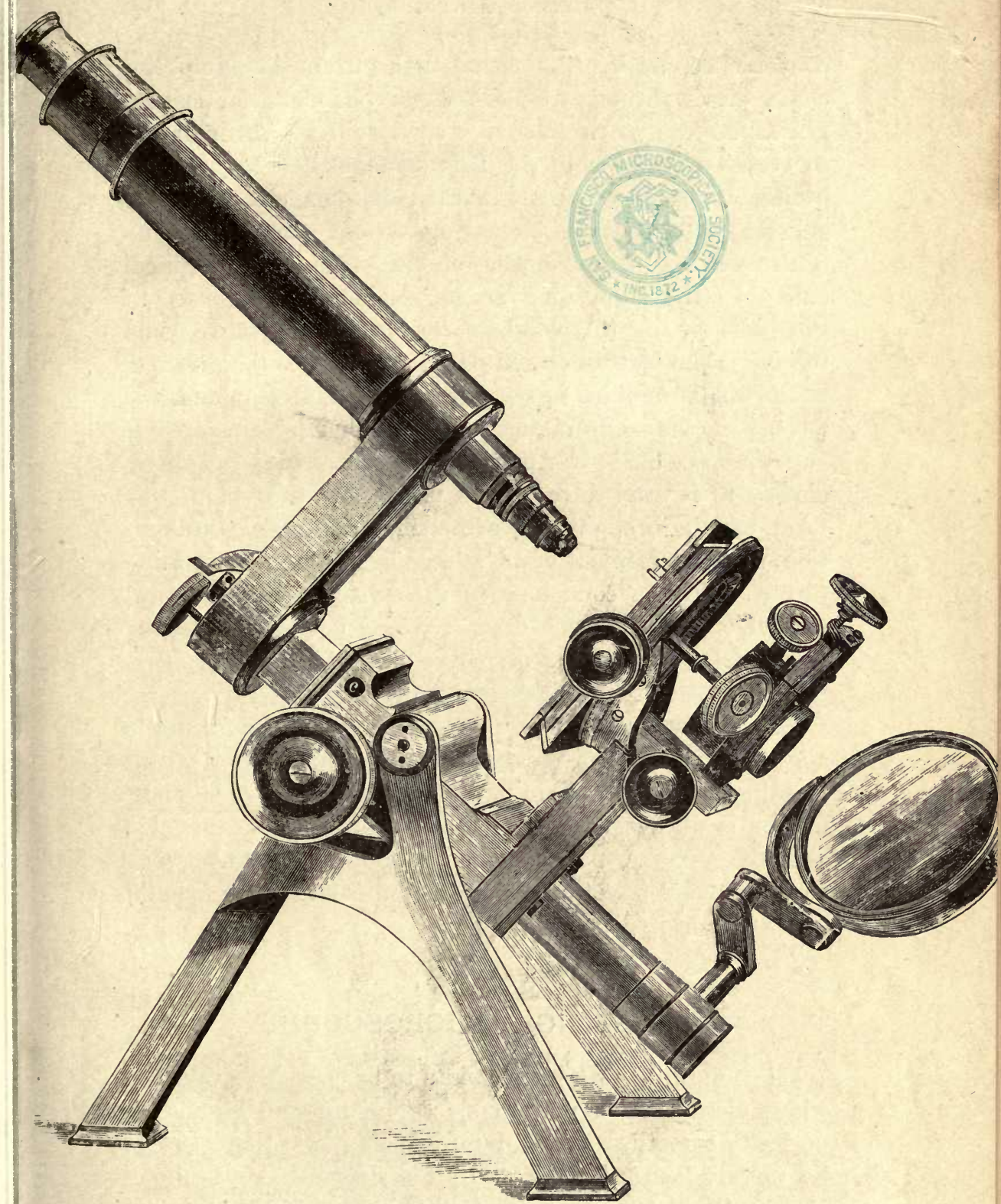

Fig. 5.-Powell and Lealand's No. 1 Microscope. A typical high-class microscope, used by nearly all the most renowned workers. 
convenience, as by this means light from the lamp can come direct through the sub-stage condenser for critical work. A few years since it was a rule in manipulation to obtain oblique light by this arrangement for the exhibition of strix on finely-marked diatoms, etc.; also the sub-stage itself could be swung on an are, having its centre on the upper surface of the stage in the optical axis. In the sub-stage, various condensers were used at the point giving the obliquest ray that the objective could receive. The instrument on page 34 illustrates the arrangement. This method is not now adopted in England, the advent of the achromatic condenser having rendered it superfluous; but our American friends still cling tenaciously to it, and advocate its use. The mirror, in this form, can be brought above the stage for opaque illustration, and this element of advantage largely influences in its favour. With a condenser in the sub-stage in the optical axis, if oblique light be desired it can be obtained to the nicest degree by means of stops, with slots cut in them, placed beneath the optical combination.

The Mirrors should be plane and concave, and hung in a gymbal, giving universal movements, and have a means of adjustment to focus in a vertical direction. The plane mirror is always used with the condenser, spot lens, etc., and with very low-power objectives, but the concave when the condenser is not employed and the maximum amount of light is desired.

\section{TESTING A MICROSCOPE.}

The following are some points to be specially examined when purchasing a microscope: The motions should be perfectly smooth, with no lumpy feeling, and there should be no backlash. This latter can be detected best by holding gently the part that is being moved by the pinion, and then attempting to rotate the pinion. If the pinion 
rotates at all, or a movement of it can be detected without a corresponding motion on the movable part, there is backlash. Then, there should be no shake in any of the fittings. In a badly-constructed microscope, even when the fittings are in their most advantageous position, by holding them and shaking them slightly a movement in the slides can be detected. The body should be racked up a considerable distance to see whether any rock or shake beyond that of the tension on the bearings can be detected. An instrument sound in construction should exhibit none whatever. The stage sho:ld be treated in the same way. A good idea of the comparative quality and finish can often be obtained by examining some hidden or unnoticed part, and observe whether the same care in finishing has been exercised there as in parts that are seen. For instance, if some microscopes be examined underneath the foot, they will be found left in the rough as cast, and merely blacked over; while another instrument will be found carefully finished in that part. It does not necessarily follow that the former is a bad instrument, but it would often be found, if taken to pieces, that there was not a careful fitting in working parts that did not catch the eye, and a probability of its not being so durable as the better-finished instrument.

\section{BINOCULAR MICROSCOPES.}

We have hitherto been treating principally of the monocular microscope, and this, it must be understood, is the only form that can be used for critical high-power work -in fact, the Continental firms as a rule do not make binocular microscopes at all, regarding them as unnecessary. Two or three of them, however, make a binocular eyepiece, which will be found described under the head of eyepieces. The advantage of a binocular microscope is that both eyes can be employed simul- 


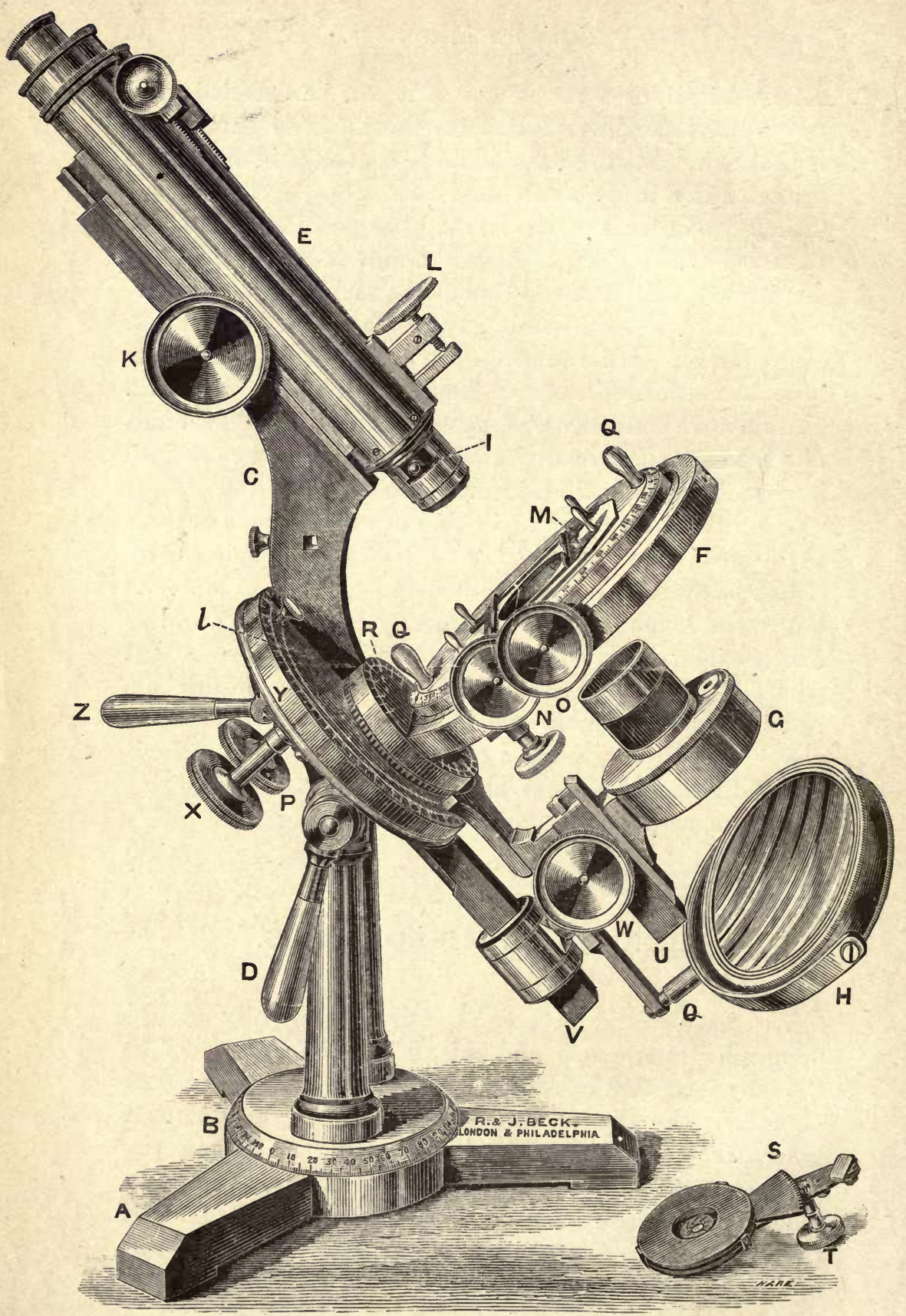

FIG. 6.-R. and J. Beck's International Microscope-stand with Swinging Sub-stage (un 'modèle de luxe'). 
taneously, saving the strain which necessarily ensues through the constant employment of the monocular microscope, and the endeavour to see in the best manner the detail in the specimens. We should recommend every buyer of the monocular microscope to train himself to use either eye, keeping the one not in use open; this will be found of the very greatest service. The universally understood binocular microseope consists of a prism designed by Wenham, which admits of the light going up a direct tube, and reflects light also into a second tube. By this means it is claimed that objects can be seen more naturally than with the monocular microscope, for the reason that stereoscopic vision is obtained, and objects having a certain amount of depth may be seen eompletely with the binocular microscope, whereas with the monocular it would be necessary to focus through the entire depth. These effects are very beautiful, but it must be borne in mind that this form of binocular cannot be used with an objective having a higher air angle than $40^{\circ}$. Provision is, however, always made whereby the prism may be withdrawn, and the light then only goes up the monocular or straight tube, and the instrument is to all intents and purposes as useful and convenient as the monocular, while the observer can rest his unused eye by looking down the blank binocular tube, when the effect of its not being illuminated will searcely be noticed. It must be understood that all vision through the microseope in the ordinary way is inverted, that is, the object is seen upside down. A very good form of binocular microscope, devised by Stevenson and made by Swift and Son, erects the image, or, in other words, it is seen the right way up. It is well spoken of for dissecting purposes, and high powers can be employed with it; still, it cannot be described as an all-round microscope, and would have to be classed with instruments for special work.

For use with the binocular microscope, the closer the posterior lens of the objective is brought to the prism the 
- better. In fact, some makers have constructed objectives in very short mounts, working quite on to the prism up to $\frac{1}{8}$ inch. These, however, are not recommended. Dr. Carpenter some time since pointed out that when an objective having more than $40^{\circ}$ air angle was employed with the Wenham binocular, spherical objects became distorted, and instead of appearing round in shape they became conical. The additional apparent advantage gained is therefore useless.

High-power prisms are also made by two or three opticians, whereby higher powers may be employed with a binocular microscope; but we doubt whether the results obtainable with them are really worth the additional outlay. In those we have seen there has been such a very unequal illumination in the two tubes, that, personally, we should prefer using the instrument monocularly. Our advice on this point would be: If you want to get the maximum comfort in the employment of your microscope, have a binocular, it will be found far more convenient and impressive in showing to friends; but if, on the other hand, it is required for strictly scientific purposes, the monocular will be found to do all that is required. Many microscopists haye separate monocular and binocular bodies fitted to their microscopes, so that they may get the best results either way. This is a very good plan.

\section{DISSECTING MICROSCOPES.}

These as a rule are of plain construction, sometimes fitted with simple unachromatized lenses, but in the best kinds with aplanatic lenses. The most important points in this instrument are, that it should afford convenient rests for the hands, should not be very high from the table, and be provided with a glass stage. The desirability of always using well-corrected lenses in this, as for all other purposes, cannot be too strongly advised. The difference in cost in 
this respect in a dissecting microscope need not exceed $£ 1$, and it requires very little comparison for the difference to be appreciated. The Steinbeil Loupes of Zeiss are excellent for this purpose, and can be had mounted on a plain stand, or can be adapted to most of the ordinary dissecting microscopes, particulars of which can be obtained from the various makers' catalogues. 
CHAPTER II.

\section{OPTICAL CONSTRUCTION.}

Is the former part of this' book we have dealt exclusively with the stand, or mechanical means of employing the various optical accessories, and important as it is that those details shall be very efficient, it is, if anything, still more so that the eyepieces, objectives and illuminating apparatus shall be of the most perfect description, properly adapted and intelligently employed, as on the optical combinations depend the results that are to be obtained with the stand; and although care and trouble may enable a person to use a bad stand, no good stand can ever compensate in any way for bad objectives. It requires a deal of practice and a long apprenticeship to learn to use the microscope to the utmost advantage, but the more it is understood the greater will be the appreciation of it.

\section{MAGNIFYING POWER.}

It is often supposed by the novice that magnification is dependent on the size of the instrument, and a large one is frequently described as a very powerful one. This is quite an error. Given similar eyepieces and objectives, the same magnification is obtained on a small microscope as on a large. It is entirely dependent on the two optical parts, the objective and the eyepiece, or ocular. Under the head of 'Objectives' in the makers' catalogues it will be noticed that the powers are expressed as 1 -inch, $\frac{1}{4}$-inch, $\frac{1}{8}$-inch, etc. This does not indicate the distance at which they focus on 
the object, but very approximately the actual magnifying power of the objective, and is based on the power afforded by a simple lens of that focus. For instance, a simple lens of 1 -inch focus has a power of 10 diameters, and an objective called a 1-inch, and composed of several lenses in order to produce achromatism, should have a similar power; the $\frac{1}{2}$-inch 20 diameters, the $\frac{1}{4}$-inch 40 , etc. The image formed by the objective is again magnified by the eyepiece. Unfortunately, the latter is rarely marked with its power, the general rule being to call them by the letters A, B, C, D, etc., or 1, 2, 3, 4, etc. This is not very intelligent, and it would be far better to either express their focal power, as in the case of objectives, or to have it marked on the cap in diameters. We will take it that the $\mathrm{A}$ eyepiece yields a magnification of 5 diameters. When this, therefore, is used in conjunction with the 1 -inch objective, which, as we have said, has a power of 10 diameters, the resultant power is 50 ; that is, the powers of the objective and eyepiece multiplied together.

\section{OBJECTIVES.}

The enormous strides that have been made in the perfection of objectives within recent years have revolutionized microscopy, and the introduction of the apochromatic objectives has put the science of microscopic optics on a higher level than had hitherto been attained. Undoubtedly, by critical comparison, these lenses in conjunction with compensating eyepieces, referred to on page 48 , are superior to the ordinary achromatic objectives, as in them residuary aberrations are eliminated in a far higher degree than in the best of previous objectives. Credit for this is due to the firm of Carl Zeiss. Subsidised by the German Government, new optical glass was made, placing in the hands of the optician a greater field from which to select the materials of which to construct his lenses, and by the most careful mathematical calculations the matter was accom- 
plished. This glass is now obtainable by any optician, and the apochromatic objectives are made in great perfection by many other firms, notably Reichert of Vienna, and Powell and Lealand of London, whose productions compare favourably with the best of the original firm, Zeiss. Now, these lenses are very expensive, and quite beyond the reach of the ordinary amateur who, taking up microscopy apart from its scientific aspect, endeavours to find his recreation in the minute, and excepting to a trained critical eye they would not be found to possess the extraordinary merit that is claimed for them, and the question naturally occurs, ' Is it worth while paying four times the price of a good high-class achromatic objective for an apochromatic objective and the incident extra cost of eyepieces?' In reply, we would say, 'Yes' and 'No.' Yes, if the intending purchaser proposes to do his work on the most exact and highest scale, and to conduct original research; no, if his aim is only to examine into nature's small things without attempting to obtain the apparently impossible in results, and the observation of structure not hitherto discovered. We would here quote from the words of Professor H. L. Tolman, President of the Illinois State Microscopical Society: 'Of the apochromatic objectives and their comparative advantages with the ordinary highest-class lenses, it must be remembered that the difference in degree between the performance of the best American and English achromatic lenses and the Zeiss apochromatics is often only detectable by the experienced eye; and, secondly, that the vast bulk of microscopical work is done with medium or low powers, where the diffracting beams play a much less important part proportionately, the image being chiefly dioptric. As to the first point, the writer may even go farther, and say that it is a contested point among many of the highest authorities in America whether the Zeiss apochromatics have any marked practical superiority. The student may rest contented, therefore, that he can work for an indefinite time with any good American or English lenses without losing his time or 
rumning any serious risks of making mistakes in what he sees.'

This opinion is borne out by many of the most careful and practical observers in the microscopical world; still, as before remarked, if original research is to be conducted, and the very finest results are to be obtained, and the minutest structure detected in the plainest manner, the apochromatics should be selected. There is another advantage which these lenses are claimed to possess: they will work with very high-power eyepieces, so that a great variety of magnification may be obtained with one objective. Presuming an apochromatic objective of $\frac{1}{4}$-inch power, having an initial magnification of 40 diameters, will stand an eyepiece power of 27, a maximum magnification of 1,080 diameters, and by means of the searcher ocular power 2, as low a power as 80 diameters can be obtained with that one lens. Now, this is a very wide range, and saves a lot of trouble in unscrewing objectives to insert those of a higher power. The best quality achromatic objectives also stand a fairly high eyepiece power, say up to 16 , or even 20 , but not in the perfect manner that the apochromatics do. Magnifying power, however, is not the primary thing in connection with an objective, unless there is a corresponding delineating power. This latter quality is dependent on the aperture.

\section{Apertures of Objectives-Angular and Numerical.}

On the aperture possessed by an objective depends the amount of detail that can be discerned, and it is a most important point in the selection of an objective. The theory of microscopic vision, as formulated by Professor Abbé, is well worth comprehending, and is continued in extenso in the larger works on the microscope. It hardly comes within the compass of this volume, which is intended to be practical only.

Until the introduction of immersion objectives, the angular aperture of an objective was always given-that is, 
the angle formed by the extreme rays that could be received by the object-glass, issuing from the object-as an expression of its power of resolution, or ability to delineate delicate structure. Theoretically it is impossible for a dry objective to receive light at a greater angle than $180^{\circ}$, and this notation answered its purpose so far as it went, but when immersion objectives were introduced this no longer held good. It was found that by interposing a medium, either water or oil, between the front lens of the objective and the covering glass on which the object is mounted, so that continuity is established between them-the objective, of course, being specially corrected for use in this waythat a larger number of rays were utilized than when working a lens dry. It is a well-known rule that rays passing from a rarer to a denser medium are refracted towards the perpendicular. Consequently, if an immersion lens be used it is able to transmit a larger number of rays from the object to the image than a dry lens could possibly do. The media used-viz., cedar-wood oil or water-have refractive indices of 1.52 and 1.33 respectively, the former being the same as crown glass, while air is 1.0 ; therefore, by employing an oil immersion lens, greater effect is obtained than with a water immersion. So great is the advantage gained by this immersion system, that a dry lens having an air angle of $180^{\circ}$ would be equalled by a water immersion lens having a water angle of $96^{\circ}$, and this latter equalled by an oil immersion lens having an oil angle of $82^{\circ}$, and each of these immersion lenses can theoretically be carried to oil and water angles respectively of $180^{\circ}$. This expression of angle would, therefore, be misleading and uncertain, and it would be necessary to have three separate expressions of angle for the different systems. To meet this Professor Abbé devised the notation termed ' numerical aperture,' represented by the formula $n \sin u$, where $u$ equals the sine of half the angle of aperture, and $n$ the index of refraction of the medium by which the objective front is surrounded. 
Numerical aperture 1.0 representing the air angle of $180^{\circ}$, and the equivalents in water and oil above given.

To enable the numerical apertures of objectives to be taken without a calculation, Professor Abbé introduced the apertometer (see Fig. 7). This consists of a semicircular plate of crown glass, with the diametrical edge ground to an angle of $45^{\circ}$. The centre of the semicircle has a silver dise with a very small opening; two pointers are fitted on the outer edge of the instrument, and a scale is marked on the upper surface. This is laid on the stage of the microscope, and the objective screwed on that it is proposed to test. A low-power object-glass is included with the instrument, and must be fitted into the lower end of the

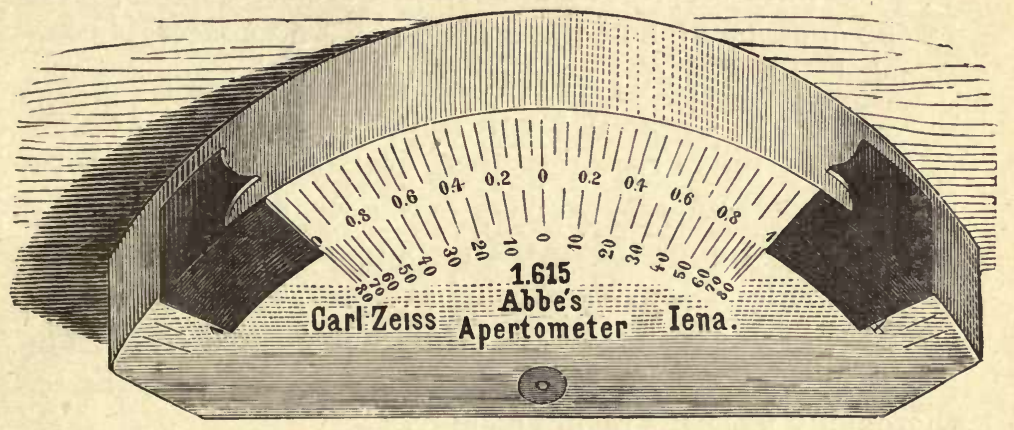

Frg. 7.--Abbé Apertometer.

drawtube of the microscope, the eyepiece being inserted as usual. The edge of the apertometer is then illuminated by means of a bull's-eye condenser and lamp, and the two pointers set at the centre of the outer circle. The drawtube must now be moved carefully up and down until these pointers are seen sharply in the centre of the field. Each is then moved round the outer circle of the apertometer in opposite directions until the edge of the field is reached. The reading is then taken.' In the case of an oil or water immersion lens, the medium must, of course, be placed in front of the object-glass.

It has been explained by Dr. Dallinger, in 'Carpenter on 
the Microscope,' that two objectives-one of much greater power than the other, but both having only the same numerical aperture-will only show the same amount of detail, the higher power on a larger'scale. That is, supposing with a $\frac{1}{4}$-inch objective of 1.0 N.A. certain structure is presented, and an $\frac{1}{8}$-inch objective with just double the magnification, but with the same N.A., were used, there would be no further power of resolution in the $\frac{1}{8}$ than in the $\frac{1}{4}$. It therefore follows that the consideration of numerical aperture must have weight in choosing an objective, and here again we come to the actual limit of operations proposed to be undertaken by the microscopist. Although large apertures are the pride of those whose ultimate microscopical ambition in life seems to be bounded by the question of how the marking on Diatomaceæ is constructed, it is doubtful whether, for the ordinary amateur, there is a real necessity for these large apertures. Lenses of this description require a great deal of trouble and care in manufacturing, and are very expensive, and if recreation alone be the aim of the intending purchaser, the best series of achromatic objectives which have fairly large apertures, or even in some instances the medium aperture lenses comprised in the second class or second series, will be found to thoroughly meet his requirements.

The best objectives for a novice at starting would be 2 inch, 1 -inch, and $\frac{1}{6}$-inch. The 2 -inch will be found extremely useful for large specimens, while the 1-inch, which is considered the working glass of the average microscopist, will, with a higher power-namely, the $\frac{1}{6}$ - show him some of the minuter detail which sooner or later he will wish to make himself acquainted with. If more object-glasses than these be required, we should recommend the $\frac{1}{2}$-inch as an intermediate between the 1 -inch and the $\frac{1}{6}$, and for a higher power a $\frac{1}{12}$-inch oil immersion objective should be added. Of course different requirements would necessitate certain series of objectives, but a practical microscopical friend will soon advise on this point, or any microscope manufac- 
turer. It should be borne in mind that the ordinary Wenham binocular will not work with an objective having a larger air angle than $40^{\circ}$. Most objectives having a numerical aperture of more than $0 \cdot 66$ have what is termed a correction collar, whereby the two back combinations of the objectives are removed farther from, or brought closer to, the front lens. As a rule, objectives are corrected for a certain thickness of cover-glass, which is placed over the object to protect it; but these cover-glasses vary considerably, and consequently disturb the corrections of the objectives. In order to compensate for this, collar adjustment is added. Its method of use is as follows: Set the lens at zero in the direction marked, uncovered, on the objective, focus some dust on the surface of the cover-glass, then turn the adjustment collar until the object itself beneath the cover-glass comes into view; the objective will then be corrected for that thickness of cover-glass. Experience alone can show how to do this correctly and to the best advantage, but it can hardly be recommended to students, as they cannot afford the time and trouble necessary to get such perfect results, and prefer the fixed mount. Corrections may be made for the fixed mount by shortening the body tube of the microscope should the cover-glass be thicker than that for which the objective is intended, and lengthening it if it be thinner.

Since the introduction of the new glass great improvements have been made in the cheaper class of achromatic lenses, many of them almost rivalling the apochromatics; but these are individual glasses, from several makers' series, the No. 6 leus by Reichert being a specially fine specimen. They are extremely sensitive to variation of thickness of cover-glass, and it will be found advantageous if the instrument be provided with the means of lengthening the body by drawtubes to 12 inches; and, on the other hand, when the drawtubes are closed, of having a body shorter than the Continental length ( 6 inches). In order that the best adjustment may be made, it is very 
essential that one of the drawtubes should be actuated by rack and pinion, and it cannot be too strongly urged on purchasers of instruments to try and obtain those having this convenience. There is no doubt that as soon as the demand is made the manufacturers will meet it with a cheaper and equally efficient rackwork drawtube than the expensive ones at present obtainable.

It is a somewhat difficult matter for the novice to choose his own object-glasses, as it is only by comparison he can judge as to their merits. For objectives varying in power from 2 inches to $\frac{1}{2}$ inch nothing is better as a test than the proboscis of a blow-fly. The spines should be focussed and each show a well-defined point; a higher power eyepiece should then be inserted, and any diminution in definition should be noted. We would here remark that it is always advisable to buy these low-power objectives composed of double combinations. Some of the cheaper ones are only composed of two or three lenses balsamed together; with these sufficient aperture cannot be obtained, nor good definition combined with flatness of field. All the best low-power lenses are constructed with two pairs of lenses a little distance apart, and can be recognised immediately. Flatness of field is an important point in a low-power objective, and the best method of testing for this quality is by either a stage micrometer focussing the ruled lines, or a piece of ground glass. With the higher powers this feature is sadly neglected, especially in lenses of Continental make, it being advocated by one or two leading workers that it is better to get the utmost perfection of definition in one central point rather than that definition should be in any degree sacrificed for flatness of field. It would certainly be a great advantage to the microscopist if the two points could be combined in a more satisfactory manner than they are at present. The English manufacturers, in their high powers, generally provide a flatter field than their Continental contemporaries. As tests for objectives from $\frac{1}{4}$ inch upwards, the internal markings of Triceratum, the striæ of Pleurosigma 
angulatum, and the markings on scales of Podura are suitable.

\section{EYEPIECES.}

The eyepiece commonly used with the microscope is what is termed the Huyghenian form, which consists of two plano-convex lenses placed at a distance apart equal to half the sum of their foci, with a stop in the principal focus of the eye-lens. This will be found to meet all ordinary requirements of microscopical work. They vary in power, and these powers are usually designated by the letters A, B, C, D, etc., A being the weakest power. On the Continent they are generally designated $1,2,3$, 4, etc., while some firms express their power in

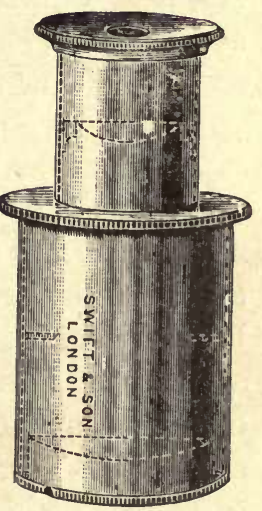

H'ra. 8.-Huyghenian Eyepiece. focal units-for instance, an eyepiece having a power of 10 would be 1 inch. It is often remarked that the Continental objectives stand a stronger power of eyepiece than the English, and on this account a superiority has been claimed for them; but it should be borne in mind that no two series of microscope-makers' eyepieces are of the same power, and where English manufacturers give in many instances as deep a power of eyepiece as 20 or 25 , the Continental manufacturers make their eyepieces much nearer one another in power, and their deepest eyepiece has usually an initial power of 10 or 12: A comparison, therefore, between the merits of an English object-glass tested with, say, a D English eyepiece and a Continental object-glass of the same power tested with a No. 4 eyepiece of Continental make would not be fair, as the former, having a deeper-power eyepiece on it, would be liable not to give such perfect results as the latter; and here we may mention that, although people very often buy deep- 
power eyepieces, it is advisable for ordinary achromatic lenses that no stronger power should be used than an eyepiece giving an initial power of 15 diameters. The best eyepiece for general purposes is the $\mathrm{B}$. This gives a nice size field, and is by far the most comfortable of the whole series. Next, and in addition to this, we should recommend either the $\mathrm{C}$ or the $\mathrm{D}$.

\section{Compensating Eyepieces.}

Under the head of 'Objectives,' it will be seen that we refer to the new apochromatic objectives introduced by Zeiss, and made by several other firms. In order to obtain the best results, it is necessary to use with them compensating eyepieces. These are over-corrected, and the apochromatic objectives under-corrected, while the Huyghenian eyepieces are under-corrected, and the ordinary objectives overcorrected. It is obvious, therefore, that Huyghenian eyepieces are unsuitable for the apochromatic objectives; also the compensating eyepieces will not work well with objectives of low power, but they give very good results with objectives of large aperture of the achromatic series; still it would not be worth while to purchase them for use with these. These eyepieces being achromatized, and consequently having more lenses in them, are more expensive than the Huyghenian form.

\section{Kelner Eyepieces.}

This is another achromatic form of eyepiece, giving an exceedingly large field, and considerably used for the examination of animalculæ, pond life, etc. A certain amount of definition is, however, sacrificed with them, and although we occasionally use them, before deciding on purchasing any, we should recommend the microscopist to judge for himself as to the desirability or otherwise of his having them; they are not by any means necessary adjuncts. We may mention that they give very good results photographically. 


\section{Projection Eyepieces.}

These were designed specially for projecting objects on to the screen and for photographic purposes. They give an exceedingly small field, but an exquisitely sharp one. There is provision for moving the position of the eye-lens in these, and in order to get good results with, them it is necessary to do this until the stop between the lenses is sharply projected on the screen. All photo-micrographers of note use these eyepieces, but as they have the same corrections as the compensating eyepieces, they cannot be employed with low power ordinary

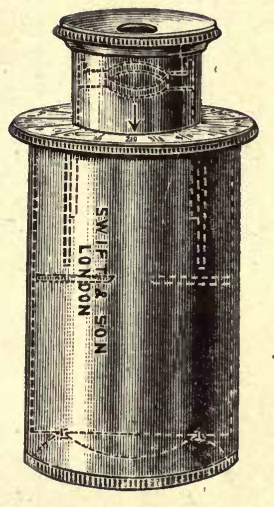

Fig. 9. - Projection Eyepiece. achromatic objectives. With the higher powers, however, from, say, $\frac{1}{6}$-inch of N.A. $\cdot 80$, they work well. For photographing with ordinary objectives of low power, the ' A' eyepiece gives good results.

\section{Binocular Eyepieces.}

As we have mentioned under 'Binocular Microscopes,' most of the Continental firms do not make the binocular microscope. Therefore, for those who desire to be able to employ both eyes, they make a binocular eyepiece, but only for the Continental length of tube, and this should be particularly understood. The one with which we are acquainted is that designed by Abbé, and manufactured by Zeiss, as figured page 50 (Fig. 10). It gives stereoscopic effects and most beautiful results with both high and low powers. It is somewhat expensive, which necessarily restricts the sale, and is therefore a luxury; although perhaps desirable, it is not necessary.

There is no universally adopted size of fitting for eyepieces, consequently every maker. has his own gauges, 
varying for nearly every instrument. This is much to be deplored, as it gives a lot of trouble to workers, especially

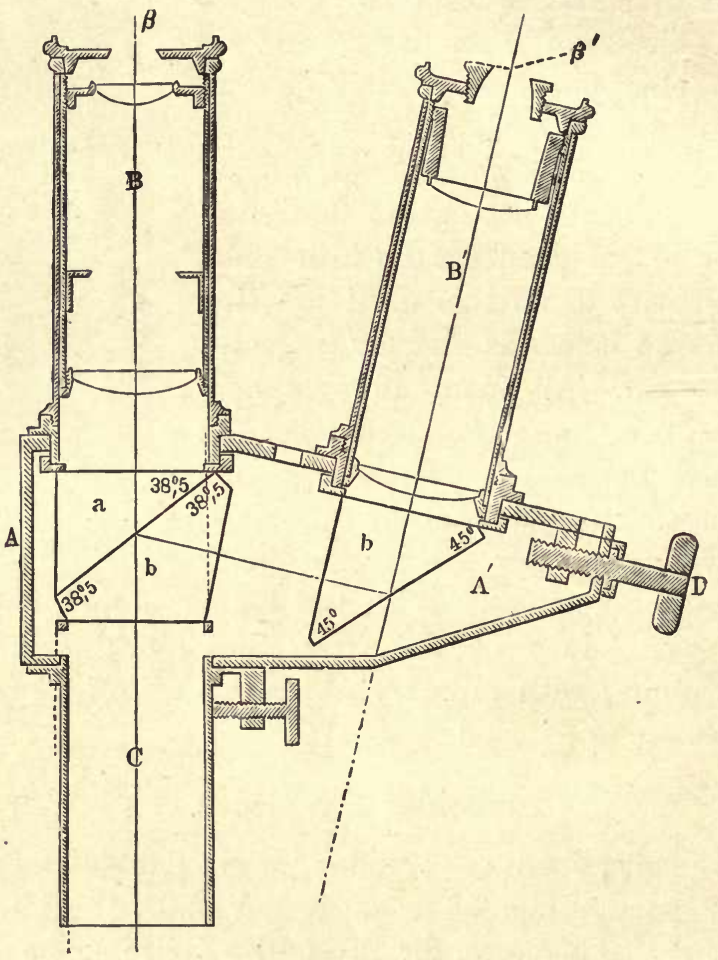

FIG. 10.-Zeiss's Binocular Eyepiece.

they require another maker's eyepiece. It could easily be remedied, and would be a great boon.

\section{ACCESSORIES.}

\section{Illuminating Apparatus.}

A few years since all that was considered necessary in order to illuminate in a proper manner an object under examination was the mirror, perhaps in conjunction with the stand condenser; and in many cases the mirror was hung on a tailpiece which could be moved in an are round 
the object, and by this means light at any angle could be reflected on to the stage. The day for this, however, has gone by, and anyone who requires to get even fair results must use a sub-stage condenser in some form or other. Especially does this apply to high-power objectives. Plenty of illumination can be obtained with the mirror only for lenses up to, say, $\frac{1}{4}$-inch, but beyond this the object becomes ill-defined and the field dark. More especially since the study of bacteriology has taken so prominent a position has the condenser come to the front. Without its aid it would be almost impossible to distinguish between these minute organisms. The condenser introduced by Prof. Abbe (of the firm of Zeiss, Jena), and termed the Abbé illuminator, is that most popularly in use for this purpose, and fulfils all ordinary requirements. It is made in two forms, having numerical apertures of $1 \cdot 20$ and $1 \cdot 40$ respectively. The former is most generally employed, and can be obtained at a very low price. On account of its large aperture it gives a most brilliant illumination with the highest powers, while with the lower powers, by removing the top lens, equally good results may be obtained, its only drawback being that it is not achromatic. It has been claimed by some that this is not an essential to a sub-stage condenser, but a comparison of this with the new achromatic form of the same maker certainly gives the advantage to the achromatic condenser, but it has not such a large aperture as the chromatic form. The chromatic form of condenser is supplied by nearly all the London microscope-makers, but the new achromatic form having a numerical aperture of 1.0 is made by only two or three firms. We should strongly advise purchasers to have these condensers of English make, as the German mounts are so exceedingly heavy, and, not being usually intended for the English form of microscope, have to be adapted, and where they are made by German firms for the English microscope are so clumsy that they are apt to impart vibration, and are awkward to handle. 
We show (Fig. 14) one of these condensers mounted for sub-stage, with iris diaphragm, by means of which the aperture may be quickly and exactly obtained. This is a most convenient method of fitting, and stops are supplied by means of which dark ground illumination may be obtained,

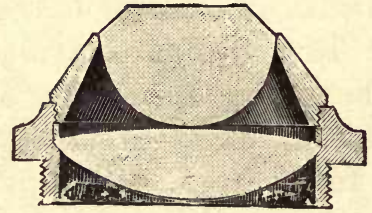

Fig. 11.-Abbé Illuminator, $1 \cdot 20$ N.A., optical part.

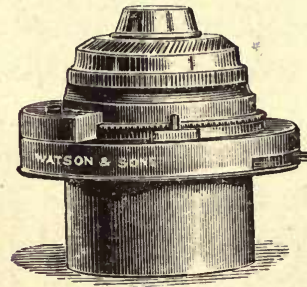

Fig. 13.-Abbé Illuminator, mounted for Sub. stage Instrument.

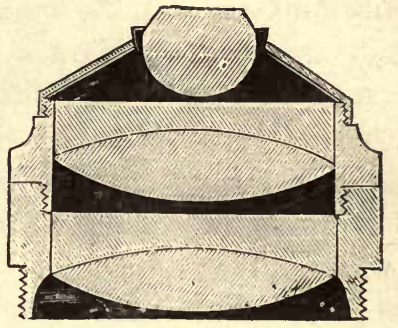

FIG. 12.-Achromatic Condenser, $1 \cdot 0$ N.A., optical part.

as with the spot lens described on page 56 , also blique illumination for the resolution of Diatomaceæ, etc. This latter procedure has been condemned by several leading microscopists, but

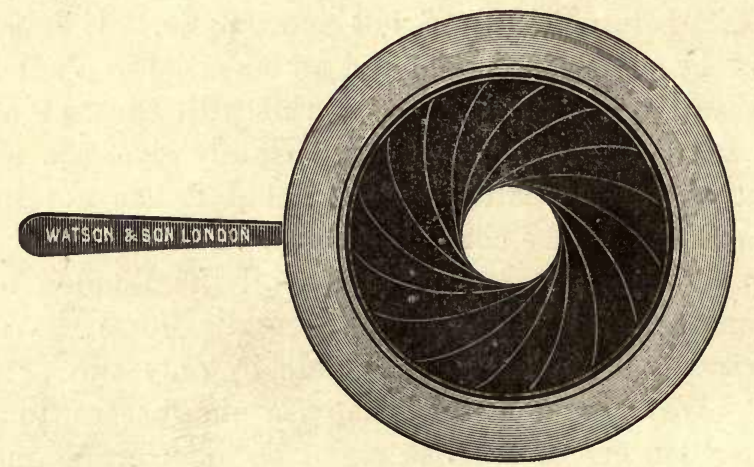

FIG. 14.-Iris Diaphragm, as fitted to Abbé Illumina tor, etc.

as it is always some satisfaction to the amateur to show striæ, etc., on Diatomaceæ in as clear a way as possible, and to be certain always of obtaining the same result, he would be well advised in having the dia- 
phragms, as by their means results are more easily and uniformly obtained in inexperienced hands.

The Webster achromatic condenser is another pattern supplied by nearly all microscope-dealers, and at one time it was very popularly used; but it is rather antiquated now, and is suitable only for comparatively low powers on account of its small aperture. Another method often adopted is to have a fitting in the sub-stage, with a screw to take an objective, and low-power glasses fitting this way will make a very efficient form of condenser. Swift and Sons make a very excellent achromatic condenser with an air angle of $150^{\circ}$, and for the most critical work of the highest character the firm of Powell and Lealand make a condenser of very large aperture of the apochromatic form. This is very expensive, and requires skill in management, but if the very best is desired this is unequalled. It is especially appropriate for use with the apochromatic objectives.

Now as to the practical working with the condenser. It will always be found best to employ the edge of the lampflame, as its image can then be projected into the field of view; and we would here mention that it is a most important element in microscopy that a suitable lamp should be employed. (For notes on lamps see page 59.) A plane mirror should be used. The first step is to centre the condenser accurately with the objective, and herein is advantage of the centring sub-stage. Where no sub-stage is fitted to an instrument, it is understood that the underfitting which receives the condenser is central; but this cannot be always perfectly accurate, for if a condenser be rotated in the sub-stage it will probably be found that it will be central in one position only. It is, therefore, essential that before starting any work this should be accurately centred. Some condensers have fitted on top of them a removable cap with a very small pin-hole. This pin-hole should be focussed with, say, an inch or a half-inch objective, the condenser centred by it; then the cap should be removed from the condenser for working. Condensers not having 
this cap can, as a rule, be centred by means of their diaphragms at the back, focussing the aerial image of it when closed with a $\frac{1}{2}$-inch objective; but the easiest way to do it is to make a very small spot in the centre of the top of the lens with ink, centre by this, and wipe it off. It will not make any difference to the performance of the condenser, and will ensure accuracy and save a lot of trouble. Having centred the condenser, it should be racked up until it touches the under-side of the slide, the objective being made to touch the object on the upper side; see that the diaphragms of the condenser are open, reflect the light with the mirror, when the field will become illuininated; then rack the microscope body upwards until the object comes into view. It may be found that there will be too great a flood of light. If so, the aperture of the condenser must be decreased a little by means of the diaphragm. Having focussed the object on the upper side with the objective, it will be necessary to focus the condenser. Rack this downwards from the object very slightly until the image of the lamp-flame is seen in the centre of the field, the remainder being comparatively dark, as in Fig. 15. If now it be desired to have the whole field equally brilliant, turn the burner of the lamp round till the flat of the wick is towards the mirror.

The next question is, What amount of light should be admitted from the condenser in order

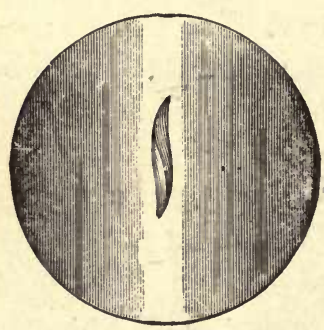

FIG. 15.-Image of Lamp-fiame. to see the object at its best? $\mathrm{Mr}$. Nelson has suggested and demonstrated that the aperture of the condenser should be about three-quarters that of the objective, and in order to ascertain this it will be necessary to remove the eyepiece from the microscope, and look at the back of the object glass, opening the diaphragm of the condenser to its fullest extent. Bearing in mind the size seen, gradually decrease the size 
of the diaphragm of the condenser until one quarter of the back of the objective is shut out, again put in the eyepiece, and this will be found to give the most accurate results. Of course, this may be varied according to the transparency or opaqueness of the object under view.

Condensers having a numerical aperture of 1.0 and over require to be immersed in order to get their full aperture; that is, a drop of immersion oil or Canada balsam should be placed between the top lens of the condenser and the object. It will be found generally that the condenser is a little too long in focus for this to be effected. Under such circumstances an additional $3 \times 1$ slip should be placed under the object, when the oil contact will be easily maintained, but the distance will vary according to the thickness of the slip on which the object is mounted, and the intermediate contact slip would have to be selected accordingly. With the majority of condensers there are also fitted diaphragms having the centre blocked out, with which dark-ground illumination is obtained. This gives a beautiful effect to very transparent objects, such as infusoria, pond life specimens, etc. In the Abbé illuminator a cell for this is generally provided just over the iris diaphragm and beneath the condenser lenses. One of these darkground stops should be fitted into the ring, the iris diaphragm opened completely, the condenser having been previously adjusted in the usual way, when it will be found that the object will be illuminated; but the ground on which it is seen will be black. Different objectives require different sizes of diaphragms. For this purpose blacked cardboard may be easily cut to the size and adapted exactly to suit the objective. For oblique illumination one of the stops having a crescent or a slight slot is fitted in this ring, the iris diaphragm being open completely, when it will be found that striated objects will be exhibited in a very concise manner. That the employment of a condenser is an absolute necessity cannot be too much impressed. No good results can be obtained without it. 
Either of the Abbé illuminators or achromatic condenser 1.0 N.A. will be found the most generally efficient and useful. The former is cheaper than the latter, but the advantages of achromatism make the latter more desirable.

\section{The Spot Lens.}

Other means are provided for obtaining dark-ground illumination, and consist of the spot lens and the paraboloid. Owing to the perfection with which this effect can be now obtained with the sub-stage condenser, these have been largely superseded. They are, however, often used, and preferred by some to the condenser. It must be understood that they cannot take the place of the condenser for ordinary direct transparent illumination. The method of using is simple, the spot lens being intended for low powers and the paraboloid for higher ones. With both of them a plane mirror and the flat of the wick of the lamp should be used. If the spot lens be employed, it should be moved up and down in the sub-stage fitting until a perfectly black ground is obtained; if additional brilliancy is required on the object, a stand condenser interposed between the lamp and the mirror, with the convex side of the condenser towards the lamp-flame, will give an additional effect. The paraboloid is adjusted in a similar manner, but instead of having a fixed black spot on the top of the lens it has an adjustable one, and the pin carrying this black spot should be moved up and down until the best effect is obtained. This latter is far more expensive than the spot lens, and the advantage gained is so slight that we can hardly recommend it.

\section{The Polariscope.}

This consists of two parts, each composed of a Nicol prism in a suitable mounting-one called the polarizer, which fits into the sub-stage, and the other the analyzer, which is inserted between the nosepiece of the microscope 
and the objective. By its means light is split up into its component parts, and most beautiful colour effects are obtained. The polarizer has a flange beneath, by means of which it can be rotated, and in this way the colours are varied. For certain chemical crystals, geological slides, etc., it brings into view structure which without it would hardly be detected, and it is largely used in analytical work. In some instruments the analyzer prism is fitted in the body. This is rather an inconvenience unless the instrument be designed especially for petrology. For a binocular microscope, however, it is better not to have it between the nosepiece and the objective, as it creates a distance between these two, which interferes with the per-

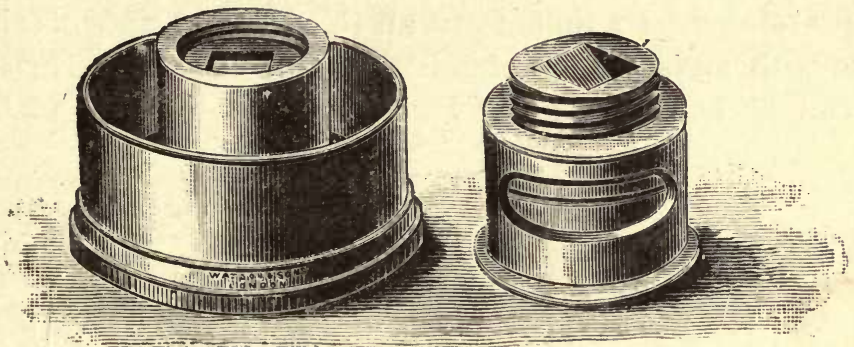

FIG. 16.-Polarizer.

Fig. 17.-Analyzer.

formance of the binocular prism; in fact, the closer the back lens of the objective can be brought to the binocular prism, the more perfect will the vision be. Under these circumstances the analyzer prism is best mounted over the top of the eyepiece and the monocular tube alone used. For use with the polariscope, varieties of tints and a background of colour can be obtained by the employment of selenite films. These, in the cheapest form, are mounted in the same way as ordinary microscopic objects; but a still greater variety of effect can be obtained by having selenites fitting into a carrier to come between the polarizer and the stage in a sub-stage microscope. We illustrate one (Fig. 18) by R. and J. Beck. In this form each of the selenites is provided with a ring which rotates. The three being one over 
the other, either two or all three can be rotated together or in opposite directions to one another, and the effect is most

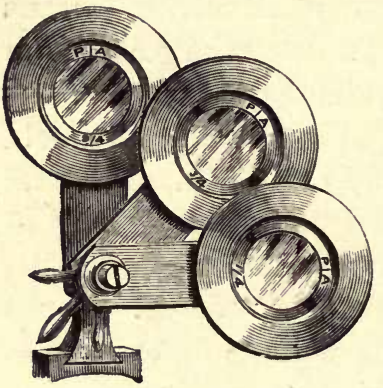

FIg. 18.-Darker's Selenites. striking. This is an expensive item, but a modification of it is made by Swift and Sons, called the mica-selenite stage, as shown in Fig. 19. This consists of a film of mica made to rotate in a brass plate, upon which the object is laid, and beneath it is a carrier with three separate selenites. These can each be pushed separately beneath the mica and the latter rotated. By this means all the different tints obtainable with any number of selenite films can be produced. It can be employed on any microscope. To get greater

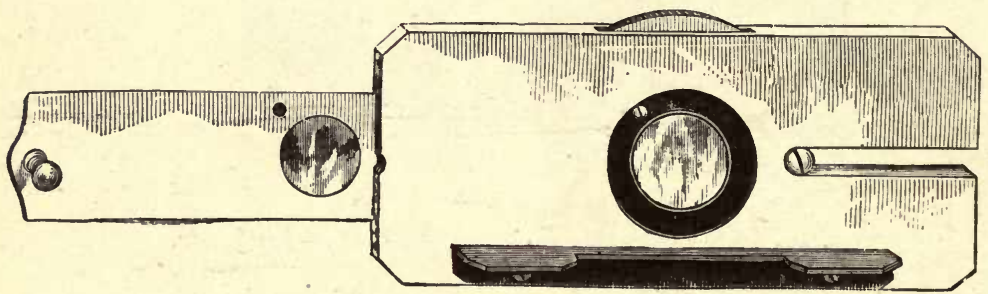

FIG. 19.-Mica-selenite Stage.

brilliancy the polarizer can be made to fit into the condenser on the under side, and the Abbe illuminator referred to previously on p. 52 is particularly suitable for this arrangement.

\section{The Bull's-eye Condenser.}

Many objects, being opaque, cannot be viewed by light from beneath, and consequently have to be illuminated from above. In order to do this a bull's-eye condenser is necessary. These are generally mounted on a stand, and may be had in varying sizes. They consist usually of a plano-convex lens mounted, as shown in the figure. This 
has a ball and socket joint and a sliding bar, by means of which the lens can be placed in any desired position. The plane side of the lens should be turned towards the object and the convex towards the source of the illumination, whether it be daylight or artificial by lamp. Latterly Mr. Nelson has suggested improvements in the construction of bull'seye condensers in order to reduce the large amount of spherical aberration which is a necessary accompaniment of the single lens. His improved form consists of either two or three lenses in combination, and the advantage obtained is well worth the additional outlay. To enhance the effects obtained with opaque objects with these stand-condensers the side silver reflector will be found very convenient. This is attached to either the stage or lamp of the microscope, or fitted between the nosepiece and the objective. It consists of a highly-polished silver parabolic speculum. This reflector

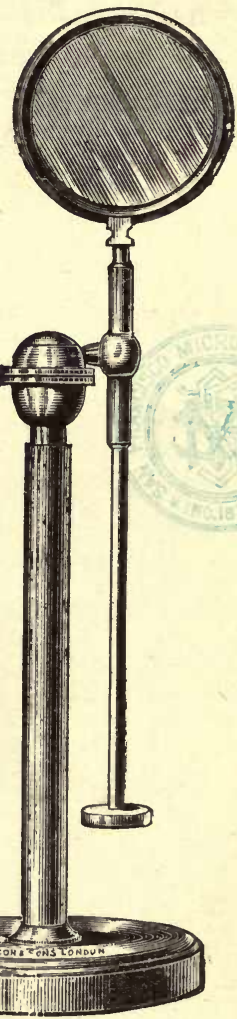
is placed by the side of the object, Frg. 20.-Stand Condenser. and light is thrown from the lamp through the bull's-eye on to its centre, and then thrown by the reflector on to the object. Most brilliant opaque illumination may be obtained by this means.

\section{The Lamp.}

This is one of the most important items in microscopy in order to get good effects. The amateur will often be 
found working with a reading-lamp or an ordinary oillamp, but no good] work can ever be done by this means. There are two or three important points which must be borne in mind. In the first place, if light is proceeding from the one illuminating point only, and the remainder of the room is dark, while using the microscope, a great deal better effect can be produced than if the whole room

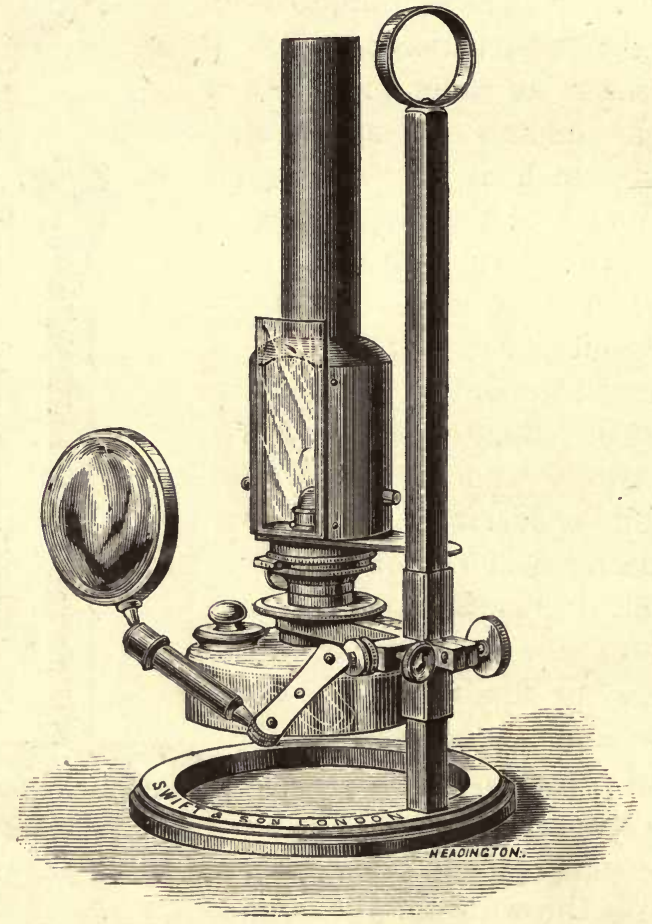

FIG. 21.-Microscope Lamp with Metal Chimney.

be illuminated. In the next place, a small brilliant source of light is far better than a large one. In recent years special attention has been paid to this matter, with the result that lamps have been constructed with which the best work may be accomplished. The following are essentials: The reservoir for oil should be flat and large in diameter, so that the light may be brought down very 
close to the table, and we should recommend glass in preference to metal, it being much cleaner, and the worker can always tell when his oil is getting exhausted; whereas with a metal reservoir, unless careful reckoning is kept, in the middle of some important observation the light will go out from want of oil. A half-inch wick is generally found to be sufficient. We strongly deprecate the use of glass chimneys. They are always liable to get broken very easily, and become a source of expense, in addition to which, if away from town, there is a possibility of not being able to get the right kind, and so work may be delayed. Far better will be found the metal chimneys now made by nearly all opticians, with a carrier for a $3 \times 1$ slip. It is obvious that if the slip be broken it can be immediately replaced, it being part of the microscopist's average stock. It is also desirable that the bar on which the lamp is raised and lowered on the stand should be a square one. If round in shape, the lamp is apt to swing round on the stand and the whole lot topple over. This is an impossibility. with the square bar. Such a lamp is shown in Fig. 21 , by Swift and Son, and modifications of it can be obtained at most dealers'. We have already referred to the methods of using the lamp on page 52.

\section{The Nosepiece.}

Time-saving arrangements will often be found useful in work, and the nosepiece is one of these. This is an arrangement which is screwed into the nosepiece of the microscope, and carries two, three or four objectives, each of which can in turn be rotated into the optical axis, thus saving the necessity of unscrewing an objective and screw-

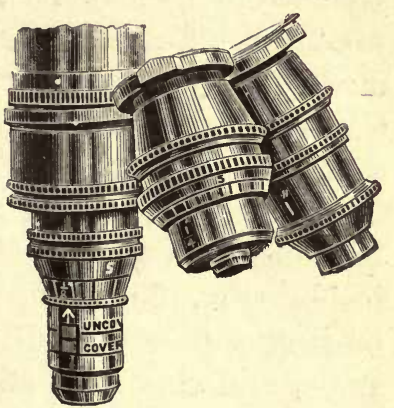

FIG. 22.-Triple Nosepiece. ing another on in order to get a variation of power. In 
hospitals, etc., it is usual to supply one of these with nearly every instrument. These are now to be had made of an aluminium alloy which is extremely light, reducing the strain on the body tube.

\section{Camera Lucida.}

This is designed to assist in drawing objects seen in the microscope. Photo-micrography has to a large extent superseded it; still, there are a great many who prefer this method to any other. Dr. Beale's neutral-tint reflector, which is supplied by all the opticians, is the cheapest and a very good form. The microscope is set in a horizontal position, with the centre of the eyepiece 10 inches from the table. Illumination is arranged in the ordinary way. The cap of the eyepiece is removed, and the camera lucida placed on so that the neural-tint glass is exactly opposite the eye-lens of the eyepiece at an angle of $45^{\circ}$. On looking on to this neutral-tint glass from the upper side, a disc of bright light will be seen on it, and if a piece of white paper be spread below on the table, on further examination the outlines of the object will be discerned. A pencil should now be taken, and the specimen can be sketched in its magnified form. This will be found somewhat difficult at first, nearly every worker having a different method, but the secret is to arrange the balance of illumination by turning the lamp-wick up and down until a degree of light is found at which the pencil-point and image can be distinctly seen. Of much more expensive description, but considered the best at present made, is the Abbe camera lucida (Fig. 23). The instrument need not be set in a horizontal position; in fact, the microscope may be at any angle, and this may still be employed. It consists of a mirror which reflects the paper to be drawn on through a right-angle prism having a silvered surface into the field of view. This prism is fitted over the eyepiece, and by 
means of an extra prism cemented to it, with a clear spot in the centre, the object is examined visually in the same way as usual, and when it is desired to draw on the paper, the pencil-point appears to be on top of the object in the field of view, and the minutest details can be exactly traced. It is necessary that the paper be inclined at exactly the same angle as the instrument, otherwise the image will be distorted. There is another very commonly-used form of camera lucida, invented by Wollaston. For this it is neces-

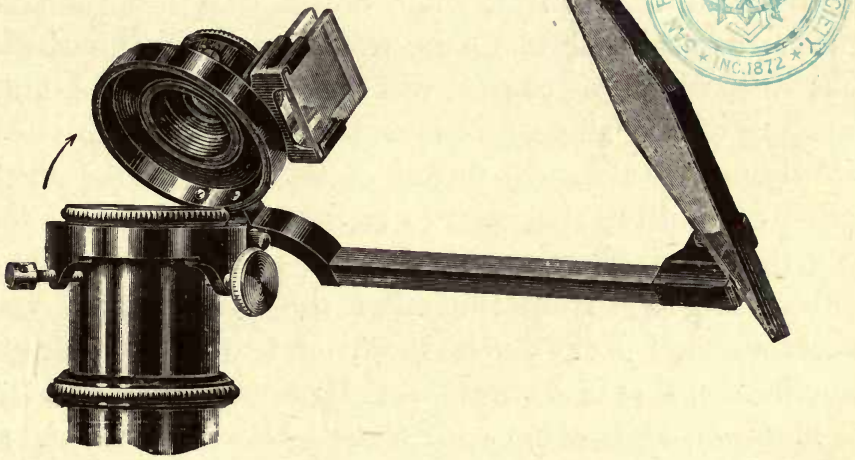

Fig. 23.-Abbé Camera Lucida.

sary to put the instrument in a horizontal position, but it is somewhat difficult to see the pencil-point with it when working, and should be used with part of the eye over the prism, while the other part views the pencil-point; a little practice soon enables this to be done. Although more expensive, we do not consider it superior to the Beale's neutral-tint. There are many other forms peculiar to individual makers possessing more or less merit, some of which may be used with the tube in any position, but particulars of these can easily be gained from respective catalogues. 


\section{The Measurement of Objects.}

There are several ways in which this may be effected :

1. By having the stage divided-applicable to mechanical stages only.

2. By means of a camera lucida and a stage micrometer.

3. By means of eyepiece and stage micrometers.

1. If the movements of a mechanical stage are divided and read by verniers to very small parts of an inch or millimetre, the measurement of an object can be effected by having in the eyepiece a dise of glass with a diamond-cut line across the centre. The object that it is desired to measure is set with one point exactly against the diamondcut line, which, of course, will appear in the field, and the reading of the stage divisions taken. The stage is then slowly moved along by means of the milled head until the other edge of the specimen to be measured is exactly touching the line. Then again read the stage divisions, and by subtracting one from the other the measurement will be ascertained. For quick work, and without extraneous appliances, this is accurate, and largely used.

2. Camera Lucida and Stage Micrometer. - A stage micrometer usually consists of a number of lines equidistant at the $\frac{1}{100}$ or $\frac{1}{1000}$ of an inch, or the $\frac{1}{10}$ and $\frac{1}{100}$ of a millimetre. This is put on the stage and focussed like an ordinary object. The camera lucida is then fixed on to the eyepiece, and the lines are projected on to a piece of paper in the same way as when drawing an object explained on page 62. The lines so projected are then measured, and supposing the lines of the micrometer, which are $\frac{1}{100}$ of an inch apart, appear when drawn on the paper 1 inch apart, it is at once known that the magnifying power in use is 100 diameters, and the object may be measured in the same manner. Measurements should be taken about the centre of the field, and not towards the edge, especially with high powers, as, owing to curvature 
of the field, the outer edges appear more highly magnified than the centre.

3. The Eyepiece Micrometer and Stage Micrometer.-The stage micrometer, as previously described, is placed on the stage, and a somewhat similar micrometer is put into the eyepiece, generally divided into hundredths of an inch. On focussing the stage micrometer the two sets of lines will appear in the field at once. It is now desirable to ascertain how many divisions of the eyepiece micrometer are included between one of the spaces-that is, $\frac{1}{100}$ of an inch-of the stage micrometer. Perhaps it will be found that there will be several lines of the eyepiece and'a fraction in that space, and in order that this fraction may be obviated the drawtube should be slightly pulled out, which will give, of course, an increased amplification, until a certain number of the lines on the eyepiece micrometer are exactly equal to the space on the stage micrometer. We will imagine that the number of eyepiece micrometer lines that fill $\frac{1}{100}$ of an inch of the stage micrometer is five. The stage micrometer is now removed, and the object to be measured replaces it. The lines of the eyepiece micrometer will still be seen in the field, and bearing in mind that five of these lines equal $\frac{1}{100}$ of an inch, any part of the object can at once be measured. It must be remembered, however, that every objective requires an estimation of the value of the eyepiece micrometer.

To give greater facility and accuracy, a form of eyepiece micrometer is used devised by Jackson, which is fitted in a frame, and by means of a micrometer screw traverses the object. If there be no mechanical stage to the instrument it is very difficult to set a special part against the micrometer for measurement, especially with high powers. This form of micrometer surmounts this difficulty. The ordinary eyepiece micrometers can be used with ordinary eyepieces, but the Jackson form requires that the outer tube of the eyepiece shall be cut to receive the carrier for the micrometer. This latter is illustrated in Fig. 24. 
There is yet another form called the Ramsden screw micrometer. This is an expensive piece of apparatus, and consists of an eyepiece containing two wires, one fixed, the other travelling by means of a screw having 100 threads to the inch. The milled head of this screw is divided into 100 parts. Across the field are very small equi-distant V-

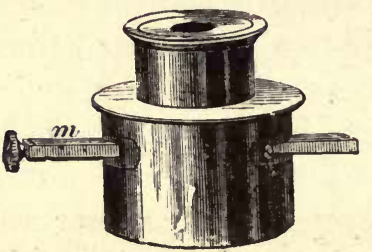

Fig. 24.-Jackson Micrometer Eyepiece.

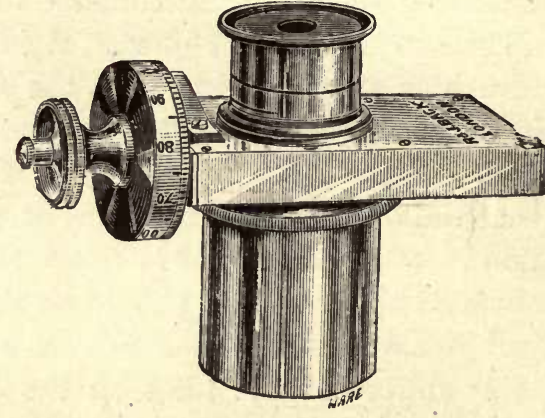

FIG. 25.-Ramsden Screw Micrometer.

shaped teeth, each of which is equal to one complete revolution of the milled head. The value of these teeth is taken against the stage micrometer, and the object placed on the stage. The object is then brought against the fixed wire, and the travelling wire moved to the other part that is desired to be gauged. By then counting the number of intervening teeth and reading the fraction on the milled head, it can at once be ascertained what magnifying power is used. This is considered the most accurate and precise method of working, but it is expensive, and with care one of the previous methods named will be, as a rule, sufficient.

\section{Troughs, Live-cages, Stage Forceps, etc.}

Troughs. - These are made of various materials, including glass, vulcanite, brass, etc., and are used for examining infusoria and animalculæ alive under the microseope. The essentials of a trough are that a medium power, say $\frac{1}{2}$ inch at least, can be used, that it may be easily cleaned, 
and that if broken it can be repaired. The ordinary commercial glass troughs unfortunately do not meet these requirements. They are difficult to clean, they are invariably hard to mend when broken, and they very often
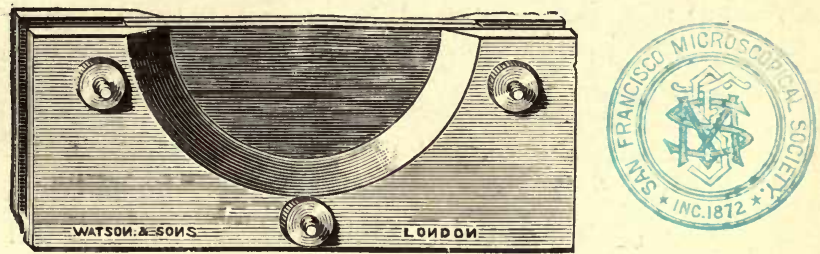

Fig. 2€.-Potterill's Trough.

leak when water is put in. The one that we have found most serviceable is the Botterill's trough, as shown in Fig. 26 , which consists of two vulcanite plates, between which
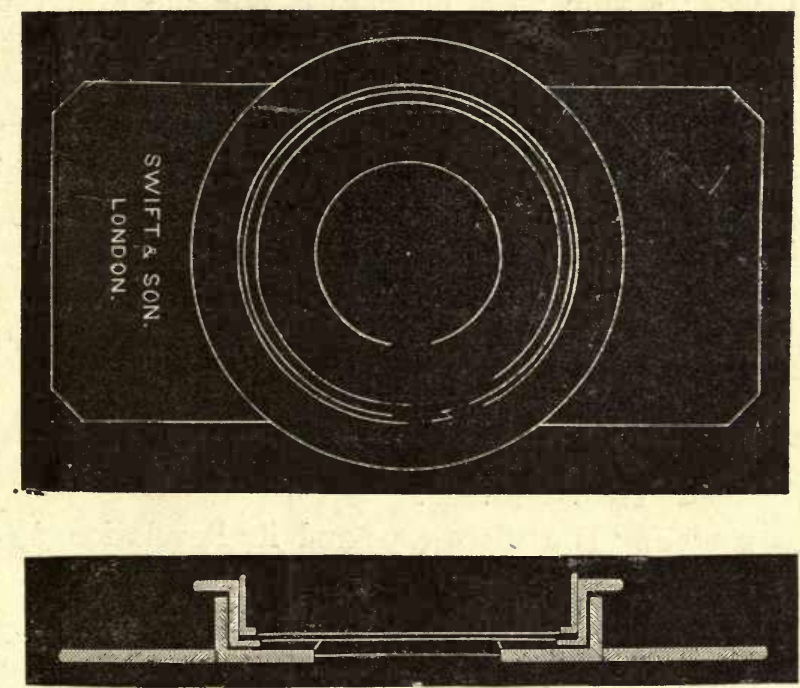

FIG. 27.-Rousselet's Live-cage.

are placed slips of glass, having between them an indiarubber band, small bolts and screws passing through the lot to hold them together. This is not an ideal trough, but it certainly answers its purpose as well as any at present made. 
Live-cages.-These are not used so largely for water objects as for insects, etc., which may be compressed. They consist of a brass plate having a glass base-plate, over which a cap slides having a very thin cover-glass. The subject to be viewed is placed between these two glasses and held firmly by compression. The best form is that designed by Mr. Rousselet, shown in Fig. 27, with which a condenser may be used conveniently. It is also so arranged that even if a specimen be fixed at the extreme edge of the glass plate, there is room for an objective to work on it. The ordinary live-cages are usually too narrow at the top for this to be done. A very good plan is often adopted by amateurs for viewing live objects as follows: A square flat piece of glass is obtained, and on this an indiarubber ring is laid, into which the animalculæ can be placed; a thin piece of glass is now put over the top of the indiarubber ring, and this really makes as serviceable a trough as can be obtained.

Forceps.-Stage forceps are used to hold unmounted specimens in the field of view while they are examined, there being a fitting on the forceps to go into a hole provided in the limb or the stage of the instrument.

There are also many modifications of the apparatus described, and which practical experience will suggest the desirability of using; but the principal ones, and those most commonly worked with, are mentioned.

Textbooks recommended :

Carpenter's 'The Microscope and its Revelations,' edited by Dr. Dallinger.

' The Microscope,' by Dr. Henri van Heurck.

'Photo-micrography,' by Dr. Bousfield.

And as periodicals the best are: International Journal of Microscopy and Natural Science, edited by A. Allen, Bath; and the American Monthly Microscopical Journal, edited by C. W. Smiley, Washington, D.C.

These journals both contain latest information with respect to the microscope. 


\section{PART II.}

\section{INTRODUCTION.}

Is publishing methods of preparing, staining, hardening and mounting microscopic objects, I have adopted the system employed in my classes for some years past; that is, each separate stage of procedure is arranged in successive lessons or chapters. Of course, a subject such as this cannot be so lucidly described in writing as by demonstration, but it has been my aim to make it as clear as possible, so that if the instructions are carefully followed and practised successful permanent work can be performed; but it is only by most scrupulous care and constant practice that any degree of success in this work can be attained.

\section{LESSON 1.}

\section{HARDENING ANIMAL TISSUES FOR MICRO- SCOPICAL EXAMINATION.}

Fresh untreated tissues are usually unsuited for microscopical purposes, but it is sometimes advisable to observe the appearance of a fresh specimen. When this is desired the tissue must be examined in a fluid that will alter its character as little as possible. Normal or $\frac{3}{4}$ per cent. salt solution answers this purpose. Tease out a small piece of the tissue on a slide in some salt solution, apply a cover- 
glass and examine. These specimens cannot be kept. For permanent preparations tissues must be hardened before they can be cut into sections. This is accomplished by subjecting the tissue to the action of certain hardening or fixing solutions. The following are most commonly used :

Absolute Alcohol.-Suitable for stomach, pancreas and salivary glands. These organs must be perfectly fresh, and they should be cut into small pieces, so that the alcohol may penetrate as quickly as possible.

Change the alcohol every day for the first three days. The hardening is usually complete in a week.

Chromic Acid and Spirit.-Chromic acid 1-6th per cent., watery solution 2 parts, and methylated spirit 1 part. This reagent hardens in about ten days. Then transfer to methylated spirit, which should be changed every day until no colour comes away from the tissues. It is suitable for cartilage, nerve-trunks, heart, lips, bloodvessels, trachea, lungs, tongue, bladder, ureter, intestines and oesophagus.

Potassium Bichromate.-Make a 2 per cent. watery solution. This will harden in about three weeks. Then transfer to methylated spirit, and change the spirit every day until no colour comes away from the tissues. It is suitable for muscle, spleen, liver and kidney.

Ammonium Bichromate.-Make a 2 per cent. watery solution. It hardens in from three to four weeks. Then transfer to methylated spirit, and change every day until no colour comes away from the tissues. It is suitable for spinal cords, medulla, pons Varolii, cerebellum and cerebrum.

Müller's Fluid. - Bichromate of potash 30 grains, sulphate of soda 15 grains, distilled water $3 \frac{1}{2}$ ounces. It hardens in from three to five weeks. Then transfer to methylated spirits, and change every day until no colour comes away from the tissues. Suitable for lymphatic glands, eyeballs, retina, tendons, and thymus gland.

Methylated Spirit.-May be used universally if pre- 
ferred, but it has a tendency to shrink some tissues too much. It hardens in about ten days. Change the spirit every twenty-four hours for the first three days. Suitable for skin, scalp, testicle, penis, prostate gland, vas deferens, epididymis, ovary, uterus, Fallopian tubes, placenta, mammary gland, supra-renal glands, tonsils and all injected organs.

Decalcifying Solution.-For bones and teeth. Make a 1-6th per cent. watery solution of chromic acid, and for every ounce add 5 drops of nitric acid. This fluid will soften the femur of a dog in about three weeks; larger bones will take longer. Change the fluid several times, and test its action by running a needle through the thickest part of the bone. If it goes through easily, the bone is soft enough; if not, continue the softening process a little longer. When soft enough transfer to water, and soak for an hour or two; then pour off the water and add a 10 per cent. solution of bicarbonate of soda, and soak for twelve hours to remove all trace of acid. Wash again in water, and place in methylated spirit until required. Bones and teeth should always be softened in a large quantity of the decaleifying solution.

\section{General Directions for hardening Tissues.}

1. Always use fresh tissues.

2. Cut the organs into small pieces with a sharp knife.

3. Never wash a specimen in water; when it is necessary to remove any matter, allow some normal salt solution to flow over the surface of the tissue, or wash in some of the hardening reagent you are going to use.

4. All specimens should be hardened in a large quantity of the reagent; too many pieces should not be put into the bottle, and they should be kept in a cool place.

5. In all cases the hardening process must be completed in spirit. 
6. Label the bottles, stating the contents, the hardening fluid used, and when changed. Strict attention to these details is necessary for successful histological preparations, for if the hardening is neglected good sections cannot be made.

\section{LESSON 2.}

\section{EMBEDDING TISSUES AND SECTION- CUTTING.}

To cut Sections with a Razor by Hand.-Take the tissue between the thumb and forefinger of the left hand. Hold the finger horizontally, so that its upper surface may form a rest for the razor to slide on. Take the razor, hold it firmly in the hand, and keep the handle in a line with the blade, and draw it through the tissue from heel to tip towards yourself. While cutting, keep the razor well wetted with dilute methylated spirit, and as the sections are cut place them in a saucer of dilute methylated spirit.

Embedding in Paraffin Wax and Lard.-Melt together by the aid of gentle heat four parts of solid paraffin and one part of lard. A quantity of this may be made and kept ready for use at any time. Melt the paraffin mass over a water-bath. Take the specimen and dry it between the folds of a cloth to remove the spirit, so that the paraffin may adhere to its surfaces, place it in a pill-box in the desired position, and pour in enough melted paraffin to cover it, then set aside to cool. When quite cold, break away the pill-box and cut sections from the embedded mass with a sharp razor. When a number of specimens are embedded, and it is desired to keep them for some time, they should be preserved in a jar of methylated spirit.

To infiltrate a Tissue with Paraffin.-Place the specimen in absolute alcohol or chloroform for an hour or two, then transfer to a bath of melted paraffin of $110^{\circ} \mathrm{F}$. (melting-point), and keep it at this temperature for several hours, so that the paraffin may penetrate to the middle of 
the tissue. Then remove the specimen from the paraffin and put it into a pill-box, pour in enough paraffin to cover it, and set aside to cool. When cold, remove the pill-box and make the sections with a good razor by hand, or the embedded mass may be fixed to a microtome with a little melted paraffin. The sections must be placed in turpentine to remove the paraffin, then in absolute alcohol to remove the turpentine, and finally in distilled water to remove the alcohol; they may then be stained. Sometimes it is desirable to stain the tissue in bulk before it is embedded. In this case the sections need only go into turpentine to wash away the paraffin; they may then be mounted in Canada balsam.

Cole's Microtome and Embedding in Carrot.-When a number of sections are wanted, or when a complete section of an organ is desired, a microtome should be used. A very good and simple instrument can be obtained from

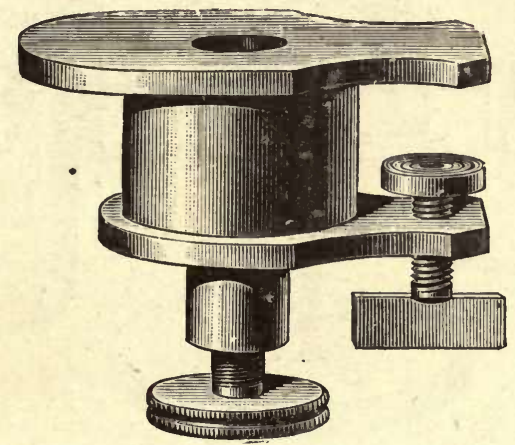

Fig. 28.-Cole's Pattern Microtome.

Messrs. Watson and Sons, 313, High Holborn. Screw the microtome firmly to the table, and with the brass tube supplied with the microtome punch out a cylinder of carrot to fit into the well of the microtome. Cut this in half longitudinally, and scoop out enough space in one half of the carrot to take the specimen; then place the other half of carrot in position, and make sure that the specimen is held firmly between them, but it must not be crushed. 
Now put the cylinder of carrot and specimen. into the well of the microtome and commence cutting the sections. A good razor will do, but it is better to use the knife which Messrs. Watson supply with the microtome. While cutting, keep the knife and plate of the microtome well wetted with dilute methylated spirit, and as the sections are cut place them in a saucer of dilute spirit. A number of sections

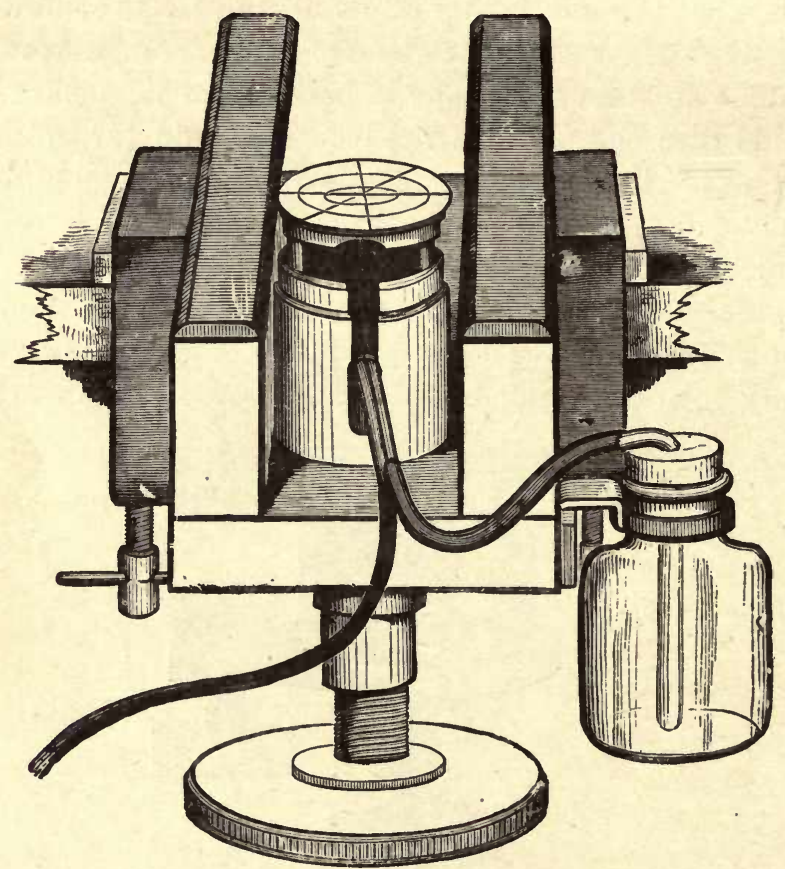

FIG. 29.-Cathcart Microtome.

may be cut and preserved in methylated spirit until required.

When a specimen has a very irregular outline, it cannot be successfully embedded in carrot. Paraffin should then be used. Place the tissue in the well of the microtome in the desired position, pour in enough melted paraffin to cover it, and when cold cut the sections.

Freezing Microtome.-Cathcart's is the most simple 
and cheapest freezing microtome, and it can be obtained from any optician.

(1) Cut a slice of the specimen about $\frac{1}{8}$ inch thick, in the direction you wish to make the section.

(2) Place in water for an hour to remove the alcohol.

(3) Transfer to a mixture of gum-water 5 parts, saturated watery solution of loaf-sugar, 3 parts, and allow it to soak in this for about twelve hours; or, if a few drops of carbolic acid are added to the mixture, tissues may remain in it for months without harm.

(4) Clamp the microtome to a table, fix the ether spray in its place, and fill the bottle with ether. Methylated ether S.G. $\cdot 720$ will do.

(5) Put a little gum-water-not gum and syrup-on the zine plate of the microtome, and place the tissue in it. Commence working the bellows, and as soon as all the gum has frozen add some more and freeze again, and so on until the tissue is completely covered and frozen into a solid mass.

(6) The best instrument for making the sections is the blade of a carpenter's plane. Hold it firmly in the right hand, and work the microtome screw under the machine with the left. Plane off the sections as quickly as possible. They should all collect on the plane iron. If they roll up or fly off, the tissue is frozen too hard, or there is not enough syrup in the gum. If the former is the case, allow the mass to thaw a little; if the latter, add some more syrup to the gum mixture, and soak the tissue again.

When the sections are cut, place them in a saucer of water, which must be changed several times until all trace of gum is removed. Water that has been boiled and allowed to cool will remove the gum sooner than cold water. When quite free of gum, the sections may be bottled up in methylated spirit until required for staining.

Embedding in Celloidin.-Dissolve celloidin in equal parts of ether and absolute alcohol until the solution is as thick as oil. 
Soak the specimen in ether for an hour or two, then transfer it to the solution of celloidin, and let it remain for twelve hours, or until required.

Take the specimen from the celloidin on the point of a needle, and hold it exposed to the air until the celloidin around the tissue has set; then push it off the needle into equal parts of methylated spirit and water, in which it should remain for an hour or two to complete the hardening. Then embed in carrot, and make the sections in an

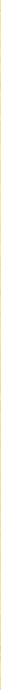

Fig. 30.-Rocking Microtome.

ordinary microtome, or the specimen may be soaked in gum and the sections made with a freezing microtome.

If it be desired to remove the celloidin from the sections, soak them in ether, and then transfer to methylated spirit, then into water, and finally into the staining solution; but specimens that are infiltrated with celloidin are usually stained in bulk before they are infiltrated, and after the sections are cut they are dehydrated in methylated spirit, cleared in oil of lavender or bergamot, and mounted in Canada balsam. 
The Rocking Microtome.-This machine is made by the Cambridge Scientific Instrument Company. It is only used for specimens infiltrated with paraffin, and it is automatic ; that is to say, it can be set to eut sections of definite thickness, and every time the handle is pulled a section is cut, and the specimen is moved forward ready for another.

Infiltrate the tissue with paraffin in the ordinary way in a pill-box, and when the paraffin has set remove the box and trim the paraffin into a rectangular block. Take care to keep the edges quite parallel, so that they may adhere together as the sections are cut and form a riband. The Cambridge Instrument Company make an apparatus for embedding, called imbedding L's. If these are used perfect rectangular blocks are formed ready for fixing to the brass cap at the end of the arm of the microtome, which is filled with paraffin; this should be warmed over a spirit-lamp, and the block containing the specimen is to be pressed against the melted paraffin until it adheres firmly.

\section{LESSON 3.}

\section{STAINING ANIMAL SECTIONS AND MOUNT- ING IN CANADA BALSAM.}

All sections of organs and tissues should be stained with some colouring reagent. so that their structure may be made more apparent. Certain parts of the tissue have a special affinity for the dyes or stain; they therefore become more deeply tinted, and stand out clearly from the surrounding tissues.

The following staining reagents are the most useful :

Borax Carmine.-Pure carmine, 1 dram; liquid ammonia, 2 fluid drams. Dissolve the carmine in the ammonia in a test-tube, with the aid of a little heat if necessary, then add 8 ounces of a saturated solution of borax in distilled water, and filter into a stoppered bottle. 
Staining Process.-(1) Place the section in distilled water to wash away the alcohol, then place a little of the carmine in a watch-glass, and immerse the section for from three to five minutes.

(2) Wash the section in methylated spirit.

(3) Take of methylated spirit 5 parts, and of hydrochloric acid 1 part, and mix them well together. A quantity of this acid solution may be made up and be kept ready for use at any time.

Immerse the section in the above, and leave it to soak for about five to ten minutes, or, if overstained, until the desired tint is obtained. Sections of skin and scalp may be left until all colour is removed from the fibrous tissues; the glands, hair follicles, and Malpighian layer will then stand out clearly.

(4) Wash the section well in methylated spirit to remove all traces of the acid, then transfer to some perfectly clean and strong methylated spirit for from ten to fifteen minutes to dehydrate.

(5) Place some oil of cloves in a watch-glass, take the section from the spirit on a lifter, and carefully float it on to the surface of the oil, in which it must remain for about five minutes. This process is called clearing; the object of it is to remove the alcohol and to prepare the section for the balsam.

(6) Transfer the section to some filtered turpentine to wash away the oil of cloves, and mount it in Canada balsam. Sections may be mounted in C. balsam direct from the oil of cloves, but it is better to wash in turpentine first, because if much oil is mixed with the balsam it will not dry; the oil also has a tendency to cause the balsam to turn a dark-yellow colour.

Logwood or Hæmatoxylin.-Hæmatoxylin 30 grains, absolute alcohol $3 \frac{1}{2}$ ounces, distilled water $3 \frac{1}{2}$ ounces, glycerine $3 \frac{1}{2}$ ounces, and ammonia alum 30 grains. Dissolve the hæmatoxylin in the alcohol and the alum in the water; mix the two solutions together, and add the glycerine 
and 3 drams of glacial acetic acid. The mixture must now be left exposed to light for at least a month, then filter, and keep in a stoppered bottle.

Staining Process.-(1) If the specimen has been hardened in any of the chromic solutions, place the section in a 1 per cent. watery solution of bicarbonate of soda for about five minutes, then wash well in distilled water. If it is a spirit preparation the soda will not be required, but all sections must be washed in distilled water before they go into logwood stain.

(2) To a watch-glass full of distilled water add from 10 to 20 drops of the logwood solution, and immerse the section for from ten to thirty minutes.

(3) Wash in distilled water, then in ordinary tap water; the latter will fix the dye and cause the colour to become blue.

(4) Dehydrate in methylated spirit.

(5) Clear in clove-oil, and mount in Canada balsam.

Double Staining with Logwood and Rosin. - Stain the section in hæmatoxylin, as directed above; then place it in an alcoholic solution of rosin, about 1 grain of rosin to an ounce of methylated spirit is strong enough, and let it soak for about five minutes; wash well in methylated spirit, clear in clove-oil, and mount in Canada balsam.

Mounting in Canada Balsam.-Take 3 ounces of dried C. balsam and dissolve in 3 fluid ounces of pure benzol, filter, and keep in an outside stoppered bottle. Clear the section in clove oil, and place it in turpentine. Clean a cover-glass and a slide, place a few drops of balsam on the centre of the latter, take the section from the turpentine on a lifter, allow the excess of turpentine to drain away, and with a needle-point pull the section off the lifter into the balsam on the slide. Now take up the cover-glass with a pair of forceps, and bring its edge in contact with the balsam on the slide; ease it down carefully, so that no airbubbles are enclosed, and with the points of the forceps press on the surface of the cover until the section lies quite 
flat and the excess of balsam is squeezed out. The slide must now be put aside for a day or two to allow the balsam to harden; the exuded medium may then be washed away with some benzol and a soft camel's hair brush, then dry the slide carefully with a cloth and apply a ring of cement, The above method answers well for mounting sections quickly, but when time will admit the following is a much better way. Clear the section and place it in turpentine. Clean a cover-glass, and moisten the surface of a slide with your breath; apply the cover-glass to the slide, and make sure that it adheres. Place a few drops of balsam on the cover, into which put the section. Now put the slide away in a box, or in some place out of reach of dust, for twelve hours, so that the benzol may evaporate from the balsam. Clean a slide, warm it gently over the flame of a spiritlamp. Apply a drop of balsam to the surface of the hardened balsam on the cover-glass; take the cover up in a pair of forceps, and bring the drop of fresh balsam in contact with the centre of the warmed slide. Ease the cover down carefully, so that the air-bubbles may escape. Now press on the surface of the cover-glass until the section lies quite flat. Set the slide aside to cool; the exuded balsam may then be washed away with methylated spirit and a soft rag, and a ring of cement applied.

\section{LESSON 4.}

\section{STAINING BLOOD AND EPITHELIUM, TEAS- ING OUT TISSUES AND MOUNTING IN AQUEOUS MEDIA.}

\section{Double-staining Nucleated Blood Corpuscles.}

Stain A.-Dissolve 5 grains of rosin in $\frac{1}{2}$ ounce of distilled water, and add $\frac{1}{2}$ ounce of rectified alcohol.

Stain B.-Dissolve 5 grains of methyl green in an ounce of distilled water.

Place a drop of frog's blood on a slide, and with the edge 
of another slide spread it evenly over the centre of the slip; now put it away out of reach of dust to dry. When quite dry flood the slide with stain A for three minutes. Then wash with water, and flood the slide with stain B for five minutes. Wash again with water, and allow the slide to dry. Apply a drop or two of C. balsam and a coverglass.

Blood of Mammals, Non-nucleated Corpuscles.Spread some blood on a slide and let it dry. Then put the slide in a turn-table, and run on a ring of any good cement; allow this to become perfectly dry, and then apply another coat, which must be allowed to become nearly dry; now clean a cover-glass and put it on the cement, and with a needle press it down until it adheres firmly to the cement.

Epithelium.-Kill a frog, cut off its head and remove the lower jaw. Open the abdomen and take out the stomach, and slit it open. Place the head, lower jaw and stomach in a 2 per cent. solution of bichromate of potash for forty-eight hours. Then wash gently in water until no colour comes away from the specimens. Now place all three portions in picrocarmine for twenty-four hours. Remove the tissues from the carmine, and allow the stain to drain away from them. Take the lower jaw and scrape the tongue for squamous epithelium, and place the scraping in a few drops of glycerine on a slide. Take the stomach, remove some columnar epithelium from its internal surface, and place it in some glycerine on another slide. Then take the head for ciliated epithelium, which will be found at the hinder part of the roof of the mouth; put some scrapings from this in glycerine on a slide as before. Clean a slide and place a drop or two of Farrant's medium on its centre ; take up a little of the epithelium on the point of a needle, and put it into the medium. Now apply a cover.glass, and with the needle-point press it down until the epithelium cells are separated and spread evenly between the cover and the slide. Set the slide aside for a day or two, so that the medium may set. Then wash away 
the excess of medium with some water and a camel's hair brush, dry the slide with a soft rag, put it in a turn-table, and run on a ring of cement.

Portions of the tongue, trachea and intestine of a rabbit or cat may be treated in the same way.

Teasing out Tissues.-Striped Muscle.-Harden small pieces of muscle of a pig in a 2 per cent. solution of bichromate of potash for three weeks, then transfer to methylated spirit, in which it may remain until required. Soak a piece in water to remove the spirit, place a very small fragment on a slide in a few drops of water, and with a couple of needles tease or tear the tissue up so as to separate the fibres. Drain away the excess of water, apply a drop or two of Farrant's medium and a cover-glass.

Fibrous Tissue.-Proceed as above.

Yellow Elastic Tissue.-Place small pieces of the ligamentum nuchæ of an ox in chromic acid and spirit for ten days. Then proceed as above.

Nerre Fibres.-Dissect out the sciatic nerve of a frog, and stretch it on a small piece of wood as follows: Take a match, make a slit in each end of it, into which put the ends of the nerve; now place it in a 1 per cent. solution of osmic acid for an hour or two. Wash in water, tease up a small fragment on a slide, and apply a few drops of Farrant's medium and a cover-glass.

Non-striped Muscle.-Harden a piece of the intestine of a rabbit in chromic acid and spirit for ten days. Wash in water, strip off a thin layer of the muscular coats, and stain it in hæmatoxylin. Wash in distilled water, and then soak in ordinary tap-water until the colour becomes blue. Clean a slide, place a small fragment of the muscle on it in a few drops of water, and with needles separate the fibres. Drain off the excess of water, apply a few drops of Farrant's medium and a cover-glass.

Farrant's Medium.-Take of glycerine and a saturated solution of arsenious acid equal parts, and mix them well together; then add as much powdered gum arabic as the 
mixture will take up, and let it stand for six weeks. Filter, and keep in an outside stoppered bottle.

The above is difficult to make; it is better to obtain it ready for use.

Glycerine Jelly.-Dissolve 1 ounce of French gelatine in 6 ounces of distilled water ; then melt in a water-bath, and add 4 ounces of glycerine and a few drops of creasote or carbolic acid. Filter through paper wbile warm, and keep in a stoppered bottle. The above may be used instead of Farrant's medium. The jelly must, of course, be warmed before use. All tissues or sections must be well soaked in water before they are mounted fn Farrant's medium or glycerine jelly, so that all trace of alcohol is removed.

Tissues containing much air should be soaked in water that has been boiled for about ten minutes and allowed to cool.

\section{LESSON 5.}

\section{STAINING AND MOUNTING MICRO- ORGANISMS.}

The investigation of bacteria may be carried out under various conditions:

(1) In fluids, such as milk, water, blood, pus, etc. (2) On solid media, bread, meat, potatoes, meat jelly, etc., or in the tissues and organs of animals. In the former case a drop of the fluid is placed on the centre of a coverglass and another cover-glass is placed on it; the two glasses are then to be rubbed together to spread the organisms evenly over their surfaces; they are then separated and allowed to dry. When bacteria are growing on solid material, scrape off a small portion, put on a coverglass, and treat as above; separate the covers, and allow to dry. When the cover is quite dry, take it up with a pair of forceps, organisms uppermost, and pass two or 
three times through the flame of a spirit-lamp; this will fix the albumen and fasten the bacteria to the glass.

To stain Bacteria on Cover-Glasses.-They should be floated with the organisms downwards on a saturated watery solution of any of the following anilin dyes: Methyl blue, methyl violet, gentian violet, fuchsin, visuvin, or Bismarck brown. From ten to fifteen minutes is enough for the first four stains; vesuvin and Bismarck brown require about an hour. When the staining is complete wash the cover in distilled water; if the colour is too deep wash in a $\frac{1}{2}$ per cent. solution of acetic acid, and then again in water; put away to dry. When quite dry add a drop of Canada balsam, and mount on a slide in the usual way.

When bacteria are present in the organs of animals the tissues should be hardened in methylated spirit for about a week; then cut very thin sections with a freezing microtome. The sections may be stained in any of the above dyes; then wash in water, dehydrate in spirit, clear in oil of cedar or bergamot, and mount in balsam.

Ehrlich's Method for Double - staining. - To 100 parts of a saturated watery solution of anilin oil add 11 parts of a saturated alcoholic solution of fuchsin, and filter. Place the covers or sections in the stain in a watch-glass, and warm slowly over a spirit-lamp until vapour rises. Wash in water, and then immerse for about a minute in dilute nitric acid, 1 part of acid to 2 parts water. Wash again in water, and stain again in a solution of methyl blue, 100 parts of distilled water to 20 parts of a saturated solution of methylated blue in alcohol for about 20 minutes. Wash in water, and in the case of sections dehydrate in spirit, clear in oil of cedar or bergamot, and mount in balsam. The cover-glasses must be dried, then add a drop or two of balsam, and mount as above. The anilin oil solution is made by adding the oil to distilled water; shake well, and let it stand for twenty-four hours before using; water will only take up about 3 per cent. of anilin oil. 
Oil of cloves is not suitable for clearing tissues stained with anilin dyes; it has a tendency to discharge the colour.

\section{LESSON 6.}

\section{INJECTION OF BLOODVESSELS.}

\section{Carmine and Gelatine Injecting Mass.-}

Pure carmine

Liq. ammonia fort.

Glacial acetic acid

Gelatine solution (1 ounce in 6 ounces
... 60 grains.

... 2 drams.

... 86 minims.
Water of water)
... 2 ounces.

Dissolve the carmine in the ammonia and water in a testtube, and mix it with one half of the warm gelatine. Add the acid to the remaining half of gelatine, and drop it little by little into the earmine mixture, stirring well all the time with a stick or glass rod. Filter through flannel, and add a few drops of carbolic acid to make the mass keep. The principle to be attended to in making this mass is this: the carmine, if alkaline, would diffuse through the vessels and stain the tissues around them; if acid, the carmine would be deposited in fine granules, which would block up the capillaries; hence the necessity for a neutral fluid. The best guides are the colour and smell of the fluid. It should be a bright red, and all trace of smell of ammonia must be removed. The gelatine solution is made by putting 1 ounce of gelatine into 6 ounces of water; it must then be left until the gelatine becomes quite soft; then dissolve over a water-bath.

\section{Prussian or Berlin Blue and Gelatine Mass.-Take} $1 \frac{1}{2}$ ounces of gelatine, place it in a vessel and cover it with water; allow it to stand until all the water is absorbed and the gelatine is quite soft. Then dissolve in a hot-water bath. Dissolve 1 dram of Prussian or Berlin blue in 6 ounces of water, and gradually mix it with the 
gelatine solution, stirring well all the time; then filter through flannel.

Watery Solution of Berlin Blue.-Dissolve $2 \frac{1}{2}$ drams of the blue in 18 ounces of distilled water and filter. This fluid is useful for injecting lymphatics.

Injecting Apparatus Required.-An injecting syringe fitted with a stop-cock and several cannulæ of various sizes.

Directions for Injecting. - The animal to be injected should be killed by chloroform, so that the vessels may be dilated, and injected while warm; if possible it should be placed in a bath of water at a temperature of $40^{\circ} \mathrm{C}$. Expose the artery of the parts to be injected, clear a small portion of it from the surrounding tissues, and place a ligature of thin twine or silk round it. With sharp scissors make an oblique slit in the wall. of the vessel, insert the cannula, and tie the ligature firmly over the artery behind the point of the cannula, into which put the stop-cock. Fill the syringe with injection fluid, which must not be too warm, and take care not to draw up any air-bubbles; now insert the nozzle of the syringe into the stop-cock and force in a little fluid; remove the syringe, so that the air may escape, insert the syringe again, and repeat the process until no air-bubbles come out of the stop-cock. You may then proceed slowly with the injection. Half an hour is not too long to take over the injection of an animal of the size of a cat. One judges of the completeness of an injection by looking at the vascular parts, such as the tongue, eyelids, and lips. When the injection is complete shut the stop-cock, remove the syringe and cannula, and tie the ligature round the artery. Now place the animal in cold water for an hour to set the injectionfluid. When quite cold dissect out the organs, cut them up into small pieces, and place them in methylated spirit to harden, and change the spirit every twenty-four hours for the first three days. The hardening will be complete in ten days. 
Injection of Lymphatics (Puncture Method).--A small subcutaneous syringe is filled with a watery solution of Berlin or Prussian blue, and the nozzle is thrust into the pad of a cat's foot. The injection is then to be forced into the tissues. Then rub the limb from below upwards. This will cause the injection-fluid to flow along the lymphatics, and find its way into the glands of the groin.

To Inject Lymph-sinuses of Glands.-Foree the nozzle of a subcutaneous syringe into the hilum of a lymphatic gland of an ox, and inject a watery solution of Prussian or Berlin blue until the blue appears on the surface of the gland. Then place it in methylated spirit to harden.

When blue injection-fluid is used, add a few drops of acetic acid to the spirit while hardening the tissues.

\section{LESSON 7.}

\section{CUTTING, STAINING, AND MOUNTING VEGETABLE SECTIONS.}

Stems, leaves, roots, ovary, etc., should be hardened in methylated spirit for a week or ten days, and the spirit changed every twenty-four hours for the first three days. The stems must not be too old. One, two, and three years' growth will show all that is required.

Section-cutting, by hand and with a mierotome, should be done in the same manner as described on page 72 .

Bleaching.-Vegetable sections generally require bleaching before they can be properly stained. Chlorinated soda is used for this purpose. Take of dry chloride of lime 2 ounces, of washing soda 4 ounces, and distilled water 2 pints. Mix the lime in one pint of the water and dissolve the soda in the other. Mix the two solutions together, shake well, and let the mixture stand for twenty-four hours. Pour off the clear fluid, filter, and keep in a stoppered bottle in a dark place, or cover the bottle with paper. Soak the sections in distilled water. Pour off the water and add a quantity of bleaching fluid. Allow this to act for from 
one to twelve hours. Wash well in water, which must be changed several times to remove all trace of soda. The sections may now be stained, or they may be preserved in spirit until required.

Staining-Borax Carmine (suitable for ovaries, fruits, etc.).-Pure carmine 1 dram, liq. ammoniæ fort. 2 drams. Dissolve the carmine in the ammonia, and add 12 ounces of a saturated solution of borax in distilled water. Filter and keep in a stoppered bottle.

(1) Put some stain in a watch-glass, and immerse the section three to five minutes.

(2) Wash well in methylated spirit.

(3) Take of hydrochloric acid 1 part and of methylated spirit 5 parts; mix well together, and soak the section until the colour changes to a bright scarlet, which takes about five minutes. The acidulated spirit may be kept ready for use at any time.

(4) Wash well in methylated spirit. Then place in some strong methylated spirit, and soak for at least ten minutes to dehydrate.

(5) Place the section on the surface of a small sancer of clove oil, and let it soak until clear.

(6) Remove from the clove oil and place in turpentine, and then mount in Canada balsam.

Hæmatoxylin. - Hæmatoxylin, 30 grains; absolute alcohol, $3 \frac{1}{2}$ ounces; distilled water, $3 \frac{1}{2}$ ounces ; glycerine, 3 ounces; ammonia alum, 30 grains; glacial acetic acid, 3 drams. Dissolve the hæmatoxylin in the alcohol and the alum in the water; then add the glycerine and acetic acid. Mix the two solutions together, and let the mixture stand for at least a month before use.

(1) Add about 30 drops of the above to an ounce of distilled water, and stain the section for fifteen to thirty minutes.

(2) Wash well in distilled water, and then in ordinary tap-water. This will fix the colour and make it deeper. 
Cutting, Staining, and Mounting Vegetable Tissues. 89

(3) Dehydrate in strong methylated spirit for at least ten minutes.

(4) Clear in clove oil and mount in Canada balsam.

\section{Double Staining.-}

$$
\begin{array}{ccc}
\text { Green Stain.- Acid green } & \ldots & 2 \text { grains. } \\
\text { Distilled water } & \ldots & 3 \text { ounces. } \\
\text { Glycerine } & \ldots & 1 \text { ounce. }
\end{array}
$$

Mix the water and glycerine together, and dissolve the green in the mixture.

$$
\begin{aligned}
& \text { Carmine Stain A.-Borax } \quad \ldots \quad \ldots 10 \text { grains. } \\
& \text { Distilled water } \quad \text {... } 1 \text { ounce. } \\
& \text { Glycerine } \quad \text {. } \frac{1}{2} \text { ounce. } \\
& \text { Alcohol rect. } \quad \text {... } \frac{1}{2} \text { ounce. }
\end{aligned}
$$

Dissolve the borax in the water, and add the glycerine and alcohol.

$$
\begin{aligned}
& \text { B.-Carmine } \quad \ldots \quad \ldots 10 \text { grains. } \\
& \text { Liq. ammoniæ } \quad \text {.. } 20 \mathrm{~min} \text {. } \\
& \text { Distilled water ... } 30 \mathrm{~min} \text {. }
\end{aligned}
$$

Dissolve the carmine in the water and ammonia. Mix $\mathrm{A}$ and $\mathrm{B}$ together and filter.

(1) Place the section in green stain for five to ten minutes.

(2) Wash in water.

(3) Place in carmine for ten to fifteen minutes.

(4) Wash well in methylated spirit.

(5) Dehydrate and clear in clove oil. Wash in turpentine and mount in Canada balsam.

Mounting in Canada Balsam.-Take 3 ounces of dried Canada balsam and dissolve in 3 fluid ounces of benzole. Filter and keep in an outside-stoppered bottle.

(1) Clean a cover-glass, moisten the surface of a slide with your breath, apply the cover-glass to it, and make sure that it adheres.

(2) Place a few drops of balsam on the cover-glass.

(3) Take the section out of the turpentine on a lifter, and put it into the balsam on the cover. 
(4) Put away out of the reach of dust for twelve hours, to allow the benzine to evaporate from the balsam.

(5) Warm a slide over a spirit-lamp and apply a drop of balsam to that on the cover-glass; take it up with a pair of forceps, and bring the drop of fluid balsam in contact with the centre of the warmed slide. Ease the cover down carefully, so that no air-bubbles may be enclosed, and press it down with the point of the forceps until the section lies quite flat and the excess of balsam is squeezed out. Now allow the slide to cool; the excess of balsam may then be washed away with some methylated spirit and a soft rag.

Eosin Stain.-Useful for sieve-tubes and plates. Make a strong solution of eosin in equal parts of water and alcohol, and stain the section for five to ten minutes. Wash well in methylated spirit, dehydrate, clear in clove oil, and mount in Canada balsam.

\section{LESSON 8.}

\section{THE PREPARATION OF VEGETABLE TISSUES FOR MOUNTING IN GLYCERINE JELLY, ACETATE OF COPPER SOLUTION, ETC.}

Epidermal Tissues for Stomata.-Get some leaves, cut them into small pieces, and place them in a jar of water, in which they must remain for several weeks, or until the cellular tissue rots and the epidermis is set free. Wash well in water, stain in a watery solution of methyl violet, and mount in glycerine jelly.

Annular Vessels. - Get some stem of maize, cut it into pieces about half an inch long, and then cut again into thin longitudinal slices; place these in water until rotten. Now put some of the broken-up material on a slide and examine with a microscope; pick out the annular vessels on the point of a needle, place them in some clean water, and wash well. Stain in a weak watery solution of acid 
green, and after washing in water mount in glycerine jelly.

Scalariform Vessels.-Treat pieces of the rhizome of Pteris aquilina in exactly the same way as stem of maize.

Spiral Vessels. - Treat pieces of the stem of rhubarb as above.

Yeast.-Get some fresh baker's yeast, place a little of it in a bottle of sugar and water, and stand in a warm place for twenty-four hours. Pour off the sugar water and add camphor water. Make a cell on a slide with black shellac cement, and let it dry; then apply a second coat of cement, and let this stand for a few minutes. Now take up some of the yeast in a glass tube and place a few drops in the cell ; clean a cover-glass, and bring its edge in contact with the cement on one side of the cell; ease it down carefully, so that no air-bubbles may be enclosed; now press on the surface of the cover with a needle until it adheres firmly to the cell all round, drain off the excess of fluid, dry the slide with a clean cloth, and apply a coat of cement.

Preserving Fluid for Green Algæ.-Acetate of copper, 15 grains; camphor water, 8 ounces; glacial acetic acid, 20 drops ; glycerine, 8 ounces; corrosive sublimate, 1 grain. Mix well together, filter, and keep in a stoppered bottle. The above fluid preserves the colour of chlorophyll for a long time; it may also be used as a mounting fluid. For very delicate specimens leave out the glycerine.

The specimens should be well washed in water; then pour off the water, and add a quantity of the copper solution.

To Mount in the above.-For example, take spirogyra as a filamentous alga. Make a cell with some black cement, and let it dry ; then apply a second coat of cement, and allow this to nearly dry, Place some spirogyra in the cell, and with needles separate the filaments; add a few drops of copper solution, and apply a cover-glass as directed for yeast. 
Protococcus.-This can be obtained by scraping the bark of trees. Place it in a bottle of water, and let it stand for a few hours; now add a little copper solutionthis will kill the specimens, and they will sink to the bottom of the bottle; pour off the water, and add more copper solution. Now make a cell as for spirogyra; take up some of the protococcus in a dipping-tube and place them in the cell; wait a minute for the forms to settle on the bottom of the cell, and then apply a cover-glass; drain off the excess of fluid, dry the slides with a cloth, and apply a coat of cement.

Volvox.-Treat as above.

Red Algæ.-The copper solution does not suit red algæ; they must be preserved in dilute methylated spirit, or dried between folds of paper. To mount same, remove from the spirit, and soak in several changes of water until all trace of spirit is washed away, then mount in glycerine jelly. The dried specimens only require soaking in water until they come off the paper. They are also to be mounted in glycerine jelly.

Antheridia and Archegonia of Mosses should be preserved in methylated spirit. Soak in water before mounting, and if very hard, in dilute potash; wash away the potash with plenty of water, tease out the specimen with needles on a slide, apply a few drops of glycerine jelly and a cover-glass.

Fertile Branch of Chara.-Chara is usually very dirty ; when so, wash well in ropeated changes of water, and then in very dilute acetic acid for a few minutes only; then wash again in water, and preserve in camphor water.

Make a cell with shellac cement as directed above, place a fertile branch of chara in it, and place under a dissecting microscope or lens; with needles clear away the leaves from the archegonia and antheridia, fill the cell with camphor water, and apply a cover-glass.

When a deep cell is required for a specimen to be mounted in acetate of copper, never use one made of any 
metal. Vulcanite or glass cells must be used. To one side of a cell apply a coat of shellac cement and let it dry ; now take a slide and warm it over a spirit-lamp; take up the cell in a pair of forceps, and bring the cemented side in contact with the centre of the warmed slide, and press it down until it adheres firmly; then add another coat of cement to the upper side of the cell, and let it nearly dry, put in the specimen, fill the cell with solution, and apply the cover-glass.

\section{LESSON 9.}

\section{CUTTING, GRINDING, AND MOUNTING SECTIONS OF HARD TISSUES.}

Bone.-Take the femur of a dog or cat, remove as much of the muscles as possible, and macerate in water until quite clean, then allow it to dry.

(1) With a fine saw make transverse and longitudinal sections.

(2) Take a hone (water of Ayr stone), moisten it with water, and rub one side of the section upon it until it is quite flat and smooth.

(3) Wash in water, and set aside until quite dry.

(4) Take some dried Canada balsam, place a piece on a square glass, and warm gently over a lamp until the balsam melts; allow it to cool a little, and then press the smooth side of the section into it, and set aside until cold.

(5) With a fine file rub the section down as thin as possible.

(6) Take the hone again, and grind the section down until thin enough, using plenty of water.

(7) Place it, glass and all, in methylated spirit until the section comes away from the glass, then wash well in clean water.

(8) Make a cell with any good shellac cement and allow it to dry; then apply another coat of cement, and after waiting a few minutes fill the cell with camphor water, and 
put the section into it; apply a cover-glass, and press it down until it adheres to the cement all round. Sections of teeth are made in the same way.

Rock Sections.-Small pieces or slices of rocks are to be ground on a zine plate with the aid of emery-powder and water until one side is quite flat and smooth. Then fasten the polished surface to a square of glass with some dried Canada balsam, as directed for bone, and allow it to cool. Grind the other side on the zinc plate with coarse emery and plenty of water. When moderately thin, take a piece of plate-glass and some fine flour-emery, and rub the section down as thin as possible. When thin enough, wash well in water and dry; then warm over a spirit-lamp, and with a needle push the section off the glass into a saucer of benzole or turpentine, and allow it to soak until all the balsam is dissolved. Wash again in some clean turpentine, and mount in Canada balsam in the usual way. Sections of echinus spines, shells, and stones of fruits are prepared in the same way as bones and teeth; but when the grinding is finished, the sections are to be passed through alcohol into clove oil, then mount in Canada balsam in the usual way.

\section{LESSON 10.}

\section{PREPARING AND MOUNTING ENTOMOLOGI- CAL SPECIMENS FOR THE MICROSCOPE.}

Insects should be killed with chloroform. They are then to be placed in methylated spirit, in which they may remain until required for mounting.

To Prepare an Insect for Mounting with Pressure in Canada Balsam.-(1) Transfer from methylated spirit to water, and let it soak for three or four hours to remove spirit.

(2) Place in liq. potassæ, 10 per cent. of caustic potash in distilled water, until soft. Some specimens will only require a few hours in the potash, others want days, and some even weeks, to soften. In all cases they must be 
carefully watched and the action of the potash tested. This can be ascertained by pressing on the thorax or chest of the insect with some blunt instrument, such as the head of a pair of curved pointed forceps.

(3) When soft enough, pour away the potash, and add water, which must be changed several times until all the potash is washed away.

(4) Pour away the water and add concentrated acetic acid, and soak for twelve hours, or until you are ready to go on with the work.

(5) Transfer from acetic acid to water, and soak for about half an hour; then place in a shallow saucer full of water, and with the aid of a needle and a camel's hair brush spread out the wings, legs, etc. Now take a slide and place it in the water under the insect, lift the slide up carefully so that the insect may be stranded on the surface of the slide with all its parts expanded. Drain off the excess of water, and lay the slide down on a piece of white paper, and with the aid of needles or brushes carefully place all the limbs, wings, antennæ, etc., in their natural positions. Now put a narrow slip of paper on each slide of the insect, and carefully lay another slide over it, press it down until the insect is squeezed quite flat, tie the two slides together with a piece of twine, and place them in a jar of methylated spirit for at least twelve hours, or until required.

(6) Remove the glasses from the spirit, carefully separate them, and with a soft eamel's hair brush push the inseet off the glass into a saucer of spirit.

(7) Take the insect up on a lifter, and float it on to the surface of a small saucer of clove oil, and allow it to soak for ten to fifteen minutes.

(8) Remove from clove oil and place in turpentine for a few minutes.

(9) Mount in Canada balsam as directed for animal and botanical sections.

To Mount an Insect in Canada Balsam without Pressure.-Treat with potash as above, wash in water and 
place in acetic acid. Wash away the acid with water, and transfer to a shallow saucer of methylated spirit. Take two needles and lay out the various parts as quickly as possible; if any parts are troublesome, hold them in position until the spirit has fixed them. Now let it soak for an hour, or until required. Remove from spirit, place in clove oil, and when clear place in turpentine.

Take a tin cell just deep enough for the specimen, and apply a coat of Miller's cement to one side of it. Allow this to nearly dry. Clean and warm a slide over a spiritlamp; take up the cell in a pair of forceps, and bring the cemented side in contact with the centre of the warmed slide; press on the upper side of the cell until it adheres firmly to the slide, and put it away to dry. Fill the cell with Canada balsam, and see that it also flows over the upper edge of the cell, so that it may serve as'a cement to fasten on the cover. Take the insect from the turpentine on a lifter, put it in the cell, and with needles rearrange the parts if necessary. Put away out of reach of dust for twelve hours to harden the balsam. Place a drop of balsam on one side of the cell. Clean a cover-glass of the same size as the cell, take it up in a pair of forceps and warm it gently over a spirit-lamp, and bring its edge in contact with the drop of fresh balsam; ease down carefully, so as to avoid air-bubbles, and press on surface of cover with a needle until it rests on the cell all round. Now take a soft brush and some benzole, and wash away the exuded balsam; dry with a clean rag, and apply a ring of any good cement.

To Mount an Insect in Glycerine without Pressure. - Many small, soft insects and their larvæ may be mounted in glycerine while fresh. The larger and harder kinds must be soaked in potash to render them transparent. Make a cell of the required size, and fasten it to a slide with Miller's cement as directed for balsam mounts. Apply a coat of Miller's cement to the upper side of the cell, and allow it to nearly dry. Fill the cell with glycerine, and put the insect into it; spread out the wings, legs, etc. Clean 
and warm a cover-glass, and apply its edge to the cell; press down, and be sure that it adheres to the cement all round. Wash away the excess of glycerine with some water, and dry the slide with a soft cloth. When quite dry, apply a ring of Miller's cement, and when this has dried add a coat of any good black varnish.

\section{LESSON 11.}

\section{CRYSTALS AND POLARISCOPE OBJECTS.}

Crystals. - Method 1.-Make a strong solution of the material in distilled water, with the aid of heat if necessary, and filter; take up a small quantity of the solution in a dipping-tube, and drop it on a cover-glass. Prepare several covers in this way, and allow some to dry slowly, and evaporate others over a spirit-lamp. When dry, add a drop or two of Canada balsam, and mount in the usual way.

Method 2.- Make a strong solution in distilled water, and add a few drops of gum water or a small piece of gelatine; mix well, and filter. Apply some of the solution to a cover-glass, and allow it to dry slowly in a place protected from dust. Mount in Canada balsam.

Method 3.-Place a small piece of the dry crystal on a slide, and apply a cover-glass ; warm over a spirit-lamp until fusion results, press the cover down with a needle, and allow the slide to cool. Clean off the exuded material, and finish off with some good cement.

Some crystals are soluble in Canada balsam ; if so, mount in castor oil.

The following salts, etc., are easily obtained, and they all give very good results :

Chloride of barium.* Chlorate of potash.* Sulphate of copper.* Spermaceti (fuse).
Sulphate of iron.* Tartrate of soda.** Salicine.

Stearine (fuse).
Asparagine. Quinidine. Santonine. Tartaric acid.

Those marked * are more effective when crystallized in gum or gelatine. 
The following specimens from the vegetable kingdom make fine polariscope objects : Starches, hairs, scales from leaves, cotton and silk fibres, cuticles of leaves, and longitudinal and transverse sections of stems.

Starches can be obtained from any vegetable substance by scraping the tissue with a knife. Place the scraping in a test-tube of water and shake well; allow the starch to settle down, and pour off the water. Repeat the washing until all the fibrous material is washed away. For polarizing purposes starches should be mounted in Canada balsam. Take up a little starch in a dipping-tube, and place it on a cover-glass; dry slowly, apply a drop or two of balsam, and mount in the usual way. Starches may also be mounted in glycerine jelly.

Cuticles containing Raphides.-The most common is the skin of the onion. Strip off the cuticle, soak in turpentine for a few days, or until transparent, and mount in Canada balsam.

Cuticles may also be mounted in glycerine jelly.

The following specimens of the animal kingdom make good objects: Fish-scales, palates of mollusca, sections of hairs and quills, horns and hoofs, whalebone, etc.

Fish-scales.-Scrape off the scales, and wash well in water if very dirty; soak in liq. potassæ for a day or two, and wash again in water. Pour off the water and add methylated spirit, and soak for an hour, or until required. Place in clove oil, and soak for several hours until quite free of air. Mount in Canada balsam.

Palates.-Dissect out, and soak in liq. potassæ for a few days. Wash well in water, spread out on a slide; put a piece of paper on each side of it to prevent crushing, and place another slide over all in the same way as directed for insects; tie the glasses together with string, and place in methylated spirit for an hour or two. Then remove the palate from the glasses, and place it in clove oil until clear. Mount in Canada balsam. 
Hairs.-Soak for a day or two in turpentine, and mount in Canada balsam.

Horns, Hoofs, and Whalebone must be. soaked in liq. potassæ until soft; then wash away the potash and place in methylated spirit. Make longitudinal and transverse sections in the usual way; dehydrate, clear in clove oil, and mount in Canada balsam.

\section{LESSON 12.}

\section{CLEANING AND MOUNTING DIATOMS, POLYCYSTINA, AND FORAMINIFERA.}

To Clean Diatoms Growing upon Algæ or Shells.Place the algæ or shells in a basin, cover them with water, add hydrochloric acid, and stir until effervescence results; add more acid little by little, until effervescence ceases, stirring from time to time. Now strain through net of sufficiently fine texture to allow the diatoms to pass, but to retain the débris. Allow the strained fluid to settle down, pour off the acid water, and place the deposit in a large test-tube. Add pure hydrochloric acid and boil for twenty minutes; add some pure nitric acid and boil again for twenty minutes, and while boiling add some crystals of chlorate of potash until complete bleaching results. Remove all trace of acid or alkali by washing in water, and examine the forms under the microscope. If clean, bottle them up in distilled water for future mounting. If, as is sometimes the case, there has been animal matter present which has not been removed, boil in pure sulphuric acid for a few minutes. Wash away all trace of acid before bottling the diatoms in distilled water.

To Clean Fossil Diatomaceous Deposits.-Break the deposit up into small pieces and place them in a large testtube, in a moderately strong solution of bicarbonate of soda, and boil gently for two hours, the disintegrated portions being from time to time poured off into a beaker and the boiling in soda continued until all the deposit has 
broken up. The alkaline solution must then be washed away, and the diatoms boiled for a short time in nitric acid, and when sufficiently clean wash away the acid in repeated changes of water, and bottle up the diatoms in distilled water.

To Clean Living Diatoms.-Remove all dirt or salt by washing well in water; shake well, and allow the diatoms to settle before pouring off the water. In this way all soluble impurities can be removed. When the water remains clear pour it off, leaving the diatoms as nearly dry as possible, and cover them with strong alcohol, which will extract the endochrome; change the alcohol daily until it ceases to be tinged with green; then wash away the alcohol with water, pour off the water, and place the diatoms in a platinum capsule and heat them to a dull red over a spiritlamp. This will separate the frustules into single valves, and finish the cleaning of the diatoms, and they may then be bottled up in distilled water.

To Clean Polycystina. - The polycystinous earth should be broken into small pieces and boiled for several hours in a strong solution of common washing soda, the disintegrated matter being from time to time poured off into a vessel, and the boiling in soda continued until all the earth is broken up. Wash the disintegrated matter in water several times to remove the soda, allow the polycystina to settle down, and pour off the water and place the forms in a test-tube; add some nitric acid and boil for twenty minutes. Remove all trace of acid with water and bottle up in distilled water.

To Clean Foraminifera.-All mud must be got rid of by repeated washing in water. Then boil the forms in a strong solution of bicarbonate of soda for an hour or two. When clean, wash away the soda and bottle in distilled water.

To Mount Diatoms in Canada Balsam (Unselected Slides).-The diatoms are to be taken out of the bottle with a dipping-tube, and should be allowed to fall upon a clean 
cover-glass. The fall of the drop causes the forms to spread evenly over the cover. It should then be dried slowly over a spirit-lamp. When dry, a small drop of Canada balsam is to be applied and the slide put away out of reach of dust to dry for twelve hours. Now place on a hot plate, and apply gentle heat from a spirit-lamp for about ten minutes. Allow it to cool. Now take the cover up with a pair of forceps, and bring its balsamed surface in contact with the centre of a warmed slide. The balsam should then run to a neat bevelled edge all round the cover ; if it does not, warm the slide a little more until it does.

Unselected Polycystina.-Take the forms from the bottle with a glass tube, and spread them on a slide; dry them over a spirit-lamp. Now clean a cover-glass, fasten it to a slip with your breath, and place a drop or two of balsam on it; take up some of the polycystina on the point of a knifeand place them in the balsam; stir them well up with a needle and put away for twelve hours. Now bake over a spirit-lamp for ten minutes, and while warm stir up again gently with a needle, and spread the forms evenly over the cover. Warm a glass slide, and proceed as directed for unselected diatoms.

Selected Diatoms and Polycystina.-Take an ounce of distilled water, add 6 or 8 drops of ordinary gum water, and filter. Clean a cover-glass and place a drop of the diluted gum upon it; put away to dry.

Spread the diatoms or polycystina on a slip and dry them over a spirit-lamp. Select the desired forms with a fine brush or bristle, and breathe upon the gummed surface of the cover, and place the forms upon it. When dry, apply a drop of balsam and put away out of reach of dust for twelve hours. Bake and finish as directed for unselected slides.

Foraminifera are generally mounted dry. Make a shallow cell, either transparent or opaque, and place some dilute gum in it, and put away until dry. Spread the 
foraminifera on a slide, and dry them in the same way as directed for diatoms and polycystina. Moisten the gummed cell with your breath, take up a small quantity of the dried foraminifera on the point of a penknife and place them in the cell. Shake out those that do not adhere to the gum, and put the slide away to dry. Then apply a coat of Miller's cement to the upper edge of the cell, and allow it to become nearly dry. Apply a cover-glass and press it down until it adheres to the cell all round; put away until quite dry, and then finish off with zine cement or asphalt.

\section{E S SON No. 13.}

\section{DRY MOUNTS.}

Opaque Cells.-Place a slide in a turn-table, and run a disc of black varnish on its centre; allow this to dry. Take a piece of black paper and punch out a dise of the same size as the one on the slide, and gum it on to the varnish spot. Take a cell, either metal or vulcanite, of the required depth and fasten it to the paper disc with gold size, asphalt or any other cement, and put the slide away until quite dry. Now place a very small quantity of gum on the centre of the paper disc, and put the specimen into it; but take care that the gum does not extend beyond the object, or the appearance of the mount will be spoiled. When the gum has dried, put the slide into the turn-table again, and run a ring of any good cement on the upper surface of the cell, and when this has become about half dry apply a cover-glass, which must be pressed down with a needle point until it adheres firmly to the cement all round the cell. Put the slide aside for an hour or two, and then run on a good coat of asphalt or zinc cement.

Transparent Cells. - Take a cell of the desired depth and apply a coat of cement to one side of it, and allow it to become very nearly dry. Take a slide and warm it 
gently over a spirit-lamp; take up the cell with a pair of forceps and place it on the centre of the slide, the warmth of which should cause the cement of the cell to melt; if not, warm a little more, and press the cell down gently with a needle point until it adheres firmly to the slide all round. If the specimen is small it must be fastened into the cell with some gum, as for opaque mounts, then put it away until the gum has dried, apply a cover, and finish off as directed for opaque mounts. Leaves of plants and wings of butterflies should be mounted on a thin slide, so that both sides may be examined. No gum will be required for these specimens, but a piece of the leaf or wing should be cut or punched out as nearly the size of the cell as possible, and a thin cell should be used, so that the cover may rest on the object and keep it flat. In all dry mounts great care must be taken that all the cements used to fasten the object in position are quite dry before the cover is put on-if not, any moisture remaining will condense on the under surface of the cover and spoil the preparation.

\section{LESSON No. 14.}

\section{FINISHING OFF SLIDES.}

Canada Balsam.-Quick Method.-Take a small saucer of benzole and a soft brush, and carefully wash away the exuded balsam. Allow the slide to dry, then place it in a turn-table and apply a coat of Miller's cement or Club Black enamel. Let this dry, then wash the slide quite clean with turpentine and apply another coat of cement.

Canada Balsam.-Exposure Method.-Put the slide into a sancer of methylated spirit, and with a small piece of soft rag gently rub away the excess of balsam; dry the slide with a clean cloth and apply a coat of any good cement.

Glycerine Jelly.-Put the slide into a sancer of cold water and allow it to soak for a few minutes, then take a penknife and carefully scrape away the jelly from the edge 
of the cover. Give the slide a good wash in water, and place it in some methylated spirit, which will remove the water. Dry with a clean soft cloth, and apply a coat of Miller's cement or Club Black enamel, and when this has dried add another.

Farrant's Medium.-Allow the slide to dry for a few days, then put it into a saucer of water and wash away the excess of medium with a soft brush. Drain off as much water as possible, and, if the cover is firm enough, dry the slide carefully with a soft cloth; if not, allow all the moisture to evaporate by exposure to the air. When quite dry, put it in a turn-table and apply a coat of cement, and when this has dried add another.

Dry Mounts do not require any washing, but they should have one or two coats of any good cement.

Asphalt and white zinc cement may be used for balsam mounts, but they are no good for glycerine jelly or Farrant's medium. The best cement for all slides is Club Black enamel. It can be bought at any cycle shop. As sold, it is a little too thin for microscopical work, but if the cork is left out of the bottle it will soon evaporate to the desired thickness. When too thick, dilute with methylated spirit. The brush must also be washed in methylated spirit after use.

THE END. 
A

\section{CATALOGUE OF THE PUBLICA'TIONS}

or

\section{BAILLIĖRE, TINDALL, \& COX,}

IN

\section{MEDICINE, SCIENCE AND ART.}

\section{CONTENTS.}

PERIODICAL PUBLICATIONS .

DIRECTORIES

ANATOMY

ART, ARTISTIC ANATOMY, ETC.

CHEMISTRY

-

MEDICINE, SURGERY, AND ALLIED SCIENCES

PHARMACY

STUDENTS' AIDS SERIES

VETERINARY MEDICINE AND SURGERY .

WHITE'S PHYSIOLOGICAL MANIKIN .

PAGE

Back of Title

9 , etc.

11, etc.

- 14, etc.

- 26 , etc.

- 30 , etc.

- 36, etc.

- 39 , etc.

- 42

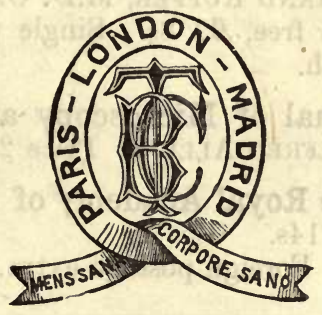

LONDON :

20, 21, KING WILLIAM STREET, STRAND. [PARIS AND MADRID.] 1893.

* * Baillière, Tindall, and Cox have special facilities for the disposal of authors' works in the United States and abroad; being in almost daily communication with the principal houses and agents. 


\section{PERIODICAL PUBLICATIONS.}

The Medical Press and Circular. Established 1838. Published every Wednesday in London, Dublin, and Edinburgh. Price 5 d. ; £1 1s. per annum, post free, in advance.

The Medical Times and Hospital Gazette. The Journal of the Practitioners' Alliance. Price 2d.; 8s. per annnm, prepaid.

Journal of the British Dental Association. A Monthly Review of Dental Surgery. Published on the 15th of each month. Price 6 d., or $7 \mathrm{~s}$. per annum, post free.

The Analyst. The Official Organ of "The Society of Public Analysts." Monthly, price 1s. ; 10s. 6d. per annum, paid in advance.

The Veterinary Journal, and Annals of Comparative Pathology. Monthly, price 1s. 6d. ; 18s. per annum ; Postal Union 19s. 6d., prepaid.

The Australasian Medical Gazette. Monthly, 2s., or yearly post free, price $21 \mathrm{~s}$.

Indian Medico-Chirurgical Review. Monthly, 1s. 6d.; yearly subscription, 16s., post free.

Pathology. A series of illustrations of Pathological Anatomy issued in monthly parts. Each part contains 4 plates in colours, with accompanying descriptive text by Professors KaST, of Breslau, and RUMPEL, of Hamburg. The English edition revised and edited by M. ARMAND RUFFER, M.D. Oxon. Twelve parts by subscription, post free, £2 8s. Single parts, 6s. each. Single plates, 1s. 6d. each.

International Journal of Microscopy and Natural Science. Edited by Mr. Alfred Allen. Price 2s. 6d. Quarterly.

Transactions of the Royal Academy of Medicine in Ireland. Annual volumes, $14 \mathrm{~s}$.

$$
\text { Foreign postage extra. }
$$

\section{DIRECTORIES.}

The Official Register of the Royal College of Veterinary Surgeons; published in accordance with the Act of Parliament. Price 2s. 6d., post free in the United Kingdom.

Commercial Directory for Spain, her Colonies and South America, containing 500,000 Names and Addresses of the Commercial Houses, Public Officers, Offices, etc., etc. Annual, price 25s. 


\section{ALPHABETICAL INDEX OF AUTHORS.}

ABERCROMBIE (J.) On Tetany in Young Clildren ....................... PAGR

ADAMS (W.) Deformities (in Gant's Surgery) ............................ 33

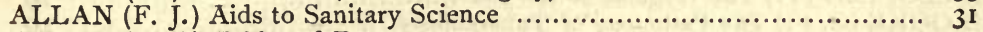

ALLAN (J. H.) Tables of Doses ...................................... 25

ALLEN (Alfred) Microscopical Science ................................... 27

ALLINGHAM (H. W.) Colotomy . ....................................... 8

BAKER (Benson) How to Feed an Infant .............................. 28

BANHAM-Veterinary Posological Tables .................................. 39

BANNATYNE (A.) Aids to Pathology ...................................... 29

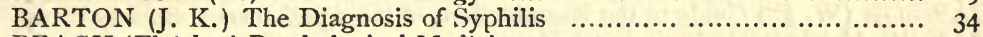

BEACH (Fletcher) Psychological Medicine ............................. $3 \mathbf{1}$

BERNARD (Claude) and HUETTE'S Text-book of Operative Surgery ...... 33

BLACK (C). Atlas of the Male Organs of Generation .......................... ro

BLACKLEY (C. H.) Hay Fever, its Causes and Treatment $\ldots \ldots \ldots \ldots \ldots \ldots \ldots \ldots \cdot 22$

BODDY (E. M.) History of Salt...................................... 32

Hydropathy ................................................... 23

BORTHWICK (T.) The Demography of South Australia .................. I6

BOWDICH (Mrs.) Confidential Chats with Mothers ...................... I5

BOWLES (R. L.) On Stertor and Apoplexy ................................. II

BOYD (Stanley) Movable Atlas of the Foot, its Bones and Muscles .......... Io

BRAND (A. T.) Pocket Case Book ......................................... 14

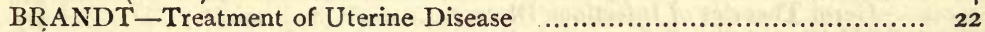

BROCHARD (J.) Practical Guide for the Young Mother......................... 28

BROWN (George) The Student's Case-book ................................ I4

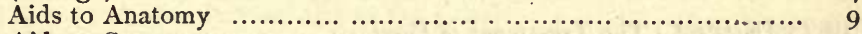

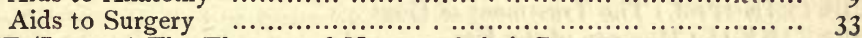

BROWNE (Lennox) The Throat and Nose, and their Iiseases ............ 34

Movable Atlases of the Throat and Ear ................................ Io

BROWNE (W. J.) The Moon, its Influence on Weather ....................... 27

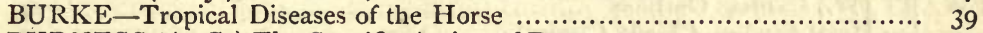

BURNESS (A. G.) The Specific Action of Drugs........................... 39

BURTON (J. E.) Translation of Ebstein's Gout ........................... 22

CADDY (D. J.) Children's Clinical Chart ............................... I6

CAMERON (Chas.) Microbes in Fermentation, Putrefaction, and Disease ... 13

The Cholera Microbe and How to Meet It ..................... I5

CAMERON (Sir C. A.) History of the Royal College of Surgeons in Ireland 23

CAMPBEIL (C. M.) Skin Diseases of Infancy and Early Life ................ 32

CANTLIE (Jas.) Atlas of the Hand ..................................... 10

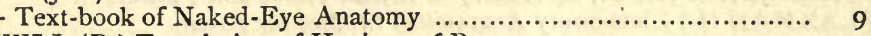

CARDWELL (B.) Translation of Hygiene of Beauty ...................... 24

CASSELLS (J. Patterson) Deaf-mutism and the Education of the Deaf-mute 17

CHARCOT (J. M.) Bright's Disease of the Kidneys........................... 25

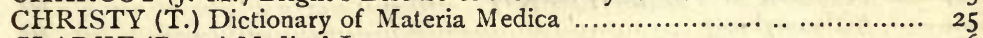

CLARKE (Percy) Medical Laws .............................................. 26

CLARKE (E. H.) The Building of a Brain .............................. 13

COCKLE (John) Contributions to Cardiac Pathology ...................... 22

Insufficiency of the Aortic Valves................................ 22

COFFIN (R. J. Maitland) Obstetrics ....................................... 28

COLE (M. J.) Modern Microscopy....................................... 27

COOMBE (Russell) Epitome of B. P. . ............................. 30

COOPER (R. T.) On Vascular Deafness .................................. is

COSGRAVE (C. M.) Botany, Glossary of ............................... I $_{3}$ 
COTTERELL (Ed.) The Pocket Gray, or Anatumist's Vade Mecum PAgB

COURTENAY (E.) Practice of Veterinary Medicine ........................ 39

COZZOLINO (V.) The Hygiene of the Ear ................................ I9

CROOKE (G. F.) The Pathology of Tuberculosis ......................... 16

CROSS (M. J.) Modern Microscopy …................................. 27

CRUISE (F. R.) Hydropathy ........................................... 23

CULLIMORE (D. H.) Consumption as a Contagious Disease ................ I6

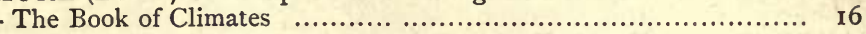

DARLING (W.) Anatomography, or Graphic Anatomy ................... 9

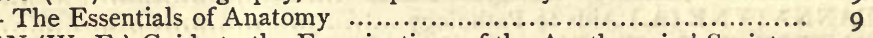

DAWSON (W. E.) Guide to the Examinations of the Apothecaries' Society I9

DAY (W. H.) Irritable Brain in Children .................................. 13

DENNIS (Hy. J.) Second-Grade Perspective Drawing ….................... I I

Third-Grade Perspective Drawing ................................ 12

DOLAN (T. M.) Whooping Cough, its Pathology and Treatment........... 35

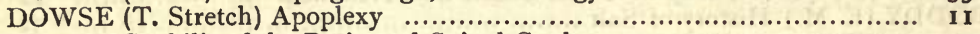

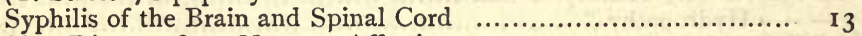

Skin Diseases from Nervous Affections ......................... 32

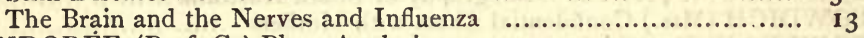

DRAGENDORFF (Prof. G.) Plant Analysis ............................. 15

DRYSDALE (C. R.) Nature and Treatment of Syphilis .................... 34

DRYSDALE (John) The Protoplasmic Theory of Life....................... 34

Germ Theories of Infectious Diseases ................................ 12

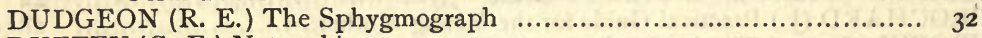

DUFFEY (G. F.) Note-taking ......................................... I4

EBSTEIN (Prof.) The Treatment of Gout ............................... 22

ERSKINE (I.) Hygiene of the Ear ........................................ I9

EVANS (C. W. De Lacy) How to Prolong Life? .......................... I 8

Consumption : its Causes, Treatment, ttc. ....................... I 6

EWART (W.) Cardiac Outlines ......................................... is

Heart-Studies, Chiefly Clinical ................................ 23

How to Feel the Pulse ........................................... 32

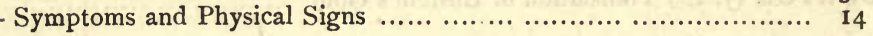

FAU (J.) Artistic Anatomy of the Human Body ............................ I I

Anatomy of the External Form of Man .......................... I I

FIELD (G. P.) Diseases of the Ear ....................................... I 8

Suppurative Diseases of the Ear .................................. 18

FINNY (F. M.) Clinical Fever Chart .................................. 2 I

FITZGERALD (H. P.) Dictionary of British Plants and Flowers ............ I3

FLAXMAN (J.) Elementary Anatomical Studies for Artists ................ II

FLEMING (G.) Text-book of Veterinary Obstetrics .......................... 39

Neumann's Parasites of Domestic Animals ...................... 39

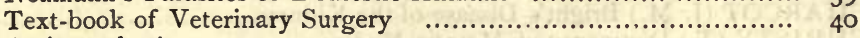

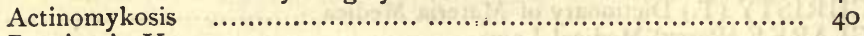

Roaring in Horses ............................................ 40

Practical Horse-Shoeing ........................................ 40

Animal Plagues, their History, Nature and Treatment ............ 40

Contagious Diseases of Animals .................................. 40

Tuberculosis..... ............................................. 40

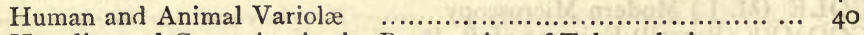

Heredity and Contagion in the Propagation of Tuberculosis ........ 40

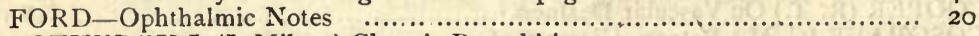

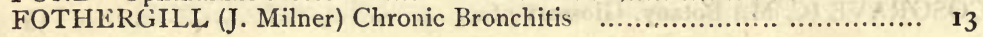




\section{Baillière, Tindall, and Cox's Books.}

FOTHERGILL (J. Milner) The Physiological Factor in Diagnosis .......... 17

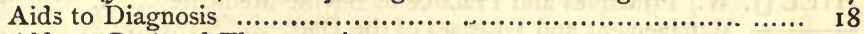

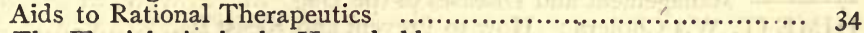

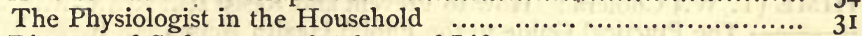

Diseases of Sedentary and Advanced Life ...................... 29

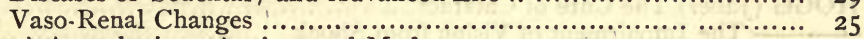

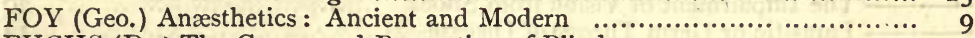

FUCHS (Dr.) The Causes and Prevention of Blindness $\ldots . \ldots \ldots \ldots \ldots \ldots \ldots \ldots . . .20$

GANT (F. J.) Text-book of the Science and Practice of Surgery ............ 33

Diseases of the Bladder, Prostate Gland, and Urethra .............. I3

Examinations by the Conjoint Board ......................... I9

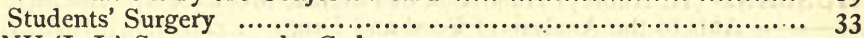

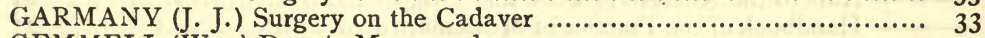

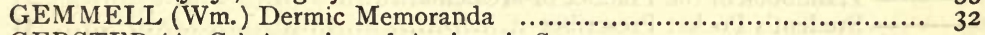

GERSTER (A. G.) Aseptic and Antiseptic Surgery.......................... 33

GIRAUD-TEULON - Anomalies of Vision $\ldots \ldots \ldots \ldots \ldots \ldots \ldots \ldots \ldots \ldots \ldots \ldots \ldots . . . \ldots$

GLASGOW-PATTESON (R.) Skin and Hair .............................. 32

GOODALL (E.) Microscopical Examination of Brain, Spinal Cord and Nerves 23

GORDON (Chas. A.) Our Trip to Burmah $\ldots \ldots \ldots \ldots \ldots \ldots \ldots \ldots \ldots \ldots \ldots \ldots \ldots \ldots$ I4

Life on the Gold Coast ........................................ 8

Lessons in Military Hygiene and Surgery $\ldots \ldots \ldots \ldots \ldots \ldots \ldots \ldots \ldots \ldots .23$

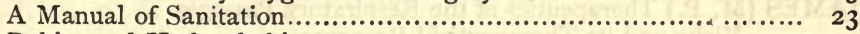

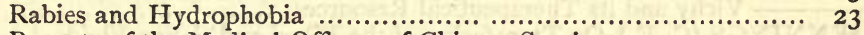

Reports of the Medical Officers of Chinese Service ............. I 5

GORDON (T. Hurd) Aids to Practical Chemistry $\ldots \ldots \ldots \ldots \ldots \ldots \ldots \ldots \ldots \ldots \ldots . . . \ldots \ldots$

GORE (Albert A.) Our Services Under the Crown . ......................... 27

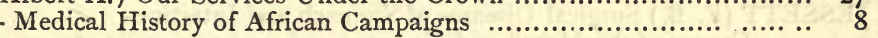

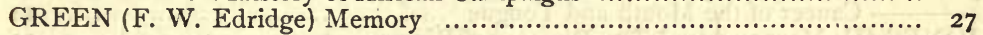

Detection of Colour Blindness...................................... 20

GREENWOOD (J.) Laws Affecting Medical Men ............................ 26

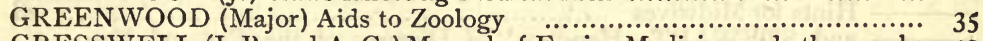

GRESSWELL (J. B. and A. G.) Manual of Equine Medicine and other works 40

GREVILLE (H. Leicester) Student's Hand-book of Chemistry............. I5

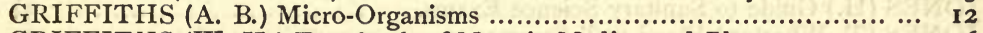

GRIFFITHS (W. H.) Text-book of Materia Medica and Pharmacy ........ 26

Notes for Pharmacopœial Preparation.............................. 30

Posological Tables ................................................. $3 \mathbf{3}$

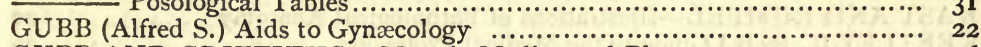

GUBB AND GRIFFITHS. Materia Medica and Pharmacy ................ 26

GUILLEMARD (F. H. H.) Endemic Hæmaturia ....................... 2I

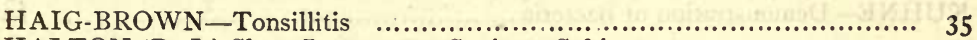

HALTON (R. J.) Short Lectures on Sanitary Subjects ..................... 24

HARRIS (Vincent) Manual for the Physiological Laboratory ................. 23

HARRIS (V. D.) Kühne's Guide to the Demonstration of Bacteria .......... I2

HARTMANN (Prof.) On Deaf-mutism, Translation by Dr. Cassells........... I 7

HAYNES (Stanley) Healthy Homes .................................... 24

HAZARD (W. P.) Diseases of Live Stock ................................. 4I

HEIBERG (Jacob) Atlas of Cutaneous Nerve Supply ...................... 27

HEMMING (W. D.) Aids to Forensic Medicine ......................... 2 I

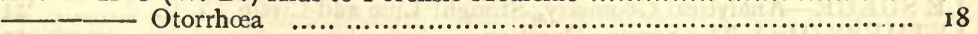

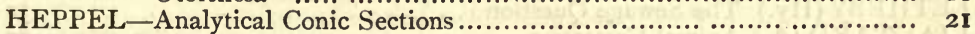

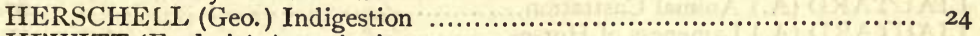

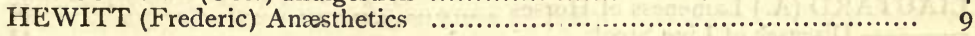


HILL (J. W.) Principles and Practice of Bovine Medicine $\ldots . . . . . . .60$ Management and Diseases of the Dog ............................ 40

HIME (T. W.) Cholera : How to Prevent and Resist It..................... I5 The Practical Guide to the Public Health Acts..................... 3I

HOGG (Jabez) The Cure of Cataract ....................................... 20

The Impairment of Vision from Shock ............................ 20

Parasitic or Germ Theory of Disease ............................. I 2

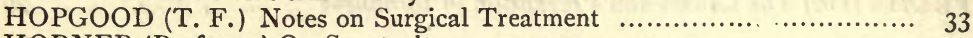

HORNER (Professor) On Spectacles .................................... ${ }_{20}$

HOWAT (G. R.) How to Prevent and Treat Consumption .................. I6

HUNTER (Ch.) Manual for Dental Laboratory ............................. I 7

HUSBAND (H. Aubrey) Handbook of Forensic Medicine ..................... 2 I

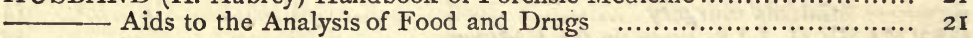

Handbook of the Practice of Medicine.............................. 27

- Student's Pocket Prescriber .................................... 3 I

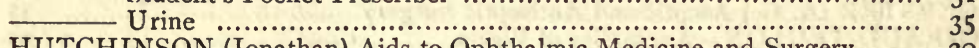

HUTCHINSON (Jonathan) Aids to Ophthalmic Medicine and Surgery ...... 20

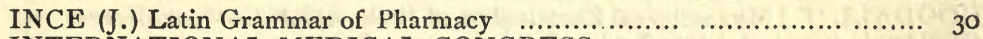

INTERNATIONAL MEDICAL CONGRESS ........................... 24

JAMES (Brindley) Replies to Questions in Therapeutics ..................... 38

JAMES (M. P.) Therapeutics of the Respiratory Passages .................... 34

Vichy and its Therapeutical Resources ......................... 35

JENNINGS (C. E.) On Transfusion of the Blood and Saline Fluids ............ 35

Cancer and its Complications ................................ 14

JENNINGS (Oscar) On the Cure of the Morphia Habit......................... 27

JESSETT (F. B. ) Surgical Diseases of Stomach and Intestines ............... 8

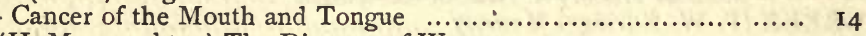

JONES (H. Macnaughton) The Diseases of Women ....................... 22

Subjective Noises in the Head and Ears........................... r 8

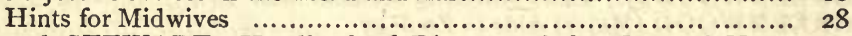

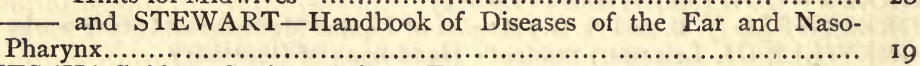

JONES (H.) Guide to Sanitary Science Exains. . .......................... 32

JONES (T. Wharton) Blood in Inflammation ............................ 24

JUKES-BROWNE (A. J.) Palæontology (in Penning's Field Geology) ...... 2 I

KAST AND RUMPEL-Illustrations of Pathological Anatomy ............. 29

KEETLEY (C.R. B.) Guide to the Medical Profession.......................... 26

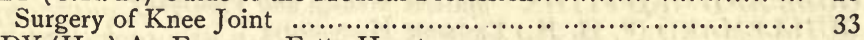

KENNEDY (Hy.) An Essay on Fatty Heart............................. 23

KUHNE-Demonstration of Bacteria .................................... I 2

LAMBERT (J.) The Germ Theory of Disease ............................. 40

LEASK (J. G.) Questions at Medical Science Examinations .................... 20

LEDWICH (J.) Anatomy of Inguinal and Femoral Regions ..................... 9

LEONARD (H.) The Pocket Anatomist ....................................... 9

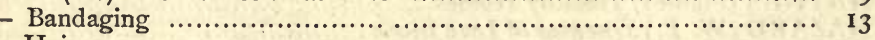

- Hair ........................................................... 22

and CHRISTY - Dictionary of Materia Medica .................... 25

LE SUEUR - Analytical Geometry, Straight Line and Circle .............. 2I

LETHEBY (Hy.) The Sewage Question …................................ $3^{2}$

LIAUTARD (A.) Animal Castration.................................... 40

LIAUTARD (A.) Lameness of Horses .................................... 40

Diseases of Live Stock ....................................... 4I 


\section{Baillière, Tindall, and Cox's Books.}

LITHGOW (R. A. Douglas) From Generation to Generation

PAGE

LOWNE (B'T) Aids to Physiology

LUNN (C.) The Philosophy of Voice

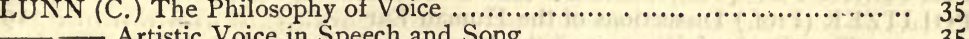

LUPTON (J. I.) Horses : Sound and Unsound................................. 45

MACDOUGALL (A. M.) The Maybrick Case ............................ 2 I

MACKENZIE (Sir M.) Diseases of the Throat (in Gant's Surgery) ........... 33

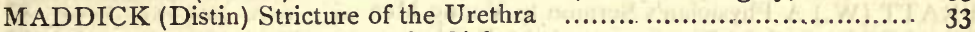

MAGN ${ }_{i}$ (Dr.) How to Preserve the Sight................................... 20

MARTIN (J. W. \& J.) Ambulance Work (Questions and Answers) .......... 8

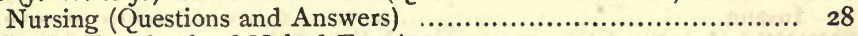

MASSE (J. N.) Text-book of Naked-Eye Anatomy ........................... 9

MCARDLE (J. S.) Notes on Materia Medica. ................................ 26

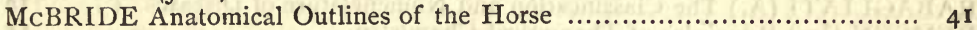

MCLACHLAN (John) Anatomy of Surgery .............................. 33

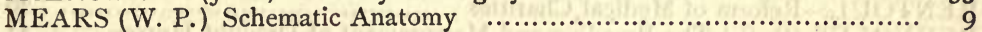

MELDON (Austin) A Treatise on Gout ................................... 22

MEYRICK (J. J.) Stable Management in India.............................. 4 I

MILLARD (H. B.) Bright's Disease of the Kidneys......................... 25

MILLER (B. E.) Diseases of Live Stock ................................. 4 I

MOLONY (M. J.) Rupture of the Perineum ............................. $3^{2}$

MONIN (E.) Hygiene of Beauty .................................... 24

MOORE (E. H.) Clinical Chart for Hospital and Private Practice............. 34

MOORE (J. W.) Text Book of Eruptive and Continued Fevers................ 2 I

MORDHORST (Carl) Rheumatism. Its Treatment by Electric Massage $\quad . . \quad 32$

MORGAN (John) The Dangers of Chloroform and Safety of Ether ........... 8

MORRIS (Malcolm) The Skin (in Gant's Surgery) …..................... 33

MUCKLEY (W. J.) Student's Manual of Artistic Anatomy.................... II

A Handbook for Painters and Art Students on the Use of Colours 16

MURRAY (R. Milne) Pregnancy............................................. Io

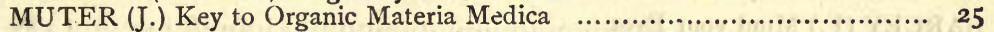

Manual of Analytical Chemistry .................................... ${ }_{5}$

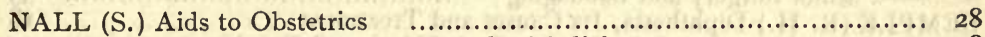

NAPHEYS (G. H.) Handbook of Popular Medicine ........................ is

Modern Therapeutics ......................................... 34

NATIONAL SOCIETY FOR PREVENTION OF BLINDNESS ...... 20

NEUMANN (L. G.) Treatise on Parasites and Parasitic Diseases of Domes-

ticated Animals

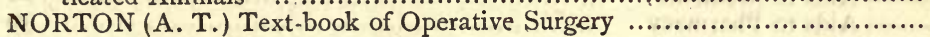

Osteology for Students

Affections of the Throat and Larynx

Movable Atlas of the Skeleton.

OGSTON On Unrecognised Lesions of the Labyrinth .................... I 8

ORMSBY (L. H.) Deformities of the Human Body .......................... I

Phimosis and Paraphimosis ................................... 30

PALFREY (J.) Atlas of the Female Organs of Generation ................... ro

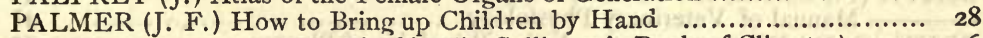

PARKE (Surgeon) Climate of Africa (in Cullimore's Book of Climates) ..... 16

PEDDIE (M.) Manual of Physics.............................................. 30

PENNING (W. H.) Text-book of Field Geology .......................... 2 I 
PENNING (W. H.) Engineering Geology ................ PAGE

Notes on Nuisances, Drains, and Dwellings ..................... 24

PETTENKOFER (Von) Cholera : How to Prevent and Resist It .......... I 5

POLITZER (Prof.) Dissections of the Human Ear ........................ I9

Text-Book of Diseases of the Ear ............................... r9

POWER (Hy.) Movable Atlas of the Eye, and the Mechanism of Vision ...... Io

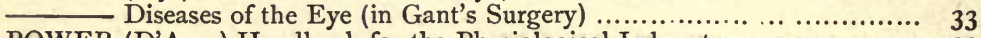

POWER (D'Arcy) Handbook for the Physiological Laboratory ................. 23

POYSER (R.) Stable Management of Troop Horses in India .................. $4 \mathbf{I}$

PRATT (W.) A Physician's Sermon to Young Men ......................... 27

PROCTOR (Richd.) The Stars and the Earth ............................ 12

PSYCHOLOGIGAL ASSOCIATION'S Handbook for Attendants on the Insane........................................................... 25

PURVES (L.) Aural Diseases (in Gant's Surgery) ............................. 33

RABAGLIATI (A.) The Classification and Nomenclature of Diseases ....... I 8

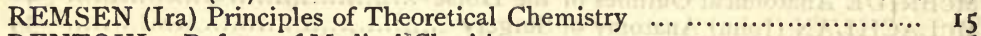

RENTOUL - Reform of Medical Charities ….......................... 26

REYNOLDS (R. S.) The Breeding and Management of Draught Horses...... 4r

RICHARDS (J. M.) A Chronology of Medicine .......................... 27

RICHARDSON (B. W.) The Healthy Manufacture of Bread ................ 2 r

RIVINGTON (W.) Medical Education and Organization $\ldots \ldots \ldots \ldots \ldots \ldots \ldots \ldots . \ldots . \ldots . \ldots 26$

ROBERTSON (William) A Handbook of the Practice of Equine Medicine... $4 \mathrm{I}$

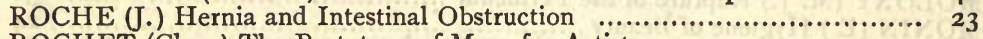

ROCHET (Chas.) The Prototype of Man, for Artists ....................... I2

ROSE (W.) Neuralgia................................................. 28

ROTH (M.) Works on Deformities, Gymnastic Exercises, etc. ............... 22

ROTH (W. E.) Elements of School Hygiene.............................. 24

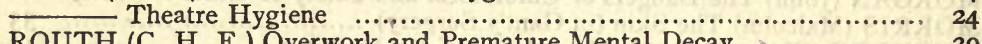

ROUTH (C. H. F.) Overwork and Premature Mental Decay .................... 29

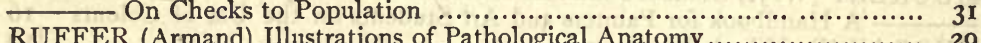

RUFFER (Armand) Illustrations of Pathological Anatomy ..................... 29

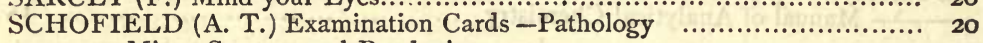

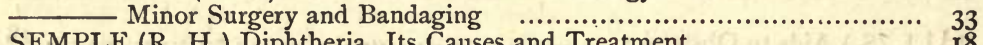

SEMPLE (R. H.) Diphtheria, Its Causes and Treatment ..................... I8

Movable Atlas of the Human Body (Neck and Trunk) ............. ro

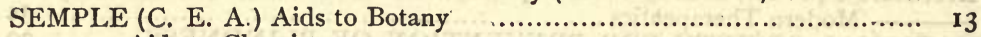
Aids to Chemistry ................................................. I4

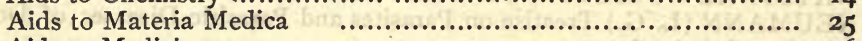

Aids to Medicine $\quad$...................................................... 26

Aids to Pharmacy $\quad$................................................. 30

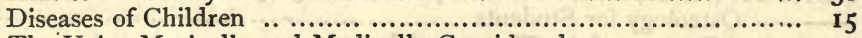

The Voice Musically and Medically Considered .................... 35

The Pocket Pharmacopœia ...................................... 30

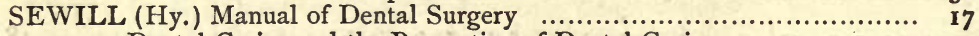

Dental Caries and the Prevention of Dental Caries ................ 17

SHARMAN (J. S.) Notes on Inorganic Materia Medica ........................ 26

SIMON (W.) A Manual of Chemistry ................................... 15

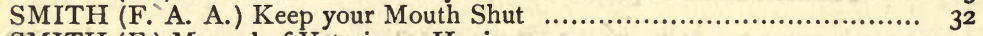

SMITH (F.) Manual of Veterinary Hygiene $\ldots \ldots \ldots \ldots \ldots \ldots \ldots \ldots \ldots \ldots \ldots \ldots, \quad \mathbf{4}_{\mathbf{I}}$

Manual of Veterinary Physiology ............................ 41

SOHN (C. E.) Dictionary of the Active Principles of Plants .................

SPARKES (John C. L.) Artistic Anatomy .............................. Ir

SQUIRE (P. W. ) Posological Tables .................................... $3 \mathbf{r}$ 


\section{Baillère, Tindall, and Cox's Books.}

STARK (A. Campbell) Practical Pharmacy

STEVENS (G (T. B.) Medicinal Kemedies.................... 27

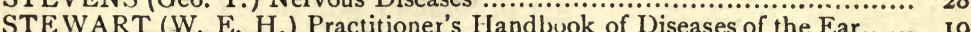

STONE (G.) Translation of Politzer's Dissections of the Human Ear ........ I

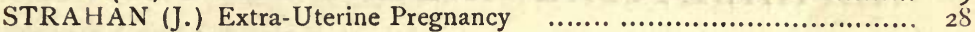

STUDENTS' AIDS SERIES ........................................ 36

SUTTON (H. G.) Lectures on Medical Pathology .......................... 29

SUTTON (Bland) Dermoids............................................... I 7

SWEETING (R. D. R) The Sanitation of Public Institutions ................ 24

SYMINGTON (J.) Anatomy of the Child .................................. 9

TELLOR (L. V.) Diseases of Live Stock ................................. 4 I

TEULON (G.) The Functions of Vision.................................... 20

THIN (George) Introduction to Practical Histology ............................ 23

THOROWGOUD (J. C.) Consumption ; its Treatment by the Hypophosphites 16

- The Treatment of Bronchial Asthma ............................. 12

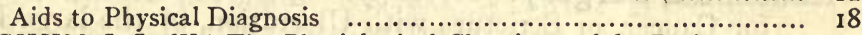

THUDICHUM (J. L. W.) The Physiological Chemistry of the Brain ......... 13

Aids to Physiological Chemistry .................................... 37

Aids to Public Health............................................. 3 I

Polypus in the Nose ........................................... $3 \mathbf{I}$

The Coca of Peru, and its Remedial Principles........................

TICHBORNE (Professor) The Mineral Waters of Europe .................... 27

TIDY (Meymott) and CLARKE (Percy) Medical Laws ..................... 26

TIMMS (G.) Consumption ; its Nature and Treatment ...................... I 6

- Alcohol in some Clinical Aspects, a Remedy, a Poison ............. 8

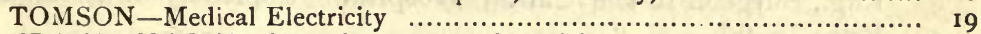

TRANSACTIONS of Royal Academy of Medicine in Ireland ......... Inside cover

TUCKEY (C. I.loyd) Psycho-Therapeutics .................................. 24

TURNEK (Dawson) Manual of Medical Electricity ........................... 19

TYSON.(J.) The Urine, a Guide to its Practical Examination ................. 35

UNDERWOOD (Arthur S.) Aids to Dental Surgery ....................... 17

Uirs to Dental Histology ........................................... I

USHER (J. E.) Alcoholism ................................................... 8

WAGSTAFFE (W. W.) Atlas of Cutaneous Nerve Supply .................. 27

WALLACE $(\mathrm{J}$.$) Localised Peritonitis........................................ 29$

WALSH (D.) Aids to Examinations …................................. I9

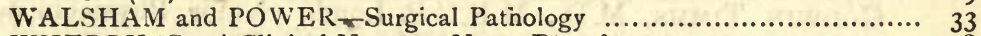

WHERRY (Geo.) Clinical Notes on Nerve Disorders ........................ 28

WILLIAMS (J. IV.) Aids to Biology .. ................................... I 3

WILLIAMSON (J. M.) Ventnor and the Undercliff............................. I6

WILLSON (A. Rivers) Chemical Notes for Pharmaceutical Students ........ 15

WILSON (J.) A Manual of Naval Hygiene ................................ 24

WINDLE (B. C. A.) Proportions of the Human Body ..................... 12

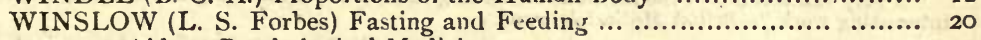

Aids to Psychological Medicine .................................. 37

IVITKOWSKI (G. J.) Movable Atlases of the Human Body ................ 10 
Baillière, Tindall, and Cox's Books.

\section{AN \\ ALPHABETICAL INDEX OF WORKS,}

IN

MEDICINE, SURGERY, SCIENCE AND ART,

PUBLISHED BY

\section{BAILLIÈRE, TINDALL, \& COX.}

Abdominal Surgery. Colotomy, Inguinal, Lumbar or Transverse ; for Cancer, or Stricture with Ulceration, of the large Intestine. By Herbert W. Allingham, F.R.C.S., Surgeon to the Great Northern Hospital, Assistant Surgeon to St. Mark's Hospital for Diseases of the Rectum, Surgical Registrar to St. George's Hospital. With six plates and numerous illustrations. Price 6s.

Abdominal Surgery. The Surgical Diseases and Injuries of the Stomach and Intestines. By F. BowREMAN JessETT, F.R.C.S. Eng., Surgeon to the Cancer Hospital. Copiously illustrated. Price 7s. 6d.

Africa. A Contribution to the Medical History of our West African Campaigns. By Surgeon-Major ALBERT A. GORE, M.D., Sanitary Officer on the Staff. Price 10s. 6d.

Africa. Life on the Gold Coast. A Description of the Inhabitants, their Modes and Habits of Life ; Hints to Travellers and others in Western Africa. By Surgeon-General GoRDon, M.D., C.B., Hon. Physician to the Queen. Price 2s. 6d.

Alcohol, in some Clinical Aspects: A Remedy, a Poison. By Godwin Timus, M.D., M.R.C.P. Lond., Senior Physician to the North London Consumption Hospital. Price 1s.

Alcoholism and its Treatment. By JoHN E. UsHeR, M.D., F.R.G.S. Price 3s. $6 \mathrm{~d}$.

"Will be found interesting and suggestive."-The Times.

"A very full account of the methods of treating the disease of inebriety is contained in this interesting work."-British Medical Journal.

Ambulance Work. Questions and Answers on "First Aid to the Injured." By JoHN W. Martin, M.D., and JoHN Martin, F.R.C.S. Twentieth thousand. Price 1s. net.

Anæsthetics. The Dangers of Chloroform and the Safety and Efficiency of Ether in Surgical Operations. By JoHn Morgan, M.D., F.R.C.S. Second thousand, price 2s. 


\section{Baillière, Tindall, and Cox's Books.}

Anæsthetics. Selected Methods in the Administration of Nitrous Oxide and Ether. By Frederic Hewitt, M.A., M.D. Cantab., Lecturer on Anæsthetics at the London Hospital. Price 2s. 6d.

Anæsthetics : Ancient and Modern. Their Physiological Action, Therapeutic Use, and Mode of Action. By GEORGE Foy, F.R.C.S., Surgeon to the Richmond Hospital. Price 3s. 6d. net.

Anatomography; or, Graphic Anatomy. A new method of grasping and committing to memory the,most difficult points required of the student. By W. DARLING M.D., F.R.C.S. Eng., Professor of Anatomy in the University of New York. Price 1s.

Anatomy. Aids to Anatomy. By George Brown, M.R.C.S., Gold Medallist, Charing Cross Hosp. Price 1s. 6d. cloth, 1s. sewn.

Anatomy. Text-Book of Naked-Eye Anatomy. With 113 Steel Plates, designed under the direction of Professor Masse. Text by JaS. CantuIE, M.B., C.M. (Honours), F.R.C.S., Charing Cross Hospital. Third edition. Plain, 25s., coloured, 50s., half calf.

Anatomy. The Essentials of Anatomy. A Text-book for Students and a book of easy reference to the Practitioner. By W. DaRling, M.D., F.R.C.S., and A. L. RANneY, M.D. 12s. 6 d.

Anatomy. The Pocket Gray, or Anatomist's Vade-Mecum. Com. piled from the works of Gray, Ellis, Holden, and Leonard. By E. CotTerel, L.R.C.P., M.R.C.S. Fourth edition, 3s. 6 d.

"A marvellous amount of information condensed into a remarkably small space."-Med. Press.

Anatomy. The Pocket Anatomist. By H. Leonard, M.D. Enlarged Edition, illustrated. Price 3s. 6d.

Anatomy. Schematic Anatomy; or Diagrams, Tables and Notes treating of the Association and Systematic arrangement of Structural Details of Human Anatomy. By William P. Mears, M.B., Professor and Examiner in Anatomy at the University of Durham. Profusely illustrated. Price 7s. 6d.

Anatomy. Anatomy of the Child. With 14 coloured plates and 33 woodcuts. By Johnson SymingToN, M.D., F.R.S.E., F.R.C.S.E., Lecturer on Anatomy, Edinburgh. Price $42 \mathrm{~s}$.

Anatomy of the Inguinal and Femoral Regions in Relation to Hernia. By E. LEDWICH, Lecturer on Anatomy in the Ledwich School of Medicine, Dublin. Price 3s. 
Anatomy. Human Anatomy and Physiology, illustrated by a series of Mivable Atlases of the Human Body, showing the relative positions of the several parts, by means of Superposed Coloured Plates, from the designs of Prof. G. J. WitKowski, M.D. Each part complete in itself.

Part I.-Neck and Trunk. With Text Descriptive and Explanatory of the physiology and functions of the several parts. By Robert Hunter Semple, M.D., F.R.C.P. Lond. Price 7s. 6 d.

The same enlarged to Life Size. Price $£ 2$ ss.

Part II.-Throat and Tongue, showing the Mechanism of Voice, Speech, and Taste. Text by Linnox Browne, F.R.C.S. Ed. Price 7s. 6d.

Part III.-The Female Organs of Generation and Reproduction. Text by James Palfrey, M.D., M.R.C.P. Lond, late Senior Obstetric Physician, London Hospital. Price 7s. 6d.

Part IV.-The Eye and the Apparatus of Vision. Text by Henry Power, F.R.C.S., Senior Ophthalmic Surgeon to St. Bartholomew's Hospital. Price 7s. 6d.

Part V.-The Ear and Teeth. The Mechanism of Hearing, and of Mastication. Text of the Ear by LenNox BRowne, F.R.C.S.E. The Teeth by H. SEwILL, M.R.C.S. Price 7s. 6 d.

Part VI.-The Brain and Skull. (Cerebrum, Cerebellum, and Medulla Oblongata.) Text by T. Stretch Dowse, M.D., F.R.C.P. Ed. Price 7s. 6d.

Part VII.-The Male Organs of Generation. Text by D. Campbell Black, M.D., Physician to the Glasgow Royal Infirmary. Price 7s. 6d.

Part VIII.-The Skeleton and its Articulations, showing the Bones and Ligaments of the Human Body and Limbs. Text by A. T. Norton, F.R.C.S. Price 7s. 6d.

Part IX. - The Hand; its Bones, Muscles and Attachments. Text by Jas. Cantule, M.B., F.R.C.S. Price 7s. 6 d.

Part X.-The Foot; its Bones, Muscles and Attachments. Text by Stanley Boyd, M.B., B.S. Lond., F.R.C.S., Assistant Surgeon, Charing Cross Hospital. Price 7s. 6d.

Part XI.-Progress of Gestation. A Synopsis of Practical Obstetrics. Text by R. Milne Murray, F.R.C.P. Edin., M.B. Ediu. Price 7s. 6d.

The Set of Eleven Parts, complete in cloth-covered Box, with lock and key, £4 net. * No such simple, reliable, and comprehensive method of learning the several parts, positions, and functions of the body has hitberto been attenipted; the entire Series being unique, will be most valuable to the Teacher, the Student, and to all who wish to become acquainted with the anatomy and physiology of the human economy. 
Apoplexy. On Stertor, Apoplexy, and the Management of the Apoplectic State. By ROBERT L. Bowles, M.D., F.R.C.P. Lond., Consulting Physician to the Victoria Hospital, and to the St. Andrew's Convalescent Hospital, Folkestone. With 13 Illustrations. Price 4s. 6d.

"The information is both practical and useful, and based on extensive clinical and experl. mental investigation. The priuciple 8 adrocated by the author deserve to be more widely known and acted on than they are at present."-British Medical Journal.

"The anthor has produced a book which is at present the only authority on the subject."Medical Press.

Apoplexy. Diagnosis and Treatment of Apoplexy. By T. Stretch DowsE, M.D., F.R.C.P.E., formerly Medical Superintendent, Central London Sick Asylum. Price 1s.

Army Hygiene. Lessons in Military Hygiene and Surgery. By Surgeon General Gordon, M.D., C.B., Hon. Physician to H.M. the Queen. Illustrated. Price 10s. 6d.

Artistic Anatomy. Anatomy of the External Forms of Man, for the use of Artists, Sculptors, etc. By Dr. J. FAU. Used at the Government School of Art, South Kensington. Twenty-nine plates. Folio. New edition. 30s. coloured, 15s. plain.

Artistic Anatomy. Elementary Anatomical Studies of the Bones and Muscles, for Students and Schools, from the drawings of J. Flaxman, R.A. Lately used as a Text-book in the Art Schools at South Kensington. 20 plates, with Text, price 2s.

Artistic Anatomy. The Student's Manual of Artistic Anatomy. With 25 etched plates of the bones and surface muscles of the human figure. By W. J. Muckley. Used at the Government School, South Kensington. Second edition. Price 5s. 6d.

Artistic Anatomy. Elementary Artistic Anatomy of the Human Body. From the French of Dr. FAU. With English Text. Used at the Government School of Art, South Kensington. Price 5s.

Artistic Anatomy. Description of the Bones and Muscles that influence the External F'orm of Man. With 43 plates. By JoHN C. L. SPARKeS, Principal of the National Art Training School, South Kensington. Adopted as a text-hook at the Government Art Schools. Price 7s. 6d.

Artistic Drawing. Second Grade Perspective (Theory and Practice), containing 21 block illustrations, 20 plates, and many examination exercises. Used at the Government Science and Art Schools. By H. J. Dennis, Art Master, Lambeth School of Art, Dulwich College, etc. Price 2s. 6d. 
Artistic Drawing. Third Grade Perspective, for the use of Art Students. By H. J. Dennis. Used at the Science and Art Schools. In two parts, 7s. 6d. each. Part 1, Angular and Oblique Perspective. Part 2, Shadows and Reflections; or, half-bound leather in one vol., price $15 \mathrm{~s}$.

Artistic Drawing. The Prototype of Man, giving the natural laws of Human proportion in both sexes. A manual for artists and professors of drawing. By Chas. Rochet, of Paris. Price 1s. Artists' Colours. Their Preparation, Uses, etc. (See Colours.)

Artistic Drawing. A Manual of the Proportions of the Human Body for Artists. By Bertram C. A. Windle, M.A., M.D., D.Sc., Queen's Professor of Anatomy in the Mason College, Professor of Anatomy to the Royal College of Artists, and Lecturer in the Municipal School of Birmingham. Price 2s.

Asthma. On Bronchial Asthma-its Causes, Pathology and Treatment. Lettsomian Lectures. By J. C. ThorowG0oD, M.D., F.R.C.P. London, Senior Physician to the City of London Hospital for Diseases of the Chest. Third edition. Price 3s.

Astronomy. The Stars and the Earth; or, Thoughts on Time, Space, and Eternity. With Notes by R. A. Proctor, B.A., Fourteenth thousand. Price 1s.

Ataxia. Nervous Affections associated with the Initial or Curative Stage of Locomotor Ataxy. By T. Stretch Dowse, M.D., F.R.C.P.E. Second Edition. Price 2s.

Aural Diseases. (See Ear.)

Bacteriology. Researches in Micro-Organisms, including recent Experimentsin the Destruction of Microbes in Infectious Diseases, etc. By A. B. Griffiths, Ph.D., F.C.S., F.R.S.E. With 52 Illustrations. Price 6s.

"An enormous amount of material, the author has taken great trouble to collect a large number of the references bearing on the points he mentions."-Lancet.

"The work... may be recommended to those who wish to have in a convenient form a very large number of facts and references relating to bacteria." -British Medical Journal.

Bacteriology. The Germ Theories of Infectious Diseases. By JoHn Drysdale, M.D., F.R.M.S., President of the Liverpool Microscopical Society. Price 1s.

Bacteriology A Parasitic or Germ Theory of Disease: the Skin, Eye, and other affections. By JABEZ HoGG, M.R.C.S., Consulting Surgeon to the Royal Westminster Ophthalmic Hospital. Second edition, price 2s. 6 d.

Bacteriology. Guide to the Demonstration of Bacteria in the Tissues. By Dr. H. KüHNE, of Wiesbaden. Translated and Edited by Vincent Dormer Harris, M.D. Lond., F.R.C.P., Demonstrator of Physiology at St. Bartholomew's Hospital. Price 2s. 6d. 


\section{Baillière, Tindall, and Cox's Books.}

Bacteriology. Microbes in Fermentation, Putrefaction, and Disease. By Charles Cameron, M.D., LL.D. M.P. Price 1s. Professor Tyndall, F.R.S., writes: "Matthew Arnold himself could not find fault with its lucidity, while as regards knowledge and grasp of the subject I have rarely met its equal."

Bandaging. A Manual for Self-instruction. By C. H. Leonard, A.M., M.D., Professor of Diseases of Women in the State College, Michigan. With 139 illustrations. Price 3s. 6d.

Biology. Aids to Biology. Specially prepared to meet the requirements of students reading for the first examination of the Conjoint Board. By JosePH W. Williams. Price 2s. sewn, and 2s. 6 d. cloth.

Bladder. On Diseases of the Bladder, Prostate Gland, and Urethra. By F. J. Gant, F.R.C.S., Senior Surgeon to the Royal Free Hospital. Fifth Edition. Price 12s. 6d.

Botany. A Dictionary of British Plants and Flowers; their names, pronunciation, origin, etc. By H. P. FitzGerald. Price 2s. 6 d.

Botany. Aids to Botany. Outlines of the Elementary Facts, including a Description of some of the most important Natural Orders. By C. E. Armand Semple, B.A., M.B. Cantab., M.R.C.P. Lond. Price 2s. 6d. cloth; 2s. paper wrapper.

Botany. The Student's Botany. Encyclopædic Glossary. By E. MacDowel Cosgrave, M.D., Lecturer on Botany, Carmichael College. Price 2s. 6d.

Brain. The Building of a Brain. By E. H. ClaRke, M.D. (author of "Sex in Education"). Price 5s.

"Carefully and elegantly written, and full of sound physiology."-Lancet.

Brain. On Irritable Brain in Children. By W. H. DAY, M.D., M.R.C.P. Lond., Physician to the Samaritan Hospital for Women and Children. Price 1s. $6 \mathrm{~d}$.

Brain. The Physiological and Chemical Constitution of the Brain, based throughout on original researches. By J. L. W. THUDICHUM, M.D., F.R.C.P. Lond. Price 10s. 6d.

Brain. Syphilis of the Brain and Spinal Cord, showing the part which this agent plays in the production of Paralysis, Epilepsy, Insanity, Headache, Neuralgia, Hysteria, and other Mental and Nervous Derangements. By T. STRETCH Dowse, M.D., F.R.C.P. Ed. Second edition, illustrated. Price 5s.

Brain. Qn Brain and Nerve Exhaustion (Neurasthenia), and on the Exhaustions of Influenza. By the same Author. Price 2s. 6d.

Bronchitis. Chronic Bronchitis : its Forms and Treatment. By J. Milner Fothergill, M.D. Ed., M.R.C.P. Lond. Second

Edition. Price 4s. 6d.

"It bristles with valuable hints for treatment."-British Medical Journal.

"The pages teem with suggestions of value."-Philadelphia Medical Times. 
Burmah. Our Trip to Burmah, with Notes on the Ethnology, Geography, Botany, Habits and Customs of that Country, by Surgeon-General Gordon, C.B., M.D., Physician to the Queen. Illustrated with numerous Photographs, Maps, Coloured Plates, and Sketches in gold by native Artists. Price $21 \mathrm{~s}$.

"We lay down this book, impressed with its many beauties, its amusing sketches and anecdotes, and its useful and instructive information."-The Times.

Cancer and its Complications. The Local Origin of Cancer from the Various Parts of the Body, Preventive and Curative Treatment, etc. By C. E. Jennings, F.R.C.S. Eng., M.S., M.B. 6 s.

Cancer of the Mouth, Tongue and Osophagus. By F. BowreMAN JESSETT, F.R.C.S. Eug., Surgeon to the Cancer Hospital. 6s.

Case Books. A Pocket Case-book for Practitioners and Students. With diagrams, charts, and suggestions for note-taking. By Alex. Theodore Brand, M.D., C.M. Bound in limp leather cover. Price 4s. Loose sheets per doz. 1s., 50 3s. 6d. $1006 \mathrm{~s}$.

Case Taking. Cardiac Outlines for Clinical Clerks and Practitioners; and First Principles in the Physical Examination of the Heart for the Beginner. By W. EwarT, M.D., F.R.C.P. Lond., Physician to St. George's Hospital, London With fifty illustrations. A Pocket Companion at the Bedside. With outlines to illustrate the methods and results of the physical examination of the heart in health and disease, and to assist in recording clinical observations. Price 5s. 6d.

* A supply of thoracic and cardiac outlines ( $4 \frac{1}{2}$ by $3 \frac{3}{4}$ inches), on gummed paper, is included in each copy.

Case Taking. Symptoms and Physical Signs, a formulary for medical note-taking, with examples. By the sameAuthor. Price 2s.

Case Books. Student's Case-book. For recording cases as seen, with full instructions for methodizing clinical study. By GEOrge Brown, M.R.C.S., Gold Medallist, Charing Cross Hospital. Fourth thousand, cloth. Price 1s. net.

Case-book. Suggestions for a plan of taking notes in medical cases. By Geo. F. Duffey, M.D. Dublin. Price 6d.

Chemistry. Aids to Chemistry. By C. E. Armand Semple, B.A., M.B. Cantab., M.R.C.P. Lond.

Part I.-Inorganic. The Non-metallic Elements. Price 2s. 6 d. cloth ; 2s. paper wrapper.

Part II.-Inorganic. The Metals. Price 2s. 6d. cloth ; 2s. paper. Part III.-Organic. Cloth, 2s. 6d.; paper, 2s.

Part IV.-Tablets of Chemical Analysis. Price 1s. 6d. and 1s.

"Students preparing for Matriculation at the London University, and other Examinations will find it simply invaluable." - Students' Journal. 


\section{Baillière, Tindall, and Cox's Books.}

Chemistry. A Manual of Chemistry ; a complete guide to Lectures and Laboratory work for beginners in Chemistry, and a textbook for students in Medicine and Pharmacy. By W. Simon, Ph.D., M.D. Coloured plates, 56 Chemical reactions. 15s.

Chemistry. Dictionary of the Active Principles of Plants: Alkaloids, Bitter Principles, Glucosides, with tabular summary and classification of Reactions. By Charles E. Sohn, F.I.C., F.C.S.

[In the Press.

Chemistry. Plant Analysis, Quantitative and Qualitative. By G. Dragendorff, Professor of Chemistry and Pharmacy in the University of Dorpat. Price 7s. 6d.

Chemistry. The Principles of Theoretical Chemistry, with special reference to the Constitution of Chemical Compounds. By IRA REmsen, M.D., Ph.D., Professor of Chemistry in the John Hopkins University. 4th Edit., enlarged and revised. 7s. 6d.

Chemistry. The Student's Hand-book, with Tables and Chemical Calculations. By H. Leicester Greville, F.I.C., F.C.S. Second Edition. Price 6s.

Chemistry. Chemical Notes for Pharmacentical Students. By A. Rivers Willson. Second Edition. Price 3s.6d.

"Of exceeding value to students going up for examination."-Pharmaceutical Journal.

Chemistry. A Short Manual of Analytical Chemistry for Laboratory Use. By John Muter, Ph.D., M.A., F.C.S. Second Edition. Price 6s. 6d.

Children. The Diseases of Children : their History, Causes and Treatment. By C. E. Armand Semple, B.A., M.B. Cantab., M.R.C.P. Lond. Price 6s.

Children. Confidential Chats with Mothers on the healthy rearing of Children. By Mrs. Bowdich. Price 2s.

Children. On Tetany in Young Children. By J. Abercrombie, M.D., M.R.C.P. Lond. Price 2s.

China. Reports of the Medical Officers of the Chinese Imperial Maritime Customs Service, from 1871 to 1882, with the History of Medicine in China. Compiled by Surgeon-General Gordon, M.D., C.B., Physician to Her Majesty the Queen. Price 21s.

Cholera: How to Prevent and Resist it. By Professor von PetrenKofer and T. Whiteside Hime, A.B., M.B. Sccond edition. Illustrated. Price 3s. $6 \mathrm{~d}$.

Cholera. The Cholera Microbe and How to Meet It. Read at the Congress of the British Medical Association. By Chartes Camerenon, M.D., LL.D., M.P. Price $1 \mathrm{~s}$. 
Climatology. Ventnor and the Undercliff. By J. M. Williamson, M.D., M.B. Ed., Hon. Surgeon to the National Hospital for Consumption. Second edition, price 1 s.

Climatology. The Demography of South Australia. By THos. BoRTHWICK, M.D. Ed., Medical Officer of Health for South Australian District. With three plates. Price 2s. 6d.

Climatology. The Book of Climates in all Lands. A Handbook for Travellers, Invalids, and others in search of Health and Recreation. By D. H. Cullimore, M.D., M.R.C.P. Lond., Surgeon in H.M. Indian Army (retired). With a chapter on the Climate of Africa as it affects Europeans by Surgeon PARKE, D.C.L. Second edition, price 4s. 6 d.

"A very useful book."-The Graphic.

"There is much which entitles it to a large circulation."-Westminster Review.

"A work of supreme interest to the traveller in search of health."-Freman's Journal.

Clinical Chart. Children's Clinical Chart designed by. Duncan J. CADDY. M.B. Price 1 d. each; 9d. per dozen, net.

Coca. The Coca of Peru, its Remedial Principles, and Healing Powers. By J. L. W. Thudichum, M.D., F.R.C.P. Price 1s.

Colours. A Hand-book for Painters and Art Students, on the use of Colours, Vehicles, etc. By W. J. Muckley. Price 3s. 6d.

Consumption. Consumption as a Contagious Disease; the Merits of the Air of Mountains and Plains. By D. H. Cullimore, M.D., M.R.C.P. Lond., formerly H.M. Indian Army. Price 5s.

Consumption. Consumption and its Treatment by the Hypophosphites. By JoHn C. Thorowgood, M.D., F.R.C.P. Lond., Physician to the City of London Hospital for Diseases of the Chest, Victoria Park. Third edition, price 2s. $6 \mathrm{~d}$.

Consumption. A Re-investigation of its Causes. By C. W. DE Lacy Evans, M.R.C.S. Eng. Price 2s. 6d.

Consumption. How to Prevent and Treat Consumption. By G. Rutland Howat, B.A. Lond. Price 2s. 6d.

Consumption. An Essay on Consumption: Its True Nature and Successful Treatment. By GoDwin W. Timms, M.D. Lond. Second edition, revised and enlarged, price 10s. 6d.

Consumption. Tuberculosis from a Sanitary and Pathological Point of View. By G. Fleming, C.B., F.R.C.V.S., President of the Royal College of Veterinary Surgeons. Price 1s.

Consumption. The Pathology of Tuberenlosis (Pulmonary Tuberculosis and Tubercular Phthisis). Past Graduate Lectures delivered at Queen's Hospital, Birmingham, 1891. By Geo. F. Crooke, M.D., Physician and Pathologist to Queen's Hospital, and Lecturer on Pathology in Queen's College. Price 2s. 6d 


\section{Baillière, Tindall, and Cox's Books.}

Deafness. (See Ear.)

Deaf-mutism. On the Education of Deaf-mutes by Lip-Reading and Articulation. By Professor Hartmann. Translated by Dr. Patterson Cassells. Price 7s. 6d.

"The instruction of deaf-mutes is here rendered easy."-Athenaum.

"We can honestly recommend it to anyone seeking for knowledge." - The Lancet.

Deformities. The Nature and Treatment of Deformities of the Human Body. By Lambert H. Ormsiy, M.B. Dub., Surgeon to the Meath Hospital and Dublin Infirmary. Price 5s.

Deformities. Three Lectures on the Growth Rates of the Body, and Especially of the Limbs, in their Relation to the Processes of Rectification of Deformity. By Walter Pye, F.R.C.S. Eng. Price 1 s.

Dental Surgery. A Manual of Dental Surgery: Including Special Anatomy and Pathology. For Students and Practitioners. By Henry SewiLl, M.R.C.S., L.D.S. Eng. Third edition, with upwards of 200 illustrations, chiefly original. Price 10s. $6 \mathrm{~d}$.

Dental. Dental Caries and the Prevention of Dental Caries. By Henry Sewill, M.R.C.S., L.D.S. Second edition. Price 2s. 6 d.

Dental. Aids to Dental Surgery. By ARTHUR S. UNDERwood. M.R.C.S., L.D.S. Eng. Price 2s. 6d. cloth ; 2s. paper.

Dental. Aids to Dental Histology. By the same Author. Illustrated. Price 2s. 6d. cloth; 2s. paper wrapper. 1892.

Dental. Journal of the British Dental Association. Monthly, price 6d.

Dental. Manual for the Dental Laboratory. A Practical Guide to its Management, Economy, and Methods of Manipulation. By Charles Hunter, Author of "A Treatise on Mechanical Dentistry." Price 5s.

\section{Dermatology. (See Skin.)}

Dermoids. A Course of Lectures delivered at the Royal College of Surgeons, 1889, on "Evolution in Pathology." By J. BLAND SutTon, F.R.C.S., Hunterian Professor. Illustrated. Price 3s.

"We commend the study of this book to all interested in the elucidation of pathological problems." - The Lancet.

Diagnosis. The Physiological Factor in Diagnosis. By J. Milner Fothergill, M.D., M.R.C.P. Lond. Seconded. Price 7s. 6d.

"An exceedingly clever and well-written book, put together in a very plain, practical, and taking way."-Edinburgh Medical Journal. 
Diagnosis, Aids to. Three Parts. Price 1s. and 1s. 6d. each.

Part I.-Semeiological. By J. Milner Fothergill, M.D.

Part II.-Physical. By J. C. Thorowgood, M.D., F.R.C.P. Part III.-What to Ask the Patient. By J. Milner Fothergill, M.D.

The three parts in 1 vol. Edited by Dr. Thorowgoon. Price 3s. 6d. cloth.

"A mine of valuable information."-Edinburgh Medical Journal.

Diphtheria. Diphtheria, its Causes, Pathology, Diagnosis, and Treatment. By R. Hunter Semple, M.D., F.R.C.P. Lond. Second edition. Price 2s. $6 \mathrm{~d}$.

Diseases. The Classification and Nomenclature of Diseases. By A. Rabagliati, M.A., M.D., Senior Surgeon Bradford Infirmary, Surgeon to the Children's Hospital. Price 2s. 6d.

Domestic Medicine. Handbook of Popular Medicine for family instruction, colonists and others out of reach of medical aid. By G. H. Napheys, A.M., M.D. With movable plate and 100 illustrations. Price 7s. 6 d.

Diet. How to Prolong Life. Showing the Diet and Agents best adapted for a lengthened prolongation of existence. By C. W. De Lacy Evans, M.R.C.S. Second edition. Price 5s.

(See also Food.)

Ear. Diseases of the Ear. By George P. Fueld, M.R.C.S., Aural Surgeon to St. Mary's Hospital, and Lecturer on Aural Surgery. Fourth edition, enlarged, rewritten and brought up to date, with 22 coloured plates and numerous woodcuts. Price 12s. 6 d.

Ear. The Pathology and Treatment of Suppurative Diseases of the Ear. By the same author. Price 2s. 6d.

Ear. On Unrecognised Lesions of the Labyrinth. The Cavendish Lecture, 1890. By Alex Ogston, M.D., C.M., Regius Professor of Surgery, University of Aberdeen. Illustrated. Price 1s.

Ear. On Vascular Deafness. By RoBert J. Cooper, M.D., Trinity College, Dublin. Price 3s. 6d.

Ear. Otorrhoea; or, Discharge from the Ears: Causes and Treatment. By W. Douglas Hemming, F.R.C.S. Ed. Price 1s.

Ear. Subjective Noises in the Head and Ears. Their Etiology, Diagnosis and Treatment. By H. MaCnaughton Jones, M.D., F.R.C.S. I. and E., Fellow of the Medical, Obstetrical, Gynæcological and Ophthalmological Societies of London. Profusely illustrated, price $4 \mathrm{~s}$. $6 \mathrm{~d}$. 


\section{Baillière, Tindall, and Cox's Books.}

Ear. The Hygiene of the Ear. By Cavaliere Vincenzo CozzoLINO, Professor in the Royal University of Naples, and Director of the Hospital Clinic for Diseases of the Ear, Nose, and Throat. Translated from the fifth Italian edition by James Erskine, M.A., M.B. Price 1s.

Ear. Practitioner's Hand Book of Diseases of the Ear and NasoPharynx. By Dr. H. Macnaughton Jones and Mr. W.E. H. STEWART, F.R.C.S.E. Fourth edition, with plates and numerous woodcuts. Price 10s. $6 \mathrm{~d}$.

Ear. Text-book of Diseases of the Ear and Adjacent Organs. By Professor Politzer, of Vienna. Translated from the third German edition by Sir WM. Dalby, B.A., M.B., F.R.C.S.

In the Press.

Ear. The Anatomical and Histological Dissection of the Human Ear, in its Normal and Diseased Conditions. By Professor Politzer of Vienna. Translated at the author's request by George Stone, F.R.C.P. Ed. Profusely illustrated. 10s. 6d.

Electricity. A Manual of Practical Medical Electricity. By Dawson Turner, B.A., M.D., F.R.C.P. Ed., M.R.C.P. Lond. Profusely Illustrated. Price 7s. 6d.

"Valuable alike to students and practitioners."-Practitioner.

"We cordially recommend this text-book, both to the student and the practitioner, as a thoroughly reliable and practical manual of the subject which it professes to teach."-Medical Press and Circular.

"Dr. Turner gives us an admirable and complete exposition of electricity, as applied to the practice of medicine and surgery, which is well up to date, and conveyed in a clear and lucid manner, such as will readily attract the attention of practitioners and sturents, for whom the book is intended."-Medical Reprints.

Electricity. Electricity in General Practice. By W. Bolton Tomson, M.D. Price 2s. 6d.

Etiquette. A few Rules of Medical Etiquette. By a L.R.C.P. Lond. Price $1 \mathrm{~s}$.

Examinations. Aids to Examinations. By D. WALsh, M.B., C.M, L.R.C.P. Being Questions and Answers on Materia Medica, Medicine, Midwifery, Pathology, and Forensic Medicine. Price 2s. 6 d. cloth; 2s. paper wrapper.

Examinations. A Guide to the Examinations of the conjoint Board in England and for the Fellowship of the College of Surgeons, with Examination Papers. By F. J. Gant, F.R.C.S. Sixth edition, revised and enlarged. Price 5s. net.

Examinations. A Guide to the Examinations of the Apothecaries' Society of London with Questions, Tables on Materia Medica, etc. By W. E. Dawson, L.S.A. Second edition. Price 2s. 6d.

"May be studied with great advantage by a student, shortly before presenting himself for examination."-British Medical Journal. 
Examinations. Examination Questions on the Medical Sciences, including the Army, Navy and University Examinations. Selected and arranged by James Greig Leask, M.B. Abdn. Second edition. Price 2s. 6d.

"Dr. Leask's questions are particularly suitable for pure examination study. Students should test themselves thereby."-British Medical Journal.

Examinations. Practical Pharmacy for Medical Students; specially adapted for the Examination in Practical Pharmacy of the Conjoint Board. By A. CAMPBell Stark, Demonstrator on Materia Medica and Pharmacy at St. George's Hospital. Price $3 \mathrm{~s} .6 \mathrm{~d}$., or interleaved for note-taking, $4 \mathrm{~s}$. $6 \mathrm{~d}$.

Examination Cards : Questions and Answers. By A. T. SсHоFIELD, M.D. Pathology, 2 sets, 9d. each, net. Minor Surgery, Bandaging, etc., $9 \mathrm{~d}$., net.

Eye. Aids to Ophthalmic Medicine and Surgery. By J. Hutchinson, jun., F.R.C.S., Ophthalmic Surgeon to the Great Northern Hospital. Cloth, 2s. 6d.; paper, 2s.

Eye. Ophthalmic Notes. A Pocket Guide to the Nature and Treatment of Common Affections of the Eye. By A. Vernon Ford, M.R.C.S. Eng., L.K.Q.C.P. Ire. Price 2s. 6 d.

Eye. The Detection of Colour Blindness, from a practical point of view. By F. W. EDridge-Green, M.D., F.G.S., Author of "Memory," etc., etc. Price 1s.

Eye. The Cure of Cataract and other Eye Affections. By JABEZ HuGG, M.R.C.S., Consulting Surgeon to the Royal Westminster Ophthalmic Hospital. Third edition. Price 2s. 6d.

Eye. On Impairment or Loss of Vision from Spinal Concussion or Shock. By the same Author. Price 1s. 6d.

Eye. The Functions of Vision and its Anomalies. By Dr. Giraud Teulon. Translated by Lloyd Owen, F.R.C.S.I., Surgeon to the Midland Eye Hospital, Ophthalmic Surgeon to the Hospital for Sick Children, Birmingham. Price 5s.

Eye. Movable Atlas of the Eye and the Mechanism of Vision. By Prof. G. J. Witkowski. Price 7s. 6d. (See Anatomy.)

(The following four works have been translated for the National Society for the Prevention and Cure of Blindness.)

Mind your Eyes. By F. SARCEY. Price 2s. 6 d.

The Causes and Prevention of Blindness. By Professor Fuchs, University of Liége. Price 7s. 6d.

How to Preserve the Sight. By Dr. Magné. Price 6d.

On Spectacles, their History and Uses. By Prof. HorNer. Price 6d.

Fasting and Feeding, Psychologically considered. By L. S. Forbes Winslow, M.B. Cantab., D.C.L. Oxon. Price 2s. 


\section{Baillière, Tindall, and Cox's Books.}

Fever. On the Endemic Hæmaturia of Hot Climates, caused by the presence of Bilharzia Hæmaturia. By F. H. H. GuILlemard, M.A., M.D., F.R.G.S. Price 2s.

Fever. Text-Book of the Eruptive and Continued Fevers. By JoHN William Moore, B.A., M.D., M. Ch. Univ. Dub., F.R.C.P.I., Joint Professor of Practice of Medicine in the Schools of Surgery of the Royal College of Surgeons in Ireland, Physician to the Meath Hospital, Dublin, Consulting Physician to Cork Street Fever Hospital, Dublin, ex-Scholar and Diplomate in State Medicine of Trinity College, Dublin. Price 15s.

Fever Charts. Daily Clinical Fever Charts, to record the progress of a case of fever. By F. Magee Finny, M.D. Price 5s.

Food. Aids to the Analysis of Food and Drugs. By H. AUBReY Husband, M.B., F.R.C.S., Lecturer on Public Health in the Edinburgh Medical School. Price 1s. 6d. cloth; 1s. paper.

Food. The Healthy Manufacture of Bread. By B. W. Richardson, M.D., F.R.S. Price 6d. paper cover; cloth, 1s., with Vignette.

Foot. Movable Atlas of the Foot; its Bones, Muscles, etc. By Prof. Witkowski. Price 7s. 6d. (See Anatomy.)

Forensic Medicine. The Maybrick Case. A Treatise by A. M. Macdougall, B.A., LL.D. Price 10s. $6 \mathrm{~d}$.

Forensic Medicine. The Student's Handbook of Forensic Medicine and Public Health. By H. Aubrey Husband, M.B., F.R.C.S.E. Sixth edition. Price 10s. 6d.

Forensic Medicine. Aids to Forensic Medicine and Toxicology. By W. Douglas Hemming, F.R.C.S.E., and H. AubreY Husband, M.B., F.R.C.S.E. Fifth thousand. Price 2s. 6d. cloth, 2s. paper.

Geology. Field Geology, with a Section on Palæontology. By W. Hy. Penning, F.G.S., of H.M. Geological Survey, and A. J. JUkes-Browne, B.A., F.G.S. With woodcuts and coloured map. Second edition, revised and enlarged. Price $7 \mathrm{~s} .6 \mathrm{~d}$.

"Others have taught us the principles of the science, but Mr. Penning, as an accomplished field-geologist, introduces us to the practice."-The Academy.

Geology. Engineering Geology. By the same Author. Illustrated with coloured maps and woodcuts. Price 3s. 6 d.

"A full and lucid description of surveying and mapping, the diagnosing of the various minerals met with, the value of sites, rocks, etc."-Popular Science Reviev.

Geometry. Aids to Analytical Geometry. I. The Straight Line and Circle. By A. Le Sueur, B.A. Cantab. Second edition, 2s.

II. The Conic Sections, with solutions of questions set at the London University and other Examinations by GEORGE Heppel, M.A. Cantab. Price 2s. 
Gout. A Treatise on Gout. By Austin MeLdon, M.K.Q.C.P., F.R.C.S.I., Senior Surgeon Jervis Street Hospital, Consulting Physician Dublin General Infirmary. Tenth edition. Price 2s.6d.

Gout. The Nature and Treatment of Gout. By Professor EBstein of Gottingen University. Translated by J. E. BuRTON, L.R.C.P. Lond. Price 3s. $6 \mathrm{~d}$.

Gymnastics. The Prevention and Cure of Many Chronic Diseases by Movements. By M. Roth, M.D., F.R.C.S. Eng. With 90 engravings, price $5 \mathrm{~s}$.

Paralysis in Infancy, Childhood, and Youth, and on the Prevention and Treatment of Paralytic Deformities. Same Author. 3s. 6d.

The Prevention and Rational Treatment of Lateral Spine Curvature. (Gold Medal of the International Health Exhibition, 1884.) 200 engravings. Price 5s.

Gynæcology. Brandt's Treatment of Uterine Disease and Prolapsus by the Movement Cure. Edited and translated by Dr. Roth. $5 \mathrm{~s}$.

Gynæcology. The Diseases of Women and their Treatment. By H. Macnaughton Jones, M.D., F.R.C.S.I., F.R.C.S.E., Examiner in Midwifery, Royal College of Surgeons, Ireland. Fifth edition. Illustrated, price 10s. $6 \mathrm{~d}$.

"A storehouse of information."-The Lancet.

"The work of a mature and experienced authority."-British Medical Joumual.

"Of exceptional merit drawn from a field of wide personal experience."-Medical Press.

Gynæcology. Aids to Gynæcology. By AlFred S. GubB, M.D. Paris, M.R.C.S., L.R.C.P., D.P.H., Obstetric Assistant and Gold Medallist Westminster Hospital. Second edition, enlarged. Cloth, 2s. 6d., and 2s. sewn.

Hair. The Hair : its Growth, Care, Diseases, and Treatment. By C. H. Leonari, A.M., M.D. Illustrated, price 7s. $6 \mathrm{~d}$.

Hair. A Synopsis of Diseases of the Skin and Hair. By R. GLASGowPatteson, M.B., Surgeon to St. Vincent's Hospital. Price 1s.

Hand. Movable Atlas of the Hand; its Bones, Muscles and Attachments. By Prof. Witkowski. Price 7s. 6d. (See Anatomy.)

Hay Fever: its Causes, Treatment, and Effective Prevention; Experimental Researches. By Chas. HaRrison BLACKLEY, M.D. Second edition, revised and enlarged. Price 10s. 6d.

Heart. On Insufficiency of Aortic Valves in connection with Sudden Death. By JoHn Cockle, A.M., M.D., F.R.C.P., Physician to the Royal Free Hospital. Second edition. Price 2s. 6d.

Heart. Contributions to Cardiac Pathology. By the same Author. Price 2s. 6d. 


\section{Baillière, Tindall, and Cox's Books.}

Heart. Heart-Studies, Chiefly Clinical. By Wm. Ewart, M.D.

Cantab., F.R.C.P., Physician to St. George's Hospital.

I.-The Pulse under the Sphygmograph and under the Finger.

In the Press.

Heart. An Essay on Fatty Heart. By Henry Kennedy, A.B., M.B. Physician to the Whitworth Hospitals. Price 3s. 6d.

Heredity and Disease. From Generation to Generation. By Douglas LiThGow, LL.D., M.R.C.P. Lond. Price 4s. 6d.

Hernia and Intestinal Obstruction. By J. Roche, M.D. $6 \mathrm{~d}$.

Histology. Manual for the Physiological Laboratory. By Vincent

D. Harris, M.D., F.R.C.P., Examiner in Physiology, the Royal College of Physicians of London, and D'Arcy POWER, M.B. Oxon., Examiner, St. Bartholomew's Hospital. Fifth edition. Price 7s. 6d.

"This manual is already well and favourably known, and the new edition contains many valuable additions."-Lancet.

Histology. Introduction to Practical Histology. By George ThIN, M.D. Price 5s.

Histology. Methods of Preparing Brain, Spinal Cord, and Nerves for Microscopical Examination. By EDwIN GoodALI, M.D. Lond.

History of the Royal College of Surgeons in Ireland. By Sir C. A. Cameron. Price 10s. 6d.

Hydrophobia. Inoculation for Rabies and Hydrophobia. A Study of the Literature of the subject. By Surgeon-General C. A. GoRDon, C.B. Price 2s. 6d.

Hydrophobia. Comments on the Reports of the Committee on M. Pasteur's Treatment. By Surgeon-General C. A. GoRDon, M.D., C.B. Price 2s. $6 \mathrm{~d}$.

Hydropathy, or the Practical Use of Cold Water. By E. MarLetT BoDDY, F.R.C.S., F.S.S., L.R.C.P. Price 1s.

Hydropathy. Notes of Visits to Contrexéville and Royat-lesBains. By F. R. Cruise, M.D. Price 6d.

Hydropathy. Vichy and its Therapeutical Resources. By Prosser JAMES, M.D., M.R.C.P. Lond., Lecturer on Materia Medica and Therapeutics at the London Hospital. Price 2s. 6d.

Hygiene. Lessons in Military Hygiene and Surgery, from the Franco-Prussian War. Prepared on behalf of Her 'Majesty's Government. By Surgeon-General Gordon, M.D., C.B., Hon. Physician to the Queen. Illustrated, price 10s. 6d.

Hygiene. A Manual of Sanitation; or, First Help in Sickness and when Wounded. Alphabetically arranged. By the same Author.

Cloth, 2s. 6d.; sewn, 1s.

"A most useful and practical manual, and should be placed in the hands of officers und men alike."-The Graphic. 


\section{Baillière, Tindall, and Cox's Books.}

Hygiene. The Elements of School Hygiene for the Use of Teachers and Schools. By W. E. Roth, B.A. Price 3s. 6d.

Hygiene. Theatre Hygiene, a study in construction, safety and healthy arrangement. By W. E. Roth, B.A. Oxon. Price 1s. 6d.

Hygiene. Healthy Homes. By Stanley Haynes, M.D., M.R.C.S., F.R.G.S. Price 1s.

Hygiene. Notes on Nuisances, Drains, and Dwellings. By W. H. Penning, F.G.S. Second Edition. Price 6d.

Hygiene. Short Lectures on Sanitary Subjects. By RICHARD J. HaLton, L.K.Q.C.P., L.R.C.P. Ed., L.R.C.S.I., etc. Price 5s.

Hygiene. A Manual of Naval Hygiene, with Instructions and Hints on the Preservation of Health and the Prevention of Disease on board Ship. By JosePh WiLson, M.D. Second edition. 10s. 6d.

Hygiene. The Sanitation of Public Institutions. The Howard Prize Essay. By R. D. R. SweEting, M.R.C.S., Medical Superintendent of the Western Fever Hospital. Price 3s. 6d.

Hygiene of Beauty. By Dr. Monin. Translated by B. CARDWfLL. Price 3s. 6d.

Hypnotism. Psycho-Therapeutics. Treatment by Hypnotism and Suggestion. By J. LLOYD TuckeY, M.D. Third Edition, enlarged. Price 6s.

Indigestion : a Manual of the Diagnosis and Modern Treatment of the Different Varieties of Dyspepsia. By George Herschell, M.D. Lond. Second edition. Price 3s. 6d.

Inflammation. The State of the Blood and the Bloodvessels in Inflammation. By T. WHARTON JONES, F.R.C.S., F.R.S., Emeritus Professor of Ophthalmic Medicine and Surgery in University College, London. Price 2s. 6d.

"The work is that of a man of genius of the highest order."-Dr. RICHardson, F.R.S., in Asclepiad.

"A thoughtful study founded on the ripe experience of an author entitled to the highest respect."-Medical Press.

International Medical Congress. The Commemorative PortraitPicture of the International Medical Congress, 1881. Designed and executed by Mr. BARRAUD ; nearly 700 Likenesses of Members, representing Medicine and Surgery in every part of the world ; special sittings accorded for every Portrait.

The Picture is Printed by the New Permanent Carbon Process in two Sizes: EXTRA SIZE, $47 \times 30$, Mounted, BUt Unframed $£ 7$ 108. Framed - $£ 10$ 08. POPULAR SIZE, $29 \times 20$, MOUNTED, BUT UNFRAMED £3 3s. Framed - £4 10s. 
Insanity. (See Lunacy.)

\section{Intestinal Surgery. (See Abdominal Surgery.)}

Kidneys. Vaso-Renal Change versus Bright's Disease. By J. Milner Fothergill, M.D. Ed. Price 7s. 6d.

Kidneys. Bright's Disease of the Kidneys. By Professor J. M. Charcot. Translated by H. B. Millard, M.D., A.M. Revised by the Author, with coloured plates, price 7s. $6 \mathrm{~d}$.

Lunacy. Handbook for the Instruction of Attendants on the Insane. Prepared under the authority of the Medico-Psychological Association. With illustrations and question for examinations. Second edition.

[In the Press.

Materia Medica. A Dictionary of Materia Medica and Therapeutics. A Résumé of the Action and Doses of all Officinal and Non-officinal Drugs now in Common Use. By C. HeNri LeONARd, A.M., M.D., and Thos. Christy, F.L.S., F.C.S. Price 6s.

This volume has been in preparation for the past four years. The drugs of as late introduction as 1891 are to be found in its pages. The authors claim to have incorporated everything of merit, whether officinal or non-officinal, that could be found either in standard works or from many manufacturers catalogues. The scheme embraces the Pronunciation, Genitive case-ending, Common Name, Dose, and Metric Dose. Then the Synonyms, English, French, and German. If a Plant the Part Used, Habitat, Natural Order, and Description of Plant and Flowers, with its Alkaloids, if any. If a Mineral, its Chemical Symbol, Atoraic Weight, looks, taste, and how found, and its peculiarities. Then the Action and Uses of the Drug, its Antagonists, Incompatibles, Synergists and Antidotes. Then follow its Officinal and Nonofficinal preparations, with their Medium and Maximum Doses. Altogether it will be found a handy volume for either the Phssician, Student, or Druggist, and will be frequently appealed to if in one's possession.

"Will, we are sure, fulfil a long-felt want."-British und Colonial Druggist.

"Well up to date. . . . Contains an index of great value."-Chemist and Druggist.

Materia Medica. Table of Doses. By J. H. Allan, F.C.S. Price 6d., cloth.

Materia Medica. A Key to Organic Matcria Medica. By JoHN Muter, Ph.I., M.A., F.C.S., President of the Society of Public Analysts. Third edition. Price 1.2s. 6d.

Materia Medica. Aids to Materia Medica and Therapeutics. By C. E. Armand Semple.

Part I.-The Non-metallic and Metallic Elements, Alcoholic and Ethereal Preparations, etc. Cloth, 2s. 6d.; paper, 2s.

Part II.-The Vegetable and Animal Substances. 2s. 6d., 2s.

Part III.-Classification of Remedies. Cloth, 1s. 6d.; paper, $1 \mathrm{s.}$ Part IV.-New Remedies of the British Pharmacopœia. Cloth, 2s. 6 d. ; paper, $2 \mathrm{~s}$.

Part V.-Tablets of Materia Medica. Price, cloth, 1s. 6d.; paper, 1s. 
Materia Medica and Pharmacy. A Text-Book for Medical and Pharmàceutical Students preparing for Examination. By W. Handsel Griffiths, Ph.D., F.C.S., F.R.C.P. Ed. Third edition. Edited by A. S. GubB, M.D. Paris, L.R.C.P. Lond., M.R.C.S., D.P.H., Gold Medallist, Prizeman in Materia Medica, Westminster Hospital. Price 7s. 6d.

"A book of great value ... a standard text-book."-Edin. Med. Journal.

"One of the ablest, if not the best, work on the subject in our language."-Med. Press.

Materia Medica. Notes on Inorganic Materia Medica, and its Chemistry, By J. S. Sharman. Second edition. Price 1s. 6d.

Materia Medica. Notes on Materia Medica and Therapeutics. Mineral Drugs, Part I. By J. S. McArdeE. Price 1s.

Medical Charities. The Reform of Our Voluntary Medical Charities. By Robert Reid Rentoul, M.D. Price 5s.

Medical Education. Medical Education and Organization. The Hunterian Oration for 1880. By Walter Rivington, B.A., M.B., F.R.C.S., Surgeon to the London Hospital. Price 1s.

Medical Etiquette. A Few Rules of Medical Etiquette. By a L.R.C.P. Lond. Price 1s.

Medical Jurisprudence. (See Forensic Medicine.)

Medical Laws. Medical Law for Medical Men: their Legal Relations popularly explained. By Professor Meimotr TIDY, M.B., F.C.S., Barrister-at-Law, and Percy Clarke, LLL.B., Solicitor. Leather, gilt edges, price 4s.

Medical Laws. The Laws Relating to Medical Men. By James Greenwood, Barrister-at-Law. Price 5s.

"Admirably suited as a guide to the busy practitioner, who frequently runs great risks of becoming involved in legal penalties, in consequence of an imperfect knowledge of the law." - Glasgino Medical Journal.

Medical Profession. A Guide to the Medical Profession in all its branches, including the Public Services. By C. R. B. KEETLEY, F.R.C.S. Second edition, revised and enlarged. Price 3s. 6 d.

Medical Profession. Medical Men anl Manners of the Nineteenth

Century. By a Physician. Third Thousand. Price 3s.

"At times scathing, at others amusing, the author is never dull, and writes as one who knows the many blots on our system, and hunestly tries to remedy them."-Medical Press.

Medicine. Aids to Medicine. By C. E. Armand Semple, B.A., M.B. Cantab., M.R.C.P. Lond.

Part I.-General Diseases. Price 2s. 6d. and 2s.

Part II.-The Urine, Kilneys, Stomach, Peritoneum, Throat, and Esiophagus. Third Thousand. Price 2s. 6d. and 2s.

Part III.-Diseases of the Brain, Nervous System, and Spinal Cord. Third Thousand. Price 2s. 6d. and 2s.

Part IV.-Fevers, Skin Diseases. Price 2s. 6d. and 2s. 


\section{Baillière, Tindall, and Cox's Books.}

Medicine. A Chronology of Medicine from the Earliest Times. By J. Morgan Richards. Price 10s. $6 \mathrm{~d}$.

Medicine. Student's Handbook of the Practice of Medicine. By H. Aurrey Husband, M.B., C.M., B.Sc. Fourth edition, revised and enlarged. - Illustrated. Price 7s. 6d.

Medicinal Remedies. Notes on Medicinal Remedies. By J. B. Srephenson. Price 1s. 6 d.

Medico-Military Services. Our Services under the Crown. A Historical Sketch of the Army Medical Staff. By Surgeon-Major A. Gore, M.D., Sanitary Officer on the Staff. Price 6s.

Memory. Its Logical Relations and Cultivation. By F. W. EDRIDGE-Green, M.D., F.G.S., Author of "Colour Blindness." Second edition. Price 6s.

Meteorology. The Moon and the Weather: the Probability of Lunar Influence Reconsidered. Showing how storms and depressions may be predicted. By Walter J. Browne (St. Petersburg). Second edition. Price 3s.

Microscopical Science. The International Journal of Microscopy and Natural Science. Edited for the Postal Microscopical Society by Alfred Allen. Quarterly, with Plates. Price 2s. 6d.

Microscopical Science. Modern Microscopy. A Handbook for Beginners, in two parts. I. The Microscope, and Instructions for iss Use. II. Microscopic Objects: How Prepared and Mounted. By M. I. Cross and Martin J. Cole. Price 2s. 6d. Midwifery. (See Obstetrics.)

Mineral Waters. The Mineral Waters of Europe. A complete Analytical Guide to all the Bottled Waters, and their Medicinal and Therapeutic Values. By Professor TichBorne, LL.D., and M. Prosser James, M.R.C.P. Lond. Price 3s. 6d.

"Such a book as this is simply invaluable."-The World.

Morals. A Physician's Sermon to Young Men. By William Pratt, M.A., M.D., etc. Eighth thousand. Price 1s. cloth.

"The delicate topic is handled wisely, judiciously, and religiously, as well as very plainly." -The Guardian.

Morals. Revelations of Quacks and Quackery. With Facts and Cases in Illustration of their Nefarious Practices. By "DETECTOR." Thirtieth thousand. Price 2s.

Morphia. On the cure of the Morphia Habit. By OSCAR Jennings, M.D. Paris, F.R.C.S. Eng. Price 2s. 6 d.

Nerve Supply. Atlas of Cutaneous Nerve Supply. By JACOB HeiberG, M.D., and W. W. WAGSTAFFe, F.R.C.S. Containing 10 plates in colours. Price 4s. 6 d. 


\section{Baillière, Tindall, and Cox's Books.}

Nervous Diseases. Functional Nervous Diseases, their Causes and Treatment. By Geo. T. Stevens, M.D., Ph.D. With plates. Price 12s.

Nervous Diseases. Clinical Notes on Nerve Disorders in Surgical Practice. By Geo. Wherry, M.A., M.S. Cantab., F.R.C.S. Price 2s.

Nervous Diseases. (See also Brain.)

Neuralgia. The Surgical Treatment of Neuralgia of the Fifth Nerve; being the Lettsomian Lectures for 1892. By WM. Rose, M.B., B.S. Lond., F.R.C.S., Joint Professor of Surgery in King's College, London, and Surgeon to King's College Hospital. Illustrated. Price 4s. 6d.

Nose. (See Throat and Nose.)

Nursing. Questions and Answers on Nursing, for St. John's Ambulance Associations, Nursing Institutes, and Nurses generally. By John W. Martin, M.D., Author of "Ambulance Work." Fourth thousand. Price 1s. 6d. net.

Nursing. How to Feed an Infant. With an Appendix on theCommon Ailments of Infancy, with their Hygienic and Curative Treatment. By Benson Baker, M.D. Price 1s. 6d.

Nursing. How to bring up Children by Hand. By J. Foster PaLMer, L.R.C.P. Price 6d.

Nursing. Practical Guide for the Young Mother. From the French of Dr. BRochaRD, Director-General of Nurseries and Crêches, with Notes and Hints by a London Physician. Price 2s.

Obstetrics. Aids to Obstetrics. By Samukl Nall, M.B. Cantab., M.R.C.P. Lond., First Class Honours Nat. Sci. Cambridge, late Resident Obstetric Assistant, St. Bartholomew's Hospital. Twelfth thousand. Price 2s. 6 d. cloth, 2s. paper wrapper.

Obstetrics. Hints for Midwives on Pregnancy and Labour. Abstracts of a Series of Lectures by H. MacNaUGHTON Jones, M.D., M.C.H., F.R.C.S. Price 1s. net.

Obstetrics. The Diagnosis and Treatment of Extra-uterine Pregnancy. By JoHn Strahan, M.D., M.Ch. (The Jenks Triennial Prize Essay awarded by the College of Physicians, 1889.) Price 4s. $6 \mathrm{~d}$.

Obstetrics. Hints for the Use of Midwives preparatory to their Examinations. By R. J. M. CoFrin, F.R.C.P. Ed. Second Edition, enlarged. Price 2s.

Odontology. (See Dental.) 


\section{Baillière, Tindall, and Cox's Books.}

Old Age. The Diseases of Sedentary and Advanced Life. By J. Milner Fothergill, M.D., M.R.C.P. Lond. Price 7s. 6d.

Ophthalmology. (See Eye.)

Osteology. Osteology for Students, with Atlas of Plates. By ARTHUR Trehern NorTon, F.R.C.S., Surgeon to, and Lecturer on Surgery at, St. Mary's Hospital. Atlas and Text in one volume, $7 \mathrm{~s} .6 \mathrm{~d}$. ; in two volumes, $8 \mathrm{~s} .6 \mathrm{~d}$.

"The handiest and most complete handbook on Osteology." - The Lancet.

Osteology. Atlas of the Skeleton and its Articulations, showing the Bones and Ligaments of the Human Body and Limbs. By Professor Witkowski. Price 7s. 6d. (See Anatomy.)

Overwork. Overwork and Premature Mental Decay : its Treatment. By C. H. F. Routh, M.D., M.R.C.P. Lond. Fourth edition. Price 2s. 6d.

Pathology. Lectures on Medical Pathology. By H. G. Sutron, M.B., F.R.C.P. Lond., late Physician to, and Lecturer on Pathology at, the London Hospital. Price 5s.

"Such a work is to be accepted with gratitude for the thoughts it contains, and the facts on which they are based."-The Lancet.

Pathology. Aids to Pathology. By Gilbert A. Bannatyne, M.D. General : Cloth, 1s. 6d. ; sewn, 1s. Special : Cloth, 2s. 6d. ; sewn, 2 s.

Pathology. A series of illustrations of Pathological Anatomy issued in monthly parts. Each part contains 4 plates in colours, with accompanying descriptive text by ProfESSORS KAST, of Breslau, and RumpeL, of Hamburg. The English edition revised and edited by M. Armand Ruffer, M.D. Oxon. Twelve parts by subscription, post free, £2 8s. Single parts, 6s. each. Single plates, 1s 6d. each.

\section{Pathology of Tuberculosis. (See Consumption.)}

Pathology. Handbook of Surgical Pathology. Edited by W. J. WalshaM, M.B., F.R.C.S., and D'Arcy Power, M.B. Oxon, F.R.C.S. Second edition. Price 9s.

"An embodiment of the most modern pathological teaching." - The Lancet.

Pathology. Examination Cards. Arranged as questions and answers for self-examination. By A. T. SCHOFIELD, M.D., M.R.C.S. Complete in two sets of cards, price 9d. net per set. Mr. Jonathan Hutchinson, F.R.C.S., writes : "It is an invaluable means of self-tuition."

Peritonitis. Localised Peritonitis: its Etiology, Diagnosis, and Treatment. By JoHn Wallace, M.D., Professor of Midwifery in the Victoria University. Illustrated. Price 1s. 


\section{Baillière, Tindall, and Cox's Books.}

Pharmacopœia. A Vest-Pocket Epitome of the British Pharmacopœia. By Russell Coombe, M.A., F.R.C.S. Cloth, price 1s.

Pharmacopœia. The Pocket Pharmacopœia. A Précis of the British Pharmacopoia, including the Therapeutical Action of the Drugs, their Natural Orders and Active Principles. By C. Armand Semple, M.D., M.R.C.P. Second edition, with the Appendix of 1890 . Price 3s. 6 d.

Pharmacopœia. Notes on the Pharmacopœial Preparations for Pharmaceutical Students. By HaNdSEL GRIFfiths ; revised by A. S. GuBB, M.D. Paris, L.R.C.P., M.R.C.S., D.P.H. Price 3s. 6d.

Pharmacy. Latin Grammar of Pharmacy, for the use of Students, with an Essay on Latin Prescriptions. By JOSEPH INCE, A.K.C.L., formerly Examiner and Member of Council, Pharmaceutical Society. Fifth edition. Price 5s.

Pharmacy. Aids to Pharmacy. By C. E. Armand Semple, M.B. Cantab., M.R.C.P. Lond. Cloth, price 2s. 6d. ; paper, 2s.

Pharmacy. Practical Pharmacy for Medical Students. By A. Campbell Stark. Demonstrator on Materia Medica and Pharmacy at St. George's Hospital. Price 3s. 6d., or interleaved for note-taking, $4 \mathrm{~s} .6 \mathrm{~d}$.

Phimosis. Its Causes, Symptoms, and Treatment; with a description of the ancient rite of circumcision. By L. H. ORMSBY, M.D., F.R.C.S.I., Lecturer on Clinical and Operative Surgery at, and Surgeon to, the Children's Hospital, Dublin. Price 1s.

Physics. A Manual of Physics. Being an Introduction to the Study of Physical Science designed for University Students. By W. PEDDIE, D.Sc., F.R.S.E., Lecturer on Physics in the

University of Edinburgh. (University Series of Manuals.) 7s. 6d.

" Altogether worthy of praise. . . - We have no hesitation in giving it high commendation. . . We wish it all success, feeling well satisfied that it meets a deciced want."Nature.

"Dr. Peddie's manual is deserving of the highest praise."-Lancet.

"Written with a precision of statement and clearness of exposition which does the writer infinite credit."-Dundee Advertiser.

"A very handy work of reference."-University Correspondent.

"The work must be pronounced inighly satisfactory, creditable to author and publishers, and calculated to be useful to the readers for whom it is intended."-Chemical News.

"The book deserves an extended circulation."- Science and Art.

Physiological Chemistry. Aids to Physiological Chemistry. By J. L. Thudichum, M.D., F.R.C.P. Lond., St. Thomas's Hospital. Cloth, price 2s. 6d. Sewn, 2s.

Physiological Factor in Diagnosis. By J. MILner FothergiLl, M.D., M.R.C.P. Lond., Physician to the City of London Hospital for Diseases of the Chest. Second edition. Price 7s. 6d. Physiology. A Manual of Physiology. By G. N. Stewart, M.A., D.Sc. University of Cambridge. (University Series of Manuals.) IIn the Fress. 


\section{Baillière, Tindall, and Cox's Books.}

Physiology. The Physiologist in the Household. By J. Mrlner Fothergill, M.D., M.R.C.P. Part I.-Adolescence. Price ls.

Physiology. Aids to Physiology. By B. Thompson Lowne, F.R.C.S, Arris and Gale Lecturer, and Examiner in Physiology, Royal College of Surgeons of England. Fourth thousand, illus-

trated. In two parts, $2 \mathrm{~s}$. each, or in one vol., cloth, $4 \mathrm{~s} .6 \mathrm{~d}$.

"As 'aids' and not substitutes, they will prove of real valus to students."-Medical Press.

"Cortainly one of the best of the now popular 'Aid Series." "- Students' Journal.

Plant Analysis. (See Chemistry.)

Polypus in the Nose and other Affections of the Nasal Cavity; their successful treatment. By J. L. W. Thudrchum, M.D., F.R.C.P. Lond. Seventh edition, enlarged. Price 2s. 6d.

Population. On the Evils, Moral and Physical, likely to follow, if practices, intended to act as checks to population, be not strongly discouraged and condemned. By C. H. F. Roytr, M.D., F.R.C.P. Second thousand. Price 1s.

Posology. Posological Tables : a Classified Chart, showing at a glance the Dose of every Officinal Substance and Preparation. By Handsel Griffiths, Ph.D., L.K.C.P. Fifth edition, revised by Peter W. Squire, F.L.S., F.C.S. Price 1s. ; or mounted on linen, rollers, and varnished, 3s. 6d.

Pregnancy. (See Obstetrics.)

Prescriptions. The Student's Pocket Prescriber. By H. AUbreY Husband, M.B., F.R.C.S.E. Price 1s. cloth.

Psychologisal Medicine in John Hunter's Time and the Progress it has made. By Fletcher Beach, M.B., F.R.C.P. Price 1 s.

\section{Psycho-Therapeutics. (See Hypnotism.)}

Public Health. Aids to Sanitary Science, for the Use of Candidates for Public Health Qualifications. By F. J. Allan, M.D., Dipl. Public Health, Camb., Assistant Professor of Hygiene, Coliege of State Medicine. $236 \mathrm{pp}$., price 4s. 6d. cloth.

"A really admirable synopsis of what it is most necessary for a candidate to know."Glasgmo Medical Journal.

"The inform ction contained is correct, well expressed and well arranged."-Public Health.

"The work his been well done. - . " Will be found a serviceable and reliable aid."Bdinburgh Mrdical Journal.

Public Health. The Practical Guide to the Public Health Acts and Correlated Acts for Officers of Health and Inspectors of Nuisances. By Thos. Whiteside Hime, B.A., M.B. Second edition, enlarged.

[n the Press.

Public Health. Aids to Public Health. By J. L. Thudichum, M.D., F.R.C.P. Lond. New edition. Price 1s. 6d. cloth ; 1 s. paper. 
Public Health. Guide to Sanitary Science Examinations. By Herbert Jones, D.P.H. Cantab. Price 2s. 6d.

Pulse. How to feel the Pulse and what to Feel in it. Practical Hints for Beginners. By William Ewart, M.D., F.R.C.P. Lond., Physician to St. George's Hospital. With a glossary and twelve illustrations. Price 3s. $6 \mathrm{~d}$.

Pulse. The Sphygmograph: its History and use as an aid to Diagnosis. By R. E. Dudgeon, M.D. Price 2s. 6d.

Rabies. (See Hydrophobia.)

Respiration. Keep your Mouth Shut; a Popular Treatise on Mouth-breathing. By FrED. A. A. SMITH, M.D., C.M. Glas. Price 2s. 6d.

Rheumatism. Its Treatment by Electric Massage, etc., in connection with the Wiesbaden Thermal Waters. By CARL MoRDHORST, M.D. Kiel. Price 1s.

Rupture of the Perineum. Its Causes, Prevention and Treatment. By Michael JosepH Molony, M.R.C.P., L.R.C.S. Price 2s. cloth, 1s. 6d. paper.

Salt. History of Salt, with Observations on its Medicinal and Dietetic Properties. By Evan Marlett Boddy, F.R.C.S., F.S.S., L.R.C.P. Price 2s. 6d.

Sewage. The Sewage Question: Reports upon the Principal Sewage Farms and Works of the Kingdom, with Notes and Chemical Analyses. By the late Dr. Letheby. Price 4s. 6d.

Skin Diseases of Infancy and Early Life. By C. M. CAMPBELL, M.D., C.M. Edin. Price 5s.

Skin. A Synopsis of Diseases of the Skin and Hair. By R. Glasgow Patteson, M.B., Surgeon to St. Vincent's Hospital. Price 1s.

Skin. Dermic Memoranda : An Introduction to the Study of Skin Disease, with Special Reference to the Exanthemata. By William Gemcmel, M.B., Resident Medical Officer, Glasgow Fever Hospital. Price 3s. net.

Skin. Some Diseases of the Skin produced by Derangements of the Nervous System. By T. STRETCH Dowse, M.D., F.R.C.P.E. Price 2s.

Stomach. The Surgical Diseases and Injuries of the Stomach and Intestines. By F. Bowreman JessetT, F.R.C.S., Surgeon to the Cancer Hospital. Numerous engravings. Price 7s. 6d. 
Stricture. Stricture of the Urethra: its Diagnosis and Treatment. By E. Distin MadDick, F.R.C.S. Edin., late Surgeon R.N. 4s.

Surgery. The Science and Practice of Surgery, a Complete Textbook. By F. J. GANT, F.R.C.S., Senior Surgeon Royal Free Hospital. Third edition, with nearly 1,100 engravings. 2 vols., price $36 \mathrm{~s}$.

"The entire work has been revised to present the modern aspects of Surgery." - Lancet.

"Does credit to the author's thorough surgical knowledge." - British Medical Journal.

Surgery. The Student's Surgery : a Multum in Parvo. By F. J. GANT, F.R.C.S. 850 pp., illustrated. Price 10s. 6d.

"It well fulfils the object for which it is written."-Lancet.

"From the student's point of view it is a necessity."-British Medical Joumal.

Surgery. Operative Surgery on the Cadaver. By JASPER J. Garmany, A.M., M.D., F.R.C.S. Price 8s. 6d.

Surgery. Aids to Surgery. By GEORGe Brown, M.R.C.S. 2 parts, price 1s. $6 \mathrm{~d}$. cloth, and 1s. sewn, each ; or in 1 vol., $2 \mathrm{~s} .6 \mathrm{~d}$.

Surgery. The Text-book of Operative Surgery. With 88 beautifully engraved steel plates, after BERNARD and HUETTE. Text by ARTHUr Trehern NorTon, F.R.C.S., Surgeon to, and Lecturer on Surgery at, St. Mary's Hospital. Second edition, half calf, plain, $25 \mathrm{~s}$. ; hand-coloured, $50 \mathrm{~s}$.

"Of the highest merit as a guide to operative surgery."-Students' Journal.

Surgery. The Anatomy of Surgery. By JoHn McLachlan, M.B., M.K.C.S. With 74 illustrations. Two vols., price $18 \mathrm{~s}$.

Surgery. The Surgery of the Knee-Joint, and the Responsibility placed on the Physician and General Practitioner by the Modern Process of Surgery. By C. B. KeETleY, F.R.C.S., Senior Surgeon to the West London Hospital, and Surgeon to its Orthopædic Department. Cloth, price 1s. 6d.

Surgery, Minor-and Bandaging. Questions and Answers for Self-examination. By A. T. Schofield, M.D. Price 9d. net.

Surgical Pathology. Handbook of Surgical Pathology. By W. J. WalshaM, M.B., F.R.C.S., and D'ARcy Power, M.B.,

F.R.C.S. Second edition. Price 9s.

"An embodiment of the most modern pathological teaching."-The Lancet.

Surgical Anatomy. (See Surgery.)

Surgical Treatment. Notes on Surgical Treatment and Minor Operations. Designed especially for House Surgeons and Students. By T. F. HoPGood, L.R.C.P., M.R.C.S. Surgeon to the Sunderland Infirmary. Price 2s. 6d. 
Syphilis. Tables for the Diagnosis and treatment of Syphilis. By J. K. Barton, M.D., F.R.C.S.I. Third edition. Price 1s. 6 d. net.

Syphilis. The Nature and Treatment of Syphilis, and the other socalled Contagious Diseases. By C. R. DrYsdale, M.D., M.R.C.P. Lond., F.R.C.S. Eng. Fifth edition. Price 5s.

Temperature Charts for Recording the Range of Temperature, Pulse, Respiration, History, Progress, and Treatment of Cases. By E. W. Moore, M.D., M.R.C.P. Price 1d. each, 91. per dozen ; or mounted, similar to a blotting-pad, 50, 3s. 6d.; 100, 7s.

Theories of Life. The Protoplasmic Theory of Life. By JoHn DRYSDALE, M.D., F.R.M.S. Price 5s.

Theories of Life. How to Prolong Life. Showing the Diel and Agents best adapted for a lengthened prolongation of existence. By C. W. De Lacy Evans, M.R.C.S. Second edition. Price 5 s.

"A good account of the changes whtch occur with the advance of age."-Lancet.

Therapeutics. Modern Therapeutics, Medical and Surgical, including the Diseases of Women and Children. By GEo. H. Napheys, A.M., M.D. Ninth edition. Revised and enlarged by Drs. Allen Smith and Aubrey Davis.

Vol. I. - General Medicine, including Diseases of Children. Price, half morocco, $£ 110$ s.

Vol. II.-Surgical and Gynæcological Therapeutics. Price, half morocco, $£ 110$ s.

Therapeutics. The Therapeutics of the Respiratory Passages. By Prosser JAMES, M.D., Lecturer on Materia Medica and Therapeutics at the London Hospital. Price 10s. $6 \mathrm{~d}$.

"Dr. Prosser James has produced a scholarly treatise."-New York Medical Record.

Therapeutics. Aids to Rational Therapeutics, for the guidance of Practitioners and Senior Students. By J. Milner Fothergill, M.D. Second edition. Price 2s. 6d. cloth; 2s. paper wrapper.

Throat. Movable Atlas of the Throat, and the Mechanism of Voice, Speech and Taste. By Prof. Witkowski. (See Anatomy.)

Throat. Diseases of the Throat and Nose. A Practical Guide to Diagnosis and Treatment. With 220 typical illustrations in chromo lithography and numerous wood engravings. By LenNox Browne, F.R.C.S. Edin., Senior Surgeon to the Central London Throat and Ear Hospital. Fourth edition. Price $21 \mathrm{~s}$

\footnotetext{
"One of the completest treatises on diseases of the throat in any language."-Britisk Midical Journal.

"The best text-book in the English language."-Edinburgh Mertirul Journal.
} 


\section{Baillière, Tindall, and Cox's Books.}

Throat. Affections of the Throat and Larynx. By ARTHUR Trehern Norton, F.R.C.S., Surgeon to St. Mary's Hospital. Second edition, illustrated. Price 6s.

"Short, simple, and thoroughly practical instruction."-Medrcal Press.

Throat. Tonsillitis in Adolescents. By C. HAIG-Brown, M.D.,

C.M., Medical Officer to the Charterhouse. Price 3s.

Transfusion. On Transfusion of Blood and Saline Fluids. By C. Egerton Jennings, F.R.C.S. Third edition, with Preface by Sir Spencer Wells, Bart. Price 4s. 6d.

Tuberculosis. (See Consumption.)

Urinary Diseases: Diseases of the Bladder, Prostate Gland, and Urethra. By F. J. GANT, F.R.C.S., Senior Surgeon to the Royal Free Hospital. Fifth edition, enlarged. Price 12s. 6d.

"The work throughout bears evidence of having been written by a thoroughly practical and experienced surgeon."-Lancet.

Urine. The Urine in Health and Disease, its Chemical Examination, etc. By H. AUbReY HUsband, M.B., B.Sc., F.R.C.S. Second edition. Price 1s. net.

Urine. The Urine; a Guide to its Practical Examination. By

J. Tyson, M.D., Professor of Morbid Anatomy in the University, and President of the Pathological Society of Philadelphia. Seventh edition, with numerous illustrations. Price 7s. 6d.

"We think it the most practically useful guide we have on the subject."-Medical Record.

Vichy. Vichy and its Therapeutical Resources. By Prosser James, M.D., M.R.C.P. Lond. Price 2s. 6d.

Voice. The Philosophy of Voice. Showing the right and wrong Action of the Breath and Vocal Cords in Speech and Song. By Charles Lunn. Seventh edition.

[In the press.

Voice. Artistic Voice in Speech and Song. Dedicated to Mr. Sims Reeves and Mr. Santley. By the same Author. 1s.

Voice. The Voice Musically and Medically Considered. By C. Armand Semple, M.B. Cantab., M.R.C.P. Lond., Physician to the Royal Society of Musicians. Part I. Musical, price 1s.; Part II., Medical, price 2s. ; or in one vol., cloth, 3s. 6d.

Whooping-Cough. Its Pathology and Treatment. Fothergillian Prize Essay. By Thos. M. Dolan, M.D., F.R.C.S.E. Price 3s.6d.

Zoology and Comparative Anatomy, Aids to. By MaJor GREENWOOD, M.D., Honours. Price 2s. 6d., and 2s. 


\section{THE STUDENTS' AIDS SERIES.}

Specially designed to assist Students in committing to memory and grouping the subjects upon which they are to be examined.

Aids to Analysis of Food and Drugs. By H. Aubrey Husband, M.B., F.R.C.S. 1s. 6d. cloth ; 1s. sewn.

Aids to Anatomy. By George Brown, M.R.C.S., Gold Medallist, Charing Cross Hospital. 1s. 6d. cloth; 1s. sewn.

Aids to Biology. By Joseph W. Wrlliams. 2s. 6d. cloth; 2 s. sewn.

Aids to Botany. By C. E. Armand Semple, B.A., M.B. Cantab., M.R.C.P. Lond., late Senior Examiner in Arts at Apothecaries'

Hall. Third thousand. 2s. 6 d. cloth; 2s. sewn.

Aids to Chemistry. By the same Author.

Part I.-Inorganic: Non-Metallic Substances. 2s. 6d. cloth ; 2s. sewn.

Part II.-Inorganic : The Metals. 2s. 6d. and 2s.

Part III.-Organic. Price, 2s. 6d. and 2s.

Part IV.-Tablets of Chemical Analysis. 1s. 6d. and 1s.

Aids to Practical Chemistry. Especially arranged for the Analysis of Substances containing a Single Base and Acid Radicle. By T. Hurd Gordon. 2s. 6d. cloth; 2s. sewn.

Aids to Dental Surgery. By Arthur S. Underwood, M.B., M.R.C.S., Lecturer on Dental Surgery at the Dental Hospital of London. 2s. 6d. cloth; 2s. sewn.

Aids to Dental Histology. By the same Author. Illustrated. 2s. 6d. cloth; 2s. sewn.

Aids to Diagnosis. Part I. - Semeiological. By J. Mrlner FotherGILL, M.D., M.R.C.P. Lond. 1s. 6d. cloth ; 1s. sewn.

Part II.-Physical. By J. C. Thorowgood, M.D., F.R.C.P. Lond. 1s. 6d. and 1s.

Part III.--What to Ask the Patient. By J. Milner Fothergill, M.D., M.R.C.P. Lond. 1s. 6d. and 1s. The three in one vol., 3s. 6 d.

"A mine of valuable information."-Edinburgh Medical Journal.

Aids to Examinations. Being Questions and Answers on Materia Medica, Medicine, Midwifery, Pathology, etc. By D. WALsh, M.B., C.M., L.R.C.P. New Edition. 2s. 6 d. and 2s.

Aids to Forensic Medicine and Toxicology. By W. D. HemMing, F.R.C.S.E., and H. Aubrey Husband, M.B., F.R.C.S.E. Third thousand. 2s. 6d. cloth; 2s. sewn. 


\section{Baillière, Tindall, and Cox's Books.}

Aids to Gynæcology. By ALfred Gubb, M.D. Paris, D.P.H., Obstetric Assistant and Gold Medallist, Westminster Hospital. New Edition. Cloth, 2s. 6d. ; sewn, 2s.

Aids to Materia Medica and Therapeutics. By C. E. ARMand SEMPLE, B.A., M.B. Cantab., M.R.C.P. Lond.

Part I.-The Non-Metallic and Metallic Elements, Alcoholic and Ethereal Preparations. 2s. 6d. cloth; and 2s. sewn.

Part II.-Vegetable and Animal Substances, 2s. 6d. and 2s.

Part III.-Classification of Remedies, 1s. 6d. and 1s.

Part IV.-New Remedies. 2s. 6d, and 2s.

Part V.-Tablets of Materia Medica. Price 1s. 6d. and 1s.

Aids to Medicine. By the same Author.

Part I.-General Diseases. Lungs, Heart, and Liver. Cloth, 2s. 6d. ; sewn, 2s.

Part II.-The Urine, Kidneys, etc. 2s. 6d. and 2s.

Part III.-The Brain and Nervous System. 2s. 6d. and 2s.

Part IV.- The Fevers, Skin Diseases, etc. 2s. 6d. and 2s.

Aids to Obstetrics. By Samuel Nall, B.A., M.B. Cantab., M.R.C.P. Lond., late House Physician and Resident Obstetric Assistant, St. Bartholomew's Hospital. Twelfth thousand. Cloth, 2s. 6d. ; sewn, 2s.

Aids to Ophthalmic Medicine and Surgery. By Jonathan Hutchinson, jun., F.R.C.S. Cloth, 2s. 6d.; sewn, 2s.

Aids to General Pathology. By Gilbert A. Bannatyne, M.D. Cloth, 1s. 6d.; sewn, 1s.

Aids to Special Pathology. By the same Author. Cloth, 2s. 6d.; sewn, $2 \mathrm{~s}$.

Aids to Pharmacy. By C. E. Armand Semple, B.A., M.B. Cantab., M.R.C.P. London. Cloth, 2s. 6d. ; sewn, 2s.

Aids to Physiology. By B. Thompson Lowne, F.R.C.S., Examiner in Physiology, Royal College of Surgeons. Fourth thousand. In two parts, price 2s. each; or in one vol., cloth, $4 \mathrm{~s}$. $6 \mathrm{~d}$.

"Certainly one of the best of the now popular Aids Series."-Students' Journal.

Aids to Practical Physiology. By J. Brindley James, M.R.C.S. Cloth, 1s. 6d. ; sewn, 1s.

Aids to Physiological Chemistry. By J. L. Thudrchum, M.D., F.R.C.P. Lond., formerly Lecturer on Physiological Chemistry, St. Thomas's Hospital. Cloth, 2s. 6d. ; sewn, 2s.

Aids to Psychological Medicine. By L. S. Forbes Winslow, M.B., D.C.L. Oxon. Cloth 1s. 6d.; ;ewn, 1s. 


\section{9}

\section{Baillière, Tindall, and Cox's Books.}

Aids to Public Health. By J. L. Thudichum, M.D., F.R.C.P., Lond. New Edition. 1s. 6d. cloth; 1s. sewn.

Aids to Sanitary Science for the Use of Candidates for Public Health Qualifications. By F. J. Allan, M.D., Assistant Professor of Hygiene, Coll. State Medicine. 236 pp. Cloth, 4s. 6d.; or in two parts, sewn, 2s. each.

Aids to Surgery. In two parts. By GEORGE Brown, M.R.C.S. 1s. 6 d. cloth, and 1s. sewn, each; or in one vol., cloth, 2 s. $6 \mathrm{~d}$.

Aids to Rational Therapeutics. By J. MILner Fothergill, M.D., M.R.C.P. Lond. 2s. 6d. cloth ; 2s. sewn.

Replies to Questions in Therapeutics. By BRINDLEY JAMES, M.R.C.S. 1s. 6 d. cloth; 1s. sewn.

Aids to Zoology. By MaJor Greenwood, M.D. Honours in Zoology, University of London. 2s. 6d. cloth ; 2s. sewn.

Aids to Analytical Geometry.

The Straight Line and Circle. By A. LE Sueur, B.A. Cantab. Second edition. Price 2s.

The Conic Sections, with solutions of questions set at the London and other University Examinations. By GEORGE HePPEL, M.A., St. John's College, Cambridge, Member of London Mathematical Society. Price 2s. 


\section{Baillière, Tindall, and Cox's Books.}

\section{WORKS}

$\mathrm{ON}$

\section{VETERINARY MEDICINE AND SURGERY.}

Amateur. Horses : their Rational Treatment and the Causes of their Premature Decay. By Amateur. Price 5s.

An Abridgment of the above. By the same Author. Price 1s.

Banham. Tables of Veterinary Posology and Therapeutics. With

Weights, Measures, etc. By Professor George A. Banham, F.R.C.V.S. Price 2s. 6d.

Beacock. Prize Essay on the Breeding, Rearing, and Fattening of Cattle and Sheep, and proper treatment of Cows at time of Calving. By Joseph Beacock. Price 3d.

Burke. The Tropical Diseases of the Horse. By Captain R. W. BURKe, M.R.C.V.S., A.V.D. Third edition. [In the Press.

Burness-Mavor. The Specific Action of Drugs, an Index to their Therapeutic Value. By A. G. Burness and F. Mavor, President of the Central London Veterinary Society. Price 10s. 6d.

Courtenay. The Practice of Veterinary Medicine and Surgery. By E. Courtenay. Price 10s. $6 \mathrm{~d}$.

"Written in a clear and concise style: will form a welcome addition to the library of the horse-owner, and those who take an interest in domesticated animals generally."-Mark Lane Express.

Fleming. A Text-Book of Veterinary Obstetrics, including the diseases and accidents incidental to pregnancy, parturition and early age in the Domesticated Animals. By George Fleming, C.B., LL.D., F.R.C.V.S., F.R.G.S., President of the Royal College of Veterinary Surgeons, late Principal of the Army Veterinary Department. Profusely illustrated. Cloth, price 30s. "Has filled up a void in a more satisfactory and complete way than any other member of his profession could have done."-The Field.

"No man who makes any pretensions to veterinary science or stock breeding can dispense with this work."-Live Stock Journal.

Fleming. Parasites and Parasitic Diseases of the Domesticated Animals. A Treatise by L. G. Neumann, Professor at the National Veterinary School of Toulouse. Translated and Edited by Geo. Fleming, C.B., LL.D., F.R.C.V.S., with 365 illustrations. Price 25s.

"The value and importance of Neumann's Treatise cannot be over-estimatcd ; it is certainly the most scientific, interesting, and useful work that has graced veterinary literature for some years." - The Veterinary Journal.

"We do not hesitate to say that this is a work which all pathologists ought to possess; and the practitioner ... will not fail to add to his reputation if he has this book on his shelves." - The Lancet.

"This is one of the most useful of the many works with which Dr. Fleming has enriched English Veterinary literature. Although intended as a text-book for the veterinary student and practitioner, the translation has rendered it so readable that every intelligent farmer may derive a fund of useful information from its copiously illustrated pages."-Mark Lane Express.

"Cannot fail to be of immense value to both the veterinary profession and to British stockbreeders."-Bell's Weekly Messenger. 
Fleming. A Text-Book of Operative Veterinary Surgery. Part I., price 10s. 6d. Part II. in the Press.

The Contagious Diseases of Animals: their influence on the wealth and health of the nation. Price $6 \mathrm{~d}$.

Animal Plagues; their History from the Earliest Times, Nature, and Prevention. Vol. I., to 1800 . Price 15s.

- Vol. II., from A.D. 1800 to 1844 . Price 12s.

Actinomykosis; an Infectious Disease of Animals and

Mankind. Price 1s.

On Roaring in Horses (Laryngismus Paralyticus). Its History, Pathology, and Treatment. With coloured plate and woodcuts. Price 6s.

Tuberculosis from a Sanitary and Pathological point of view. Price 1s.

Human and Animal, Variolæ. A Study of Comparative Pathology. Price 1s.

- Practical Horse Shoeing. With 37 illustrations. 2s. of Tuberculosis. By G. Fleming, F.R.C.V.S., Herr A. Lydtin, and M. Van Hertsen. Price 6s.

Gresswell. AManual of the Theory and.Practice of Equine Medicine. By J. Brodie Gresswell, F.R.C.V.S., and Albert GresswELL, M.R.C.S. Eng. Second edition, enlarged. Price 10s. 6d. BY THE SAME AUTHORS.

Equine Hospital Prescriber. Second edition. Price 2s. 6d.

Bovine Prescriber. Price 2s. 6d.

Veterinary Pharmacopoia. Materia Medica and Therapeutics. Price 10s. 6d.

Diseases and Disorders of the Horse. A Treatise on Equine Medicine and Surgery. Price 5s.

Hill. Principles and Practice of Bovine Medicine and Surgery, with woodcuts and coloured plates. By J. WoodrofFE HILL, F.R.C.V.S. New edition.

The Management and Diseases of the Dog. By J. W. HiLL, F.R.C.V.S. Third edition. Illustrated. Price 7s. $6 \mathrm{~d}$.

Lambert. The Germ Theory of Disease, Concisely and Simply Explained. By Colonel JAMES LAMBERT, F.R.C.V.S., Army Veterinary Department. Price 1s.

Liautard. Animal Castration. By A. Liautard, M.D., H.F.R.C.V.S. Price 7s. 6d.

- Lameness of Horses and Diseases of the Locomotor Apparatus. Price 10s. 6d.

Lupton. Horse: Sound and Unsound, with the Law relating to Sales and Warranty. By JAMES Irvine Lupton, F.R.C.V.S. Price 5s. 
Miller-Tellor. The Diseases of Live Stock, and their most efficient. remedies. A Popular Guide for the Treatment of Horses, Cattle, Cows, Sheep, Swine, Fowls, Dogs, etc. By WM. B. E. Mrluler, D.V.S., President of U.S. Veterinary Association, WILlIs P. Hazard, A. Liautard, M.D., F.R.C.V.S., and Lloyd V. Tellor, M.D. New Edition. Price 10s. 6d.

McBride. Anatomical Outlines of the Horse. By J. A. McBrIDE, Ph.D., M.R.C.V.S. Third edition. Illustrated. Price 8s. 6d.

Meyrick. Stable Management and the Prevention of Diseases among Horses in India. By J. J. MeYrick, C.B., F.R.C.V.S., Superintendent of Horse Breeding for the Punjab. Price 2s. 6d. Poyser. The Stable Management of Troop Horses in India. "The Collinsian" Prize Essay. By Major R. Poyser, A.V.D., F.R.C.V.S. Price 2s.

Reynolds. The Breeding, Rearing, and Management of Draught Horses. By RichaRd Reynolds, M.R.C.V.S. Price 3s. 6d.

Robertson. A Handbook of the Practice of Equine Medicine. By WM. Robertson, F.R.C.V.S., late Principal of the Royal Veterinary College, London. Second edition. Price 25s.

Smith. A Manual of Veterinary Hygiene. By Captain Frederick Smith, A.V.D., M.R.C.V.S., Professor in the Army Veterinary School, Aldershot. Second edition. Price 10s. 6d.

"The work is a very solid one, and it is a pleasure to recommend it."-Army and Navy Mag.

"It should be on the bookshelf of every horseman, horsekeeper, and veterinary surgeon." - United Service Gazette.

A Manual of Veterinary Physiology. By the same Author.

Price 12s. 6d.

"The work will commend itself to those for whom it was written by its conciseness and the able manner in which the important facts are dealt with and arranged."-Lancet.

"We offer our hearty congratulation to Captain Smith for his welcome contribution to our seanty professional literature."-Veterinary Journal.

"A valuable addition to the too small list of good veterinary text-books."-Journal of" Comparative Pathology (Mac Fadyean).

"We do not remember to have met with a scientific book which is more readable; and it supplies one of the greatest wants in our literature."-Veterinary Record.

"This work ought to delight the heart of the veterinary student."-Nature.

Veterinary Diagrams in Tabular Form. With coloured and plain engravings. Size of sheet $28 \frac{1}{2}$ by 22 inches.

No. 1. - The External Form and Elementary Anatomy of the Horse. Price 3s. 6d., or mounted on roller and varnished, $6 \mathrm{~s} .6 \mathrm{~d}$.

No. 2.-The Age of Domestic Animals. Price 2s. 6d., or mounted, $5 \mathrm{~s} .6 \mathrm{~d}$.

No. 3. - The Unsoundnesses and Defects of the Horse. Price 2 s. 6 d., or mounted, $5 \mathrm{~s}$. 6 d.

No. 4. - The Shoeing of the Horse, Mule and Ox. Price 2 s. 6 d., or mounted, 5 s. 6 d.

No. 5.-The Elementary Anatomy, Points and Butcher's Joints of the Ox. Price 3s. 6d., or mounted, 6s. 6 d.

Price per set of Five, 12s. ; or mounted, 27s. 
NOW READY. Price £6 nett.

\section{A NEW AND GREATLY IMPROVED EDITION}

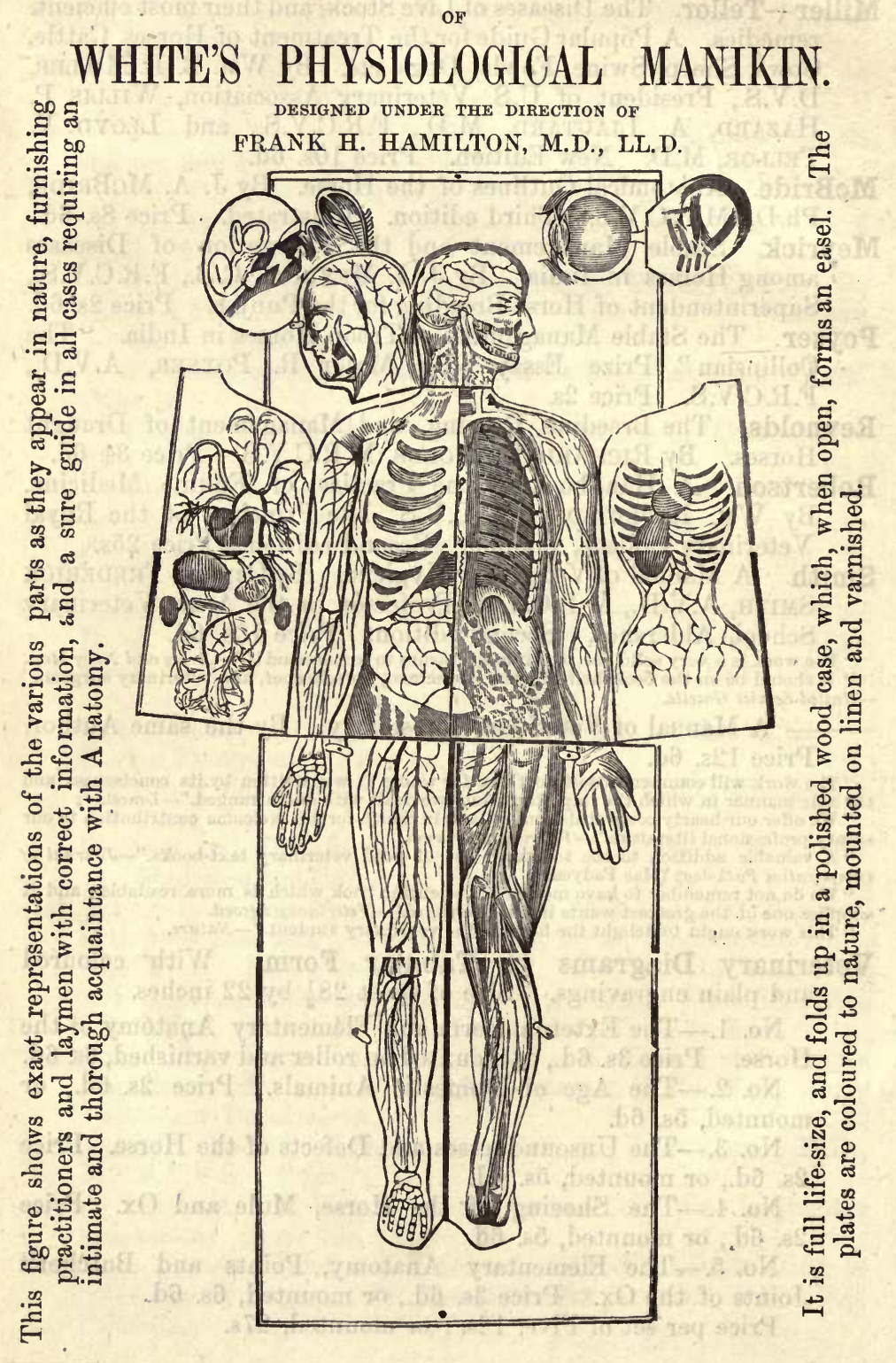




THIS BOOK IS DUE ON THE IAST DATE
STAMPED BELOW

AN INITIAL FINE OF 25 CENTS WILL BE ASSESSED FOR FAILURE TO RETURN THIS BOOK ON THE DATE DUE. THE PENALTY WILL INCREASE TO 50 CENTS ON THE FOURTH DAY AND TO $\$ 1.00$ ON THE SEVENTH DAY OVERDUE.

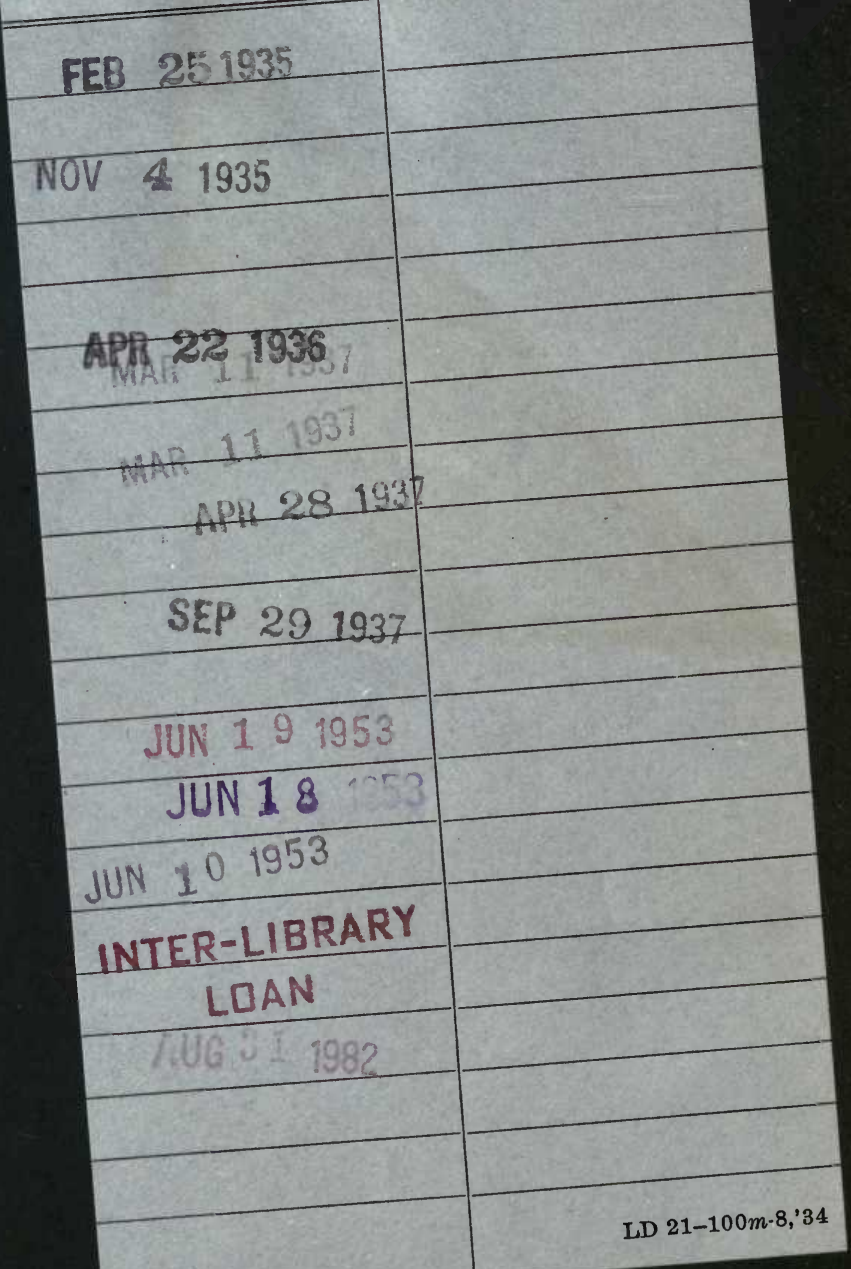


$3 x+25$

yom 


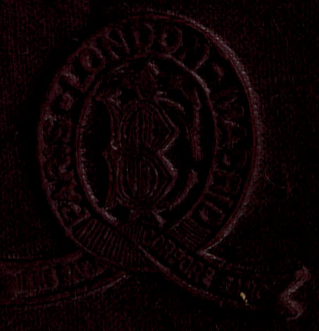

